Eng. Luiz Carlos Rodrigues Morenghi

\title{
PROPOSTA DE UM SISTEMA INTEGRADO DE MONITORAMENTO PARA MANUTENÇÃO
}

Dissertação apresentada à Escola de Engenharia de São Carlos da Universidade de São Paulo, como parte dos requisitos para a obtenção do Título de Mestre em Engenharia de Produção.

ORIENTADOR: Prof. Dr. João Fernando Gomes de Oliveira

São Carlos

2005 


\section{DEDICATÓRIA}

Dedico este trabalho à minha esposa, Sonia, pelo amor, apoio e cumplicidade de toda uma vida, ao meu filho, Caio Théo, fonte eterna de inquietação que me despertou o desejo de voltar à vida acadêmica e aos meus pais, Armando e

Carmem, exemplos raros de vida que completam 50 anos de casados no momento em que escrevo essas linhas. 


\section{AGRADECIMENTOS}

Á Deus, por nunca nos abandonar, por pior que sejamos.

Ao professor João Fernando, pela orientação e mais ainda pela vida em comum que tenho o prazer de desfrutar há 26 anos. Felizmente amigos são coisas que podemos escolher para guardar do lado esquerdo do peito. Valeu Muka, Saaco for ever!

Ao meu irmão, Wilson, que nos longínquos anos 70 e ao meu filho, Caio Théo, que nos últimos anos, nunca se negaram a servir de motoristas para que eu pudesse chegar à Rodoviária, por mais esdrúxulos que fossem os horários. Obrigado Pavão e Teco.

Aos meus primos, José e Leonedes, por cobrirem minhas funções no trabalho durante as aulas. Obrigado Português e Nedes.

Aos colegas do OPF, professor Reginaldo, Fabinho, Lincoln, Américo, Tobias, Marcelinho, Salete, Luciano, Adriano, Eraldo, Roger, Daniel, Irene, Cristiano, Ariel, Adolfo, que muito contribuíram para este trabalho, e principalmente, me aturaram durante todo esse tempo.

A toda turma da pós, aos professores e funcionários da Produção, pelo companheirismo, ensinamentos e favores prestados.

Em especial, aos colegas Rogério e Moacir, do mestrado da produção, e aos colegas Dinho e Flavim, do OPF, sem os quais não seria possível a realização desse trabalho. 


\section{SUMÁRIO}

LISTA DE FIGURAS …...........................................................................

LISTA DE TABELAS ................................................................................

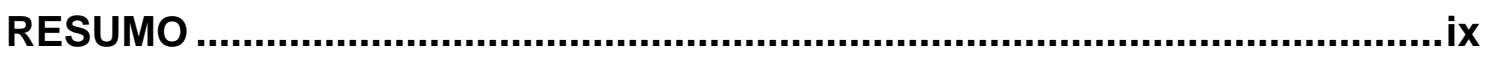

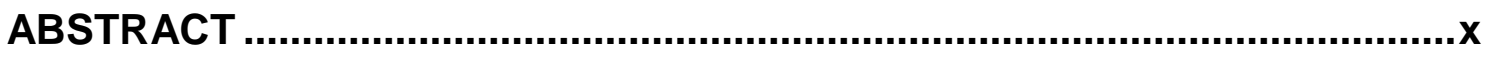

1. INTRODUÇÃO

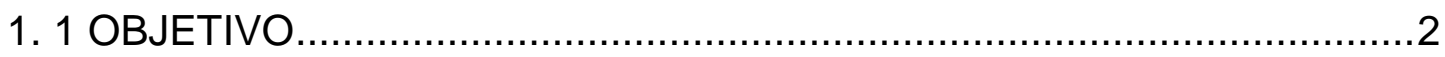

1. 2 DEFINIÇÃO DO PROBLEMA DE PESQUISA ……...............................

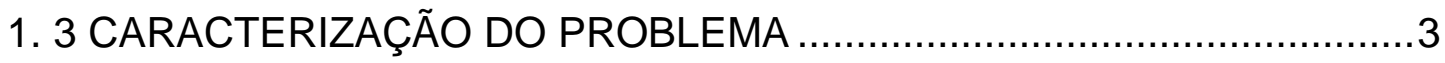

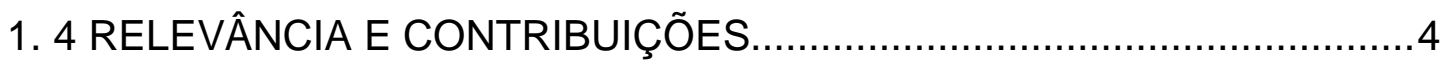

1. 5 DEFINIÇÃO DA METODOLOGIA DE PESQUISA …..............................

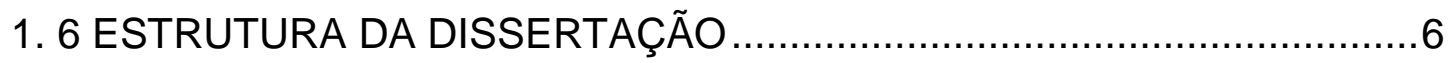

2. TÓPICOS SOBRE GESTÃO DE MANUTENÇÃO …....................................

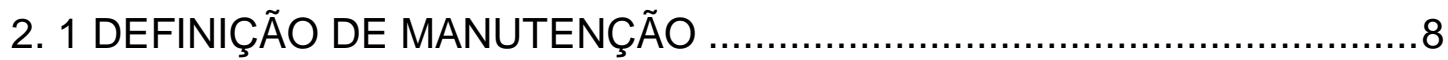

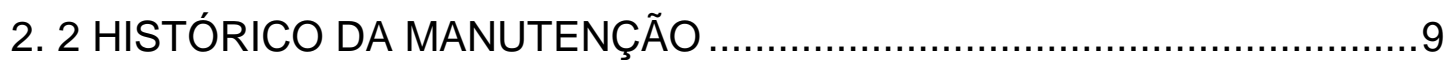

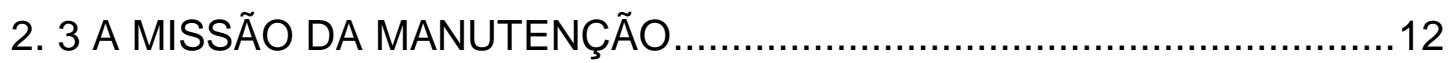

2. 4 IMPORTÂNCIA ESTRATÉGICA DA MANUTENÇÃO ..........................13

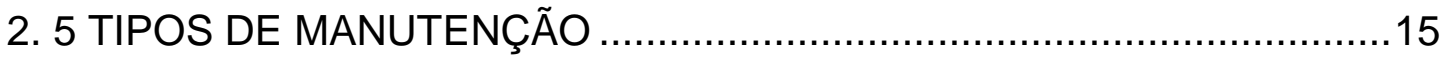

2. 5. 1 MANUTENÇÃO CORRETIVA..................................................................................... 15

2. 5. 2 MANUTENÇÃO PREVENTIVA ……………………………………………………….....

2. 5. 3 MANUTENÇÃO PREDITIVA ...................................................................................22

2. 5. 4 MANUTENÇÃO DETECTIVA ................................................................................... 35

2. 5. 5 ENGENHARIA DE MANUTENÇÃO ……………………………………………........

2. 6 FERRAMENTAS E TÉCNICAS DE MANUTENÇÃO..............................38

2. 6. 1 ANÁLISE DOS MODOS E EFEITOS DAS FALHAS - FMEA.......................................38

2. 6. 2 ANÁLISE DA ÁRVORE DE FALHAS - FTA ...........................................................

2. 6. 3 MANUTENÇÃO CENTRADA EM CONFIABILIDADE - RCM ...................................... 46

2. 7 DIMENSÕES ESTRATÉGICAS DA MANUTENÇÃO ............................57

3. CONCEITOS E TECNOLOGIAS ENVOLVIDOS........................................60 
3. 1 EMISSÃO ACÚSTICA .60

3. 2 A COMUNICAÇÃO NAS EMPRESAS. 62

3. 3 SENSORES 70

4. PROPOSIÇÃO DO SISTEMA DE MONITORAMENTO INTEGRADO PARA MANUTENÇÃO. 72

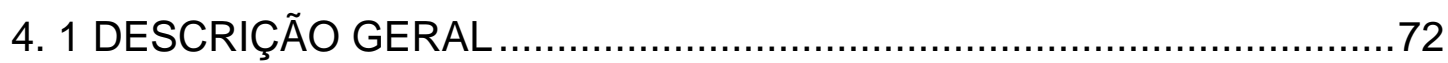

4. 2 INTEGRAÇÃO DO SISTEMA DE MONITORAMENTO.......................75

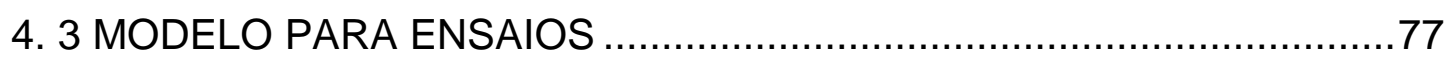

4. 4 DESCRIÇÃO DO PROGRAMA MANUTENÇÃO PREDITIVA................80

5. TESTES E AVALIAÇÃO DOS RESULTADOS .........................................89

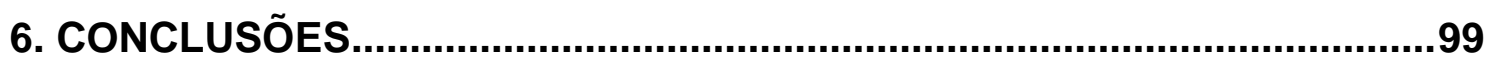

7. PROPOSTAS PARA TRABALHOS FUTUROS.......................................100

REFERÊNCIAS BIBLIOGRÁFICAS .....................................................101

APÊNDICE A - Manutenção Produtiva Total (TPM) ...............................106

APÊNDICE B - Metodologia de pesquisa: Revisão bibliográfica..............113 


\section{LISTA DE FIGURAS}

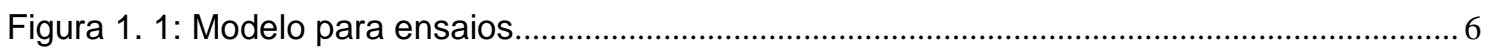

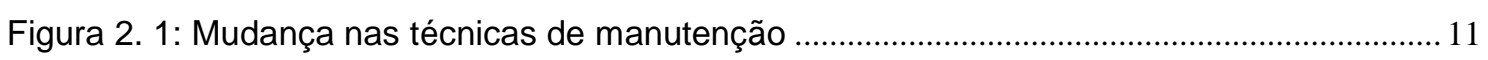

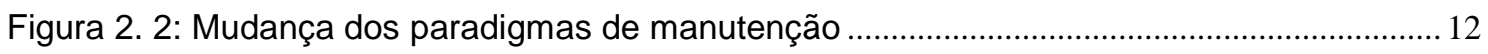

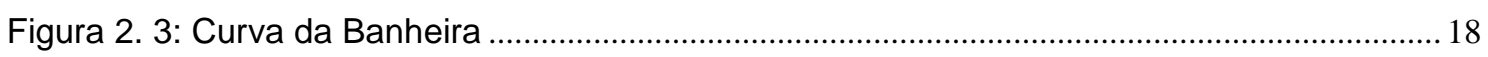

Figura 2. 4: Planejamento de Preventiva e Corretiva Integrado ................................................. 20

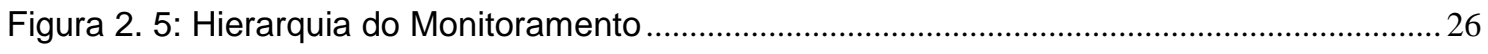

Figura 2. 6: Quadro de manutenção preditiva por monitoramento de vibrações............................. 30

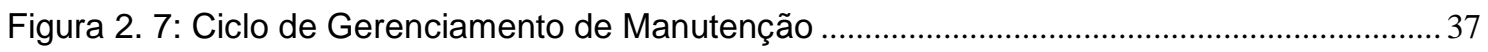

Figura 2. 8: Importância que a FMEA pode proporcionar para a empresa ..................................... 41

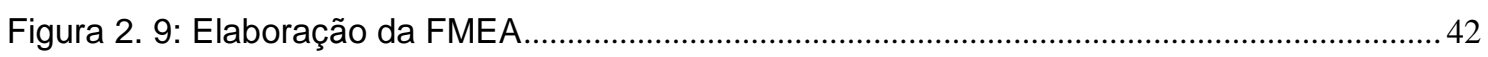

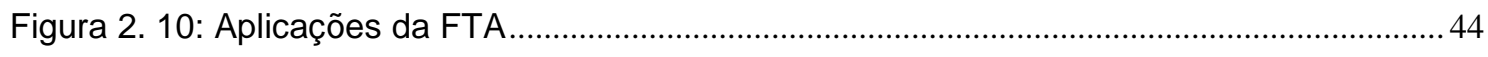

Figura 2. 11: Tipos de curvas de falhas - ocorrências de falhas $X$ tempo........................................ 51

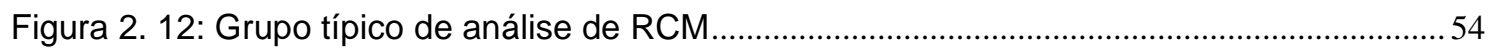

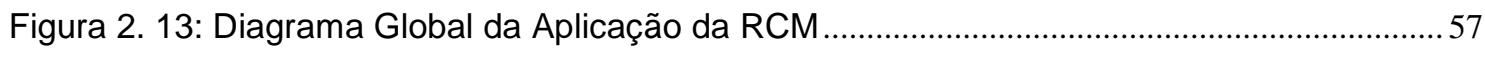

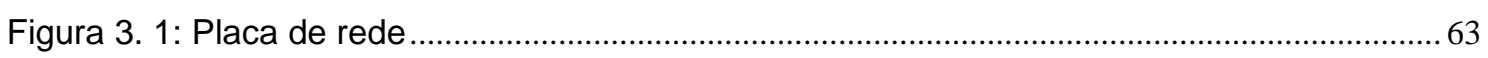

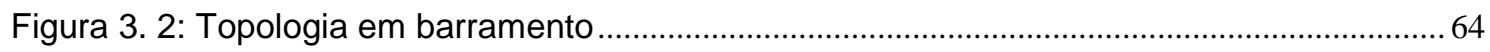

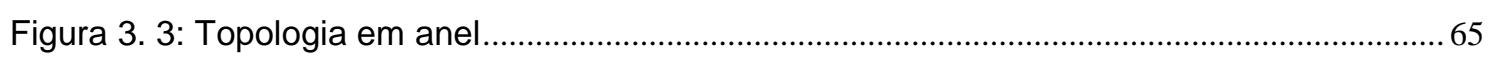

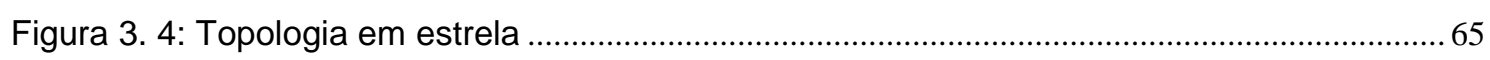

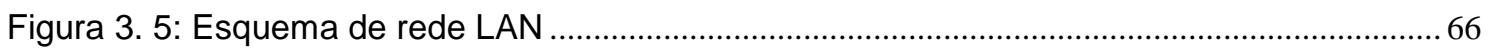

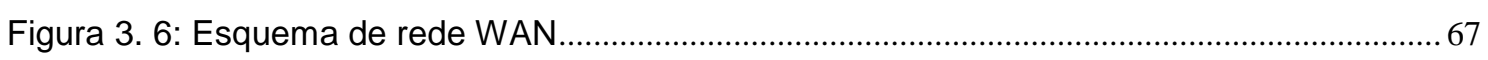

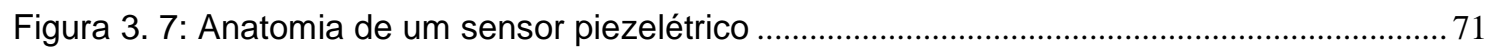

Figura 4. 1: Sensor e condicionador de EA DM 42 fabricados pela Sensis ..................................... 73

Figura 4. 2: Esquema do sistema de monitoramento e gestão da manutenção proposto............ 74

Figura 4. 3: Integração do sistema proposto à rede local ................................................................ 76

Figura 4. 4: Sistema de monitoramento conectado à Internet........................................................... 76

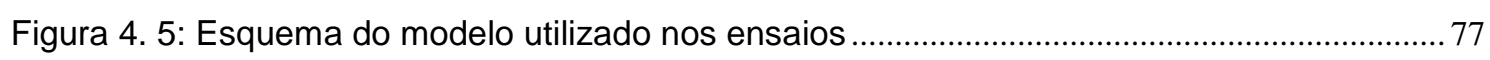

Figura 4. 6: Diagrama das atividades de manutenção para o modelo.............................................79

Figura 4. 7: Diagrama do subprograma de aquisição de dados .................................................. 80

Figura 4. 8: Primeira tela - Estrutura de seqüência que zera o contador do programa.................. 82

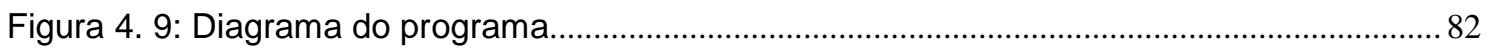

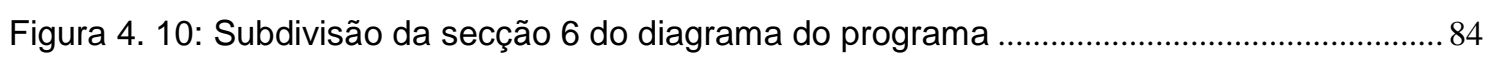

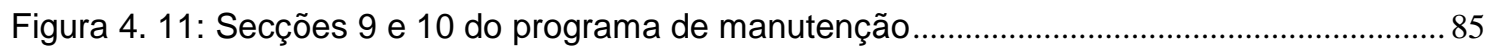

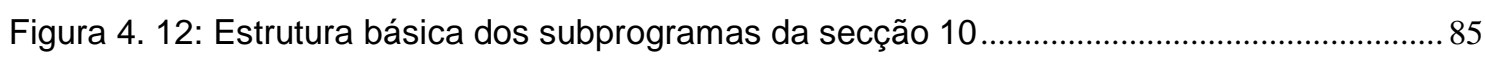

Figura 4. 13: Sub-rotina que dispara a atividade de manutenção "engraxar os rolamentos"...... 86

Figura 4. 14: Tela que apresenta a atividade de manutenção "engraxar" ........................................ 86 
Figura 4. 15: Sub-rotina que dispara a atividade "alinhamento dos eixos" .86

Figura 4. 16:Tela que apresenta a atividade "alinhamento dos eixos"...

Figura 4. 17: Sub-rotina que dispara a atividade "substituição da borracha do acoplamento" ... 87

Figura 4. 18: Tela que apresenta a atividade "substituição da borracha do acoplamento" .......... 87

Figura 4. 19: Sub-rotina que dispara a atividade "substituição dos rolamentos"............................ 88

Figura 4. 20: Tela que apresenta a atividade "substituição dos rolamentos"................................... 88

Figura 5. 1: Resultados para o mancal 1 e 2 com rolamentos bons e o sensor de EA posicionado no mancal $1-75 \mathrm{kHz}$.

Figura 5. 2: Resultados para o mancal 1 e 2 com rolamentos bons e o sensor de EA posicionado no mancal $1-100 \mathrm{kHz}$.

Figura 5. 3: Resultados para o mancal 1 com rolamento bom e mancal 2 com rolamento ruim e o sensor de EA posicionado no mancal 1 - $75 \mathrm{kHz}$

Figura 5. 4: Resultados para o mancal $1 \mathrm{com}$ rolamento bom e mancal $2 \mathrm{com}$ rolamento ruim e o sensor de EA posicionado no mancal $1-100 \mathrm{kHz}$ 91

Figura 5. 5: Resultados para os mancais 1 e 2 com rolamentos ruins e o sensor de EA posicionado no mancal $1-75 \mathrm{kHz}$

Figura 5. 6: Resultados para os mancais 1 e 2 com rolamentos ruins e o sensor de EA posicionado no mancal $1-100 \mathrm{kHz}$

Figura 5. 7: Resultados para o mancal 1 com rolamento ruim e o mancal 2 com rolamento bom e o sensor de EA posicionado no mancal $1-75 \mathrm{kHz}$

Figura 5. 8: Resultados para o mancal 1 com rolamento ruim e mancal 2 com rolamento bom e o sensor de EA posicionado no mancal $1-100 \mathrm{kHz}$ .94

Figura 5. 9: Medidas efetuadas com o sensor de EA posicionado no mancal $1-75 \mathrm{kHz}$........... 95

Figura 5. 10: Medidas efetuadas com o sensor de EA posicionado no mancal 1-100 kHz .........95

Figura 5. 11: Medidas efetuadas com o sensor de EA posicionado no mancal 2- $75 \mathrm{kHz}$.........96

Figura 5. 12: Medidas efetuadas com o sensor de EA posicionado no mancal 2- $100 \mathrm{kHz}$........96

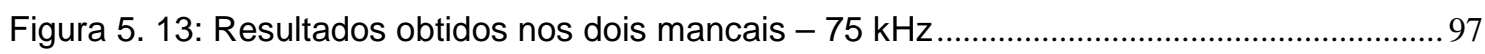

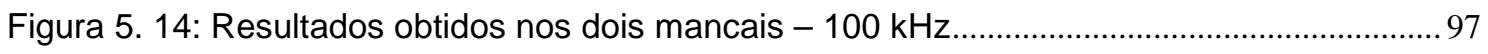

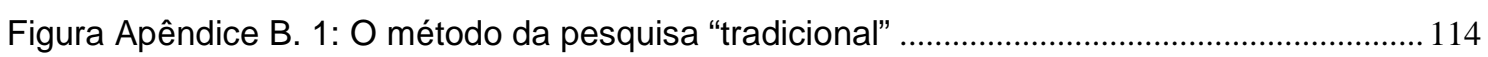




\section{LISTA DE TABELAS}

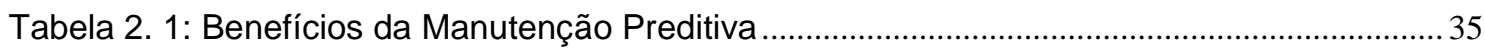

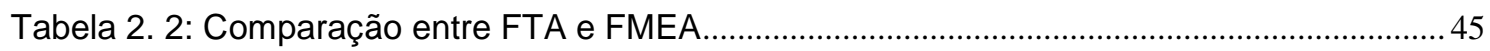

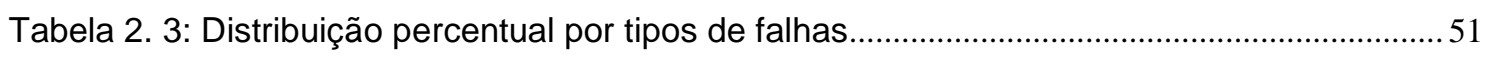

Tabela 2. 4: Benefícios da Confiabilidade e Manutenibilidade ............................................................56

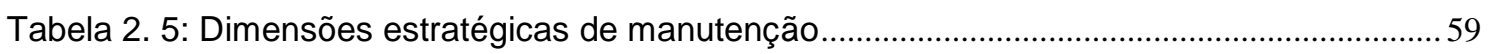

Tabela 3. 1: Sistemas de monitoramento e sensores utilizados ....................................................... 70

Tabela Apêndice A. 1: As 12 etapas para implantação da TPM......................................................... 111

Tabela Apêndice A. 2: Resultados alcançados com a implementação da TPM ...........................112 


\section{RESUMO}

MORENGHI, L. C. R. (2004). Proposta de um sistema integrado de monitoramento para manutenção. Dissertação (Mestrado) - Escola de Engenharia de São Carlos, Universidade de São Paulo, São Carlos, 2004.

Historicamente, as atividades de manutenção têm sido caracterizadas como um problema dentro das organizações. Entretanto, nos últimos anos, esta atitude tem sido revista e tem levado a um reconhecimento da manutenção como uma função estratégica nas empresas. Esta mudança do papel da manutenção é fruto da globalização de mercados, que forçam as organizações a competir não somente em qualidade, diferenciação ou preço, mas também, em inovações tecnológicas, redução de tempo de atendimento e tecnologia de informação. A informação é um recurso essencial para direcionar e atingir os objetivos da gestão. No caso da manutenção, a coleta e análise de dados são recursos indispensáveis para o monitoramento e controle de suas atividades. O sistema proposto visa 0 atendimento dessas expectativas, através da aquisição de dados por sensores de emissão acústica em equipamentos rotativos. A pesquisa buscou a confirmação de que é possível a detecção de falhas em mancais de rolamentos, a partir do monitoramento dos níveis de emissão acústica, e assim conseguir uma forma pró-ativa de gerir a manutenção. A análise dos dados coletados fornece parâmetros para que se possam gerar informações que disparem ações, tanto do departamento de manutenção como dos demais setores envolvidos (direta ou indiretamente) com suas atividades, de maneira integrada.

Palavras-chave: manutenção; monitoramento; emissão acústica 


\section{ABSTRACT}

MORENGHI, L. C. R. (2004). Proposal of an integrated monitoring system for maintenance. Dissertação (Mestrado) - Escola de Engenharia de São Carlos, Universidade de São Paulo, São Carlos, 2004.

Historically, the maintenance activities have been characterized as a problem for the organizations. However, in the last years, maintenance has been recognized as strategic for the enterprises. This change in the role played by maintenance is a result of the globalization of markets that force the organizations to compete not only in quality, prices, but also in technology innovation, time to market and information technology. Information is an essential resource for achieving the objectives of managing. Regarding to maintenance, the gathering and analysis of data are of fundamental importance for the monitoring and control of the related activities. The system proposed in this research has the objective of improving the managing of maintenance through the data acquisition of acoustic emission in rotary equipments. This research aims at the confirmation of the possibility of monitoring failure in ball bearings though the monitoring of acoustic emission and from this information to manage the maintenance processes. The analysis of the collected data offered parameter for the generation of a list of integrated actions for the maintenance department as well other involved sectors of the company.

Key words: maintenance, monitoring, acoustic emission. 


\section{INTRODUÇÃO}

No cenário mundial atual, a qualidade e o baixo custo são elementos fundamentais para que a empresa mantenha sua competitividade.

Nesse quadro, a manutenção representa um segmento importante. $\mathrm{O}$ desenvolvimento de programas de gestão de manutenção, assim como o de novas técnicas de execução e monitoramento de tarefas, pode proporcionar condições para que a empresa atinja um diferencial competitivo que permita a organização se transformar numa ilha de excelência.

A Associação Brasileira de Manutenção (ABRAMAN), em sua pesquisa "A Situação da Manutenção no Brasil", informa que os custos de manutenção no país representam $4,2 \%$ do PIB, o que totaliza algo próximo de US\$28 bilhões por ano. Esta cifra significa que aproximadamente $4 \%$ do faturamento bruto das empresas são gastos com manutenção. Para tratar com os altos valores envolvidos, é necessário que as empresas procurem trabalhar de maneira adequada às ações de manutenção bem como localizar o ponto ótimo entre custo, disponibilidade e confiabilidade de instalações e equipamentos.

Uma análise crítica da evolução da manutenção mostra que, na maioria das empresas, este setor ainda não atingiu um patamar de gestão e desenvolvimento técnico compatível com outras funções da produção (DIAS, 2003, p.35).

Por outro lado, a introdução de novos recursos tecnológicos nas telecomunicações tem provocado considerável impacto nas organizações. Sistemas operacionais, bem como outros de finalidade completamente dedicados, têm demonstrado reação a esta mudança. Redes de computadores que há dez anos eram consideradas artigos de luxo para poucas empresas, hoje povoam o ambiente empresarial de forma tão rotineira que algumas organizações já não distinguem as próprias fronteiras.

Os avanços tecnológicos transformam rapidamente a forma, a velocidade e a qualidade das informações bem como o conhecimento disponível. Desta maneira, a definição precisa de informações relevantes e o adequado monitoramento das mesmas são extremamente importantes no que tange a estratégia das empresas. $O$ desenvolvimento de microprocessadores e 
outros instrumentos baseados em computador usados para monitorar a condição operativa de plantas e equipamentos têm oferecido meios para se gerenciar a operação de manutenção.

Em geral, as máquinas rotativas são apoiadas por mancais. $O$ monitoramento desses componentes possibilita que os responsáveis pela manutenção possam tomar atitudes pró-ativas em relação a ocorrência de falhas, evitando, assim, paradas que comprometam as plantas e equipamentos.

Atualmente existem vários sistemas de gestão de manutenção que monitoram componentes. O monitoramento de mancais, em geral, é executado através de análise de vibrações. Esses procedimentos, além de complexos, tendem a ser dispendiosos, o que dificulta o acesso a esta tecnologia a uma gama maior de empresas.

A motivação para a realização desse trabalho veio do fato de não existir um sistema que possibilite o monitoramento de máquinas e equipamentos rotativos de maneira tecnicamente simples e a baixo custo, bem como pela oportunidade oferecida pela tecnologia de informação de que este monitoramento seja feito de forma remota e em tempo real.

Portanto, um sistema de informação capaz de propiciar os requisitos descritos acima é de vital importância para que a função manutenção assuma definitivamente o papel estratégico que realmente lhe cabe no âmbito da organização.

\section{1 OBJETIVO}

O objetivo deste trabalho é o desenvolvimento de um sistema de monitoramento integrado para manutenção, a partir da aquisição de dados através de sensores de emissão acústica em equipamentos rotativos. Para tanto serão utilizados produtos, componentes e tecnologias já existentes, entretanto de uma forma inovadora, uma vez que o trabalho apresentado busca a agregação de novas funções aos sensores de emissão acústica já em uso.

Meireles (2000, p.3-4) destaca que genericamente um sistema de aquisição de dados é composto de duas partes:

- Coleta de dados 
- Comunicação.

A coleta de dados é feita através de sensores, que captam as informações a serem monitoradas e as transformam em sinais elétricos que serão analisados, em última instância, por um sistema supervisor.

Uma vez tendo sido realizada a coleta de dados se faz necessário o envio dos mesmos para a unidade de gerenciamento do sistema. Para isso se deve escolher a melhor forma de transmissão para o atendimento do sistema em termos de velocidade, segurança, confiabilidade, robustez, etc.

Para se atender essas premissas, foi criado um modelo de testes que serviu como base para a realização do trabalho.

\section{2 DEFINIÇÃO DO PROBLEMA DE PESQUISA}

A idéia inicial do trabalho de dissertação apresentado surgiu da constatação, por parte do pós-graduando, da reduzida utilização de conceitos de gestão de manutenção por parte das empresas da área de construção civil, principalmente as médias e pequenas companhias deste setor.

A princípio, o trabalho visava o desenvolvimento de um programa de gestão, que contemplasse a introdução de práticas de Engenharia de Produção, com o objetivo de se alcançar um nível de excelência compatível com os setores de operação.

As conversas iniciais com o Orientador do trabalho, Prof. Titular João Fernando Gomes de Oliveira, e uma breve revisão bibliográfica levaram a uma redefinição do problema, o que confere com a teoria desenvolvida nos estudos da disciplina sobre metodologia em pesquisa de engenharia de produção, que mostra que esses são os passos iniciais para o desenvolvimento de um trabalho que busca o reconhecimento acadêmico.

Com a redefinição do problema, o objetivo do mesmo passou a ser: "Proposta de um sistema integrado de monitoramento para manutenção".

\section{3 CARACTERIZAÇÃO DO PROBLEMA}

Uma vez tendo sido redefinido o problema, deve-se caracterizá-lo.

A primeira questão a ser levantada é se o escopo do trabalho pertence à Engenharia de Produção. De acordo com o AllE - American Institute of 
Industrial Engineers a "Engenharia de Produção será reconhecida como a profissão de vanguarda, cujos praticantes planejam, projetam, implantam e gerenciam sistemas integrados de produção e de serviços, que asseguram desempenho, confiabilidade, manutenibilidade, aderência ao programa e controle de custos. Tais sistemas têm natureza sócio-técnica e devem integrar pessoas, informações, materiais, equipamentos, processos e energia através de todo o ciclo de vida do produto, serviço ou programa". Conclui-se, portanto, que o problema se encaixa perfeitamente nessa área, pois trata do planejamento e implantação de um sistema integrado de monitoramento de manutenção, que auxilie na gestão da mesma.

Segundo a classificação de Popper $^{1}$ (1995 apud ABRAMCZUK, 2003), trata-se de um problema incompleto, científico e praxiológico, pois o mesmo nunca terá uma solução definitiva; surgiu de aspectos da realidade, que atraíram a atenção do ser humano, e desencadeou um processo crítico destes aspectos pela mente humana; finalmente, constitui-se de uma ação humana, sem levar em conta quaisquer elementos da vida interior que determinam esta ação.

Analisando-se os níveis de caracterização de Boulding (1956), nota-se que o problema proposto, localiza-se no nível 3, já que trata de um sistema de controle, contudo, como visa à implantação de um plano de gestão, enquadrase também no nível 8.

Da mesma forma, pode-se concluir, que segundo Lovejoy (1998) o problema se situa no eixo engenharia-procedimentos organizacionais.

\section{4 RELEVÂNCIA E CONTRIBUIÇÕES}

A gestão de manutenção efetuada de forma preditiva minimiza não só o número e os custos de paradas não programadas, como também as intervenções por vezes desnecessárias da manutenção preventiva, já que o monitoramento possibilita que as tarefas de manutenção sejam baseadas em condição e não fundadas em estatísticas de vida útil.

No que tange a contribuição da pesquisa em desenvolvimento, pode-se responder a seguintes questões: 
- O que é novo?

- Por que dessa forma?

As repostas encontradas são:

- Os sensores de emissão acústica são utilizados, em manutenção, para o monitoramento de componentes estáticos. O objetivo é a utilização destes sensores na análise de componentes rotativos, o que é feito muito raramente nos dias atuais.

- A utilização de emissores acústicos vem crescendo nas empresas nos setores de manufatura, visto que os mesmos possibilitam medidas precisas de disponibilidade das máquinas.

\section{5 DEFINIÇÃO DA METODOLOGIA DE PESQUISA}

Pela definição do problema proposto, a realização de uma pesquisa quantitativa parece ser a mais indicada para a solução do mesmo.

Com o objetivo de atender as premissas propostas para um sistema de aquisição de dados, criou-se um modelo de testes. Composto por um motor elétrico que aciona um eixo apoiado em dois mancais de rolamentos, através de um acoplamento elástico, e um sistema de captura de informações, utilizando-se sensores de emissão acústica, conectado a rede local do laboratório do NUMA (Núcleo de Manufatura Avançada da EESC - USP), o modelo permite simular situações onde as condições dos mancais variam desde um ponto considerado bom, até um ponto em que a ocorrência de falhas é praticamente certa. Dessa maneira, é possível o acompanhamento da variação do sinal de emissão acústica em função do estado de deterioramento dos rolamentos dos mancais.

Para a simulação do estado de desgaste dos rolamentos, foram utilizados dois pares de rolamentos:

- Um par de rolamentos novos, considerados em perfeito estado, entretanto não foram realizados testes que garantissem este fato, simplesmente foram aceitos como em bom estado por serem novos.

- Um par de rolamentos comprovadamente deteriorados.

${ }^{1}$ POPPER, K. (1995) Philosophy and problems apud ABRAMCZUK, A.A. (2003) Qual o seu problema? 
Com estes dois pares de rolamentos, foram realizadas todas as possíveis variações de montagem com rolamentos bons e ruins. Foram, também, variadas as condições de lubrificação, a fim de se avaliar a influência da mesma na emissão acústica.

A figura 1. 1 apresenta o modelo desenvolvido para a realização do experimento.

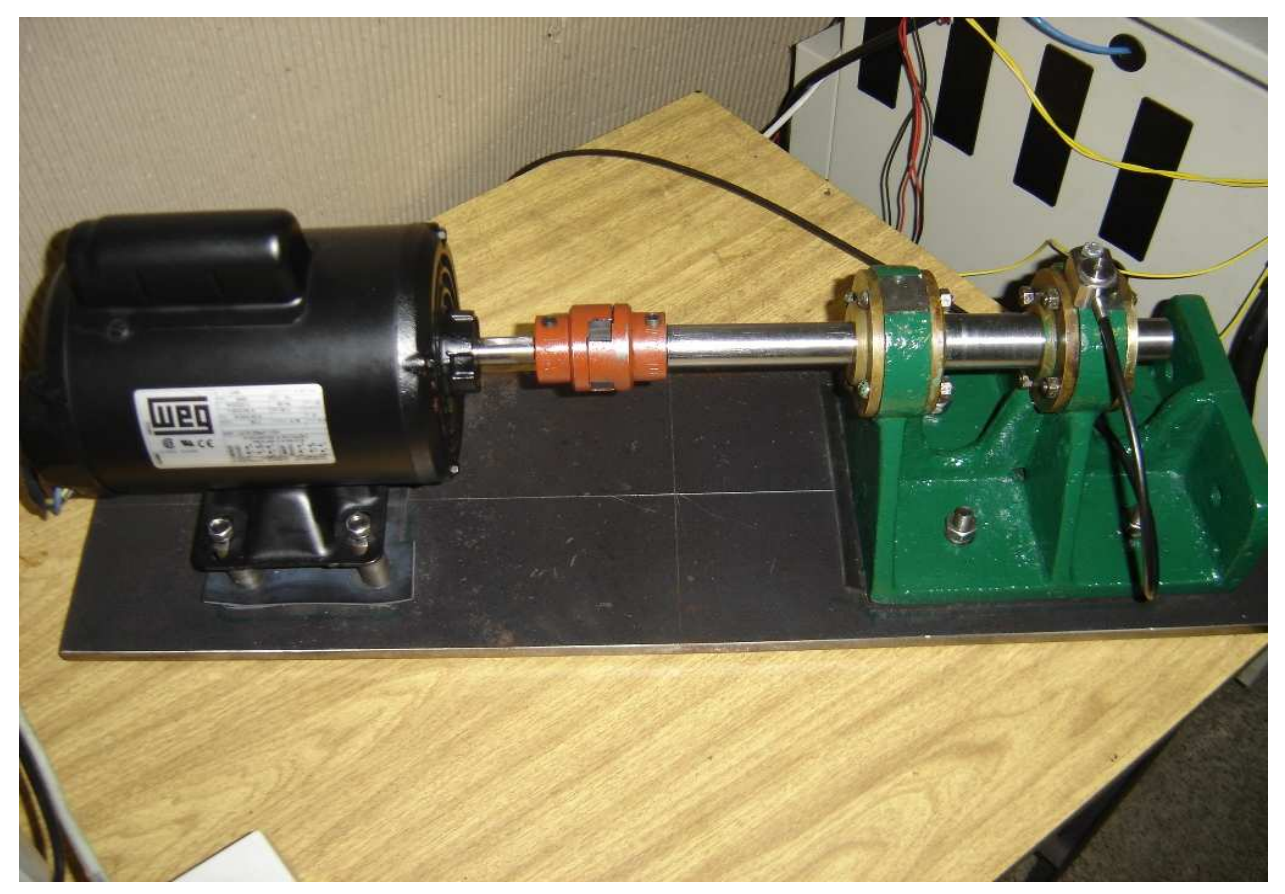

Figura 1. 1: Modelo para ensaios

\section{6 ESTRUTURA DA DISSERTAÇÃO}

A dissertação será estruturada em sete capítulos:

Capítulo 1 - INTRODUÇÃO

Nesse capítulo são apresentados um breve sumário da situação atual da manutenção nas empresas, os principais objetivos do trabalho e a metodologia de pesquisa em Engenharia de Produção.

Capítulo 2 - TÓPICOS SOBRE GESTÃO DE MANUTENÇÃO

Nessa parte da dissertação, é apresentada a revisão bibliográfica acerca da gestão de manutenção. Os tópicos são apresentados de forma que propiciem uma visão geral da função manutenção, bem como auxiliem no entendimento do sistema de aquisição de dados no monitoramento de equipamentos. 


\section{Capítulo 3 - CONCEITOS E TECNOLOGIAS ENVOLVIDOS}

São apresentados neste capítulo os conceitos e tecnologias necessários à elaboração do sistema que será apresentado posteriormente.

Capítulo 4 - PROPOSTA DE UM SISTEMA INTEGRADO DE MONITORAMENTO PARA A MANUTENÇÃO

Neste capítulo é apresentado o sistema de monitoramento proposto, bem como uma descrição dos componentes do mesmo.

Este capítulo mostra, ainda, como foi montado o banco de ensaios no Núcleo de Manufatura Avançada (NUMA) da EESC - USP, afim de que realizasse os testes necessários para a avaliação do sistema proposto.

Neste ponto do trabalho, reside a elaboração do modelo necessário para o reconhecimento da dissertação.

Como regra geral, o delineamento do experimento deve ser criterioso, e o modelo proposto deve ser validado.

Capítulo 5 - TESTES E AVALIAÇÃO DOS RESULTADOS

Mostra a forma como foram realizados os testes, os resultados obtidos e a discussão sobre os mesmos.

Capítulo 6 - CONCLUSÕES

São apresentadas algumas conclusões a respeito do presente trabalho.

Capítulo 7 - PROPOSTAS PARA TRABALHOS FUTUROS

São dadas algumas sugestões para a complementação e o aperfeiçoamento do projeto realizado. 


\section{TÓPICOS SOBRE GESTÃO DE MANUTENÇÃO}

Neste capítulo é apresentada à revisão bibliográfica sobre os principais conceitos de manutenção, necessária para o desenvolvimento do trabalho realizado.

\section{1 DEFINIÇÃO DE MANUTENÇÃO}

Existem várias definições para manutenção, porém de certa forma estes conceitos têm vários pontos de convergência, ao mesmo tempo em que estas definições mostram os estágios evolutivos da manutenção.

A norma NBR 5462 da ABNT² (1994 apud PASQUA, 1999, p.12), define manutenção como sendo "a combinação de todas as ações técnicas e administrativas, incluindo as de supervisão, destinadas a manter ou recolocar um item em um estado no qual possa desempenhar uma função requerida".

Para Slack et al. (1999, p.491) "manutenção é o termo usado para abordar a forma pela qual as organizações tentam evitar as falhas cuidando de suas instalações físicas".

Tavares (1987) considera manutenção como sendo todas as ações necessárias para que um item seja conservado ou restaurado, de modo a poder permanecer de acordo com uma condição especificada.

Para Ariza (1978) manutenção é manter os equipamentos em funcionamento como foram projetados.

Motta (1999) diz que no primeiro quarto do século XX, manutenção significava "consertar o que quebrou", já atualmente significa também tomar atitudes preventivas para reduzir a probabilidade de ocorrência de falhas.

Mirshawka e Olmedo (1993) conceituam manutenção como o conjunto de atividades técnicas e administrativas, que visam conservar ou restituir um item para que o mesmo cumpra a função dele exigida.

2 ABNT (1994) Norma NBR 5462 apud PASQUA, M.C. (1999). Desenvolvimento de uma sistemática para padronização e gerenciamento da programação da manutenção de equipamentos e instalações a partir dos conceitos da qualidade. 
A norma TB - 116 da ABNT (1975), (substituída pela ABNT NBR 5462, 1994), trazia a seguinte definição:

Todas as ações necessárias para que um item seja conservado ou restaurado de modo a poder permanecer de acordo com uma condição especificada.

Percebe-se que as definições mais antigas (ABNT, 1975; Ariza, 1978), destacam a conservação do equipamento, enquanto as mais atuais destacam a função do mesmo, o que evidencia a evolução do conceito de manutenção.

\section{2 HISTÓRICO DA MANUTENÇÃO}

A função manutenção aparece, efetivamente, no século $\mathrm{XVI}$, com a invenção das primeiras máquinas a vapor, embora a prática conservação de instrumentos e ferramentas sempre tenha sido observada pelo homem. Nesses primeiros tempos da manutenção, quem projetava e construía as máquinas, treinava as pessoas para operarem e consertarem, e só intervinha em situações mais complexas. Somente quando as máquinas passaram a ser acionadas por motores elétricos, é que aparece a figura do mantenedor eletricista (WYREBSKI, 1997).

Moubray (1992, p.2) considera que dos anos 30 até a segunda guerra mundial, a indústria não era altamente mecanizada e, portanto o tempo ocioso não era substancial, assim muitos gerentes tinham a idéia de que a prevenção de falhas de equipamentos não era prioritária. Nessa época as máquinas eram simples e super-dimensionadas, o que acarretava confiança e facilidade de reparo. Como resultado, não havia necessidade de uma sistemática de manutenção para simples limpeza ou rotinas de serviços de lubrificação.

Tavares (1987, p.3) sustenta que com o advento da Primeira Guerra Mundial e com a implantação da produção em série por parte de Ford foi estabelecido um programa mínimo de produção, o que levou a necessidade de criar equipes capazes de efetuar reparos em máquinas operatrizes com menor intervalo de tempo possível.

Nos tempos da Segunda Guerra Mundial, houve uma considerável evolução das formas de manutenção, em virtude da necessidade de se manter os equipamentos bélicos e de apoio em funcionamento. 
Para Monchy ${ }^{3}$ (1989 apud WYREBSKY, 1997, p.8)
o termo 'manutenção' tem sua origem no vocábulo militar, cujo
sentido era 'manter, nas unidades de combate, o efetivo e o material
num nível constante'. É evidente que as unidades que nos interessam
aqui são as unidades de produção, e o combate é antes de tudo
econômico. O aparecimento do termo 'manutenção' na indústria
ocorreu por volta do ano de 1950 nos Estados Unidos da América. Na
França, esse termo se sobrepõe progressivamente à palavra
'conservação'.

Até o início da segunda metade do século $X X$, a manutenção praticada era a corretiva, somente a partir de 1950 é que começam a surgir preocupações em programar a função manutenção.

Nakajima (1989, p.11) destaca que, a partir de 1951, tem início a prática de manutenção preventiva, em 1954 surge à manutenção do sistema produtivo (MSP) e em 1957 a manutenção corretiva com incorporação de melhorias (MM).

Ainda conforme Nakajima (1989, p.11), durante a década de 60 , os conceitos de confiabilidade, segurança e economicidade passam a ser encarados como pontos fundamentais dentro do sistema produtivo (é a era da manutenção do sistema produtivo). Na década de 70 , a ênfase passa a ser a pessoa do homem, administração participativa e a visão de um sistema total ou global, mesmo no campo da manutenção esses conceitos foram incorporados, com o desenrolar da manutenção produtiva total (TPM).

Moubray (1992, p.2-3) destaca que, a partir da metade dos anos 70, a indústria colecionou grandes mudanças de processos. Desse modo o tempo ocioso afetava a capacidade produtiva de itens físicos pela redução de saída de produtos, aumentando os custos de produção e interferindo com o serviço ao consumidor. Com o advento dos sistemas de just in time, onde a redução de estoques é fundamental, pequenas falhas podem levar a parada das plantas.

A partir de 1980, com o desenvolvimento dos microcomputadores, com custos mais reduzidos e linguagem simples, os órgãos de manutenção passaram a desenvolver seus próprios programas, eliminando a dependência de um computador central, aumentando assim a autonomia organizacional desses órgãos (TAVARES, 1987, p.3).

${ }^{3}$ MONCHY, F. (1989). A função manutenção - Formação para a gerência d manutenção industrial. São Paulo: Durban apud WYREBSKI, J. (1997). Manutenção produtiva total: Um modelo adaptado. 
Para alguns autores, entre eles Tavares (1987) e Rodrigues (2003), o aumento da complexidade dos equipamentos levou a uma especialização dos times responsáveis pela conservação dos mesmos, o que acabou gerando a desvinculação entre produção e manutenção. Este processo de separação só começará a ser revertido na década de 80 , com a introdução da Manutenção Autônoma, um dos pilares da Manutenção Produtiva Total (TPM).

Em 1986 é introduzida a TPM no Brasil.

$\mathrm{Na}$ década de 90, com o aumento das exigências em relação à qualidade dos produtos e serviços, a partir dos consumidores, a manutenção adquire um maior grau de importância equiparando-se a operação (PASQUA, 1999, p.17).

Durante os anos 90, graças principalmente a um maior desenvolvimento das técnicas de monitoramento, a manutenção preditiva ganha um impulso maior passando a ser o foco da gestão de inúmeras empresas.

Moubray (1992, p.5) resume a evolução da manutenção em três gerações, como mostra a figura 2. 1:

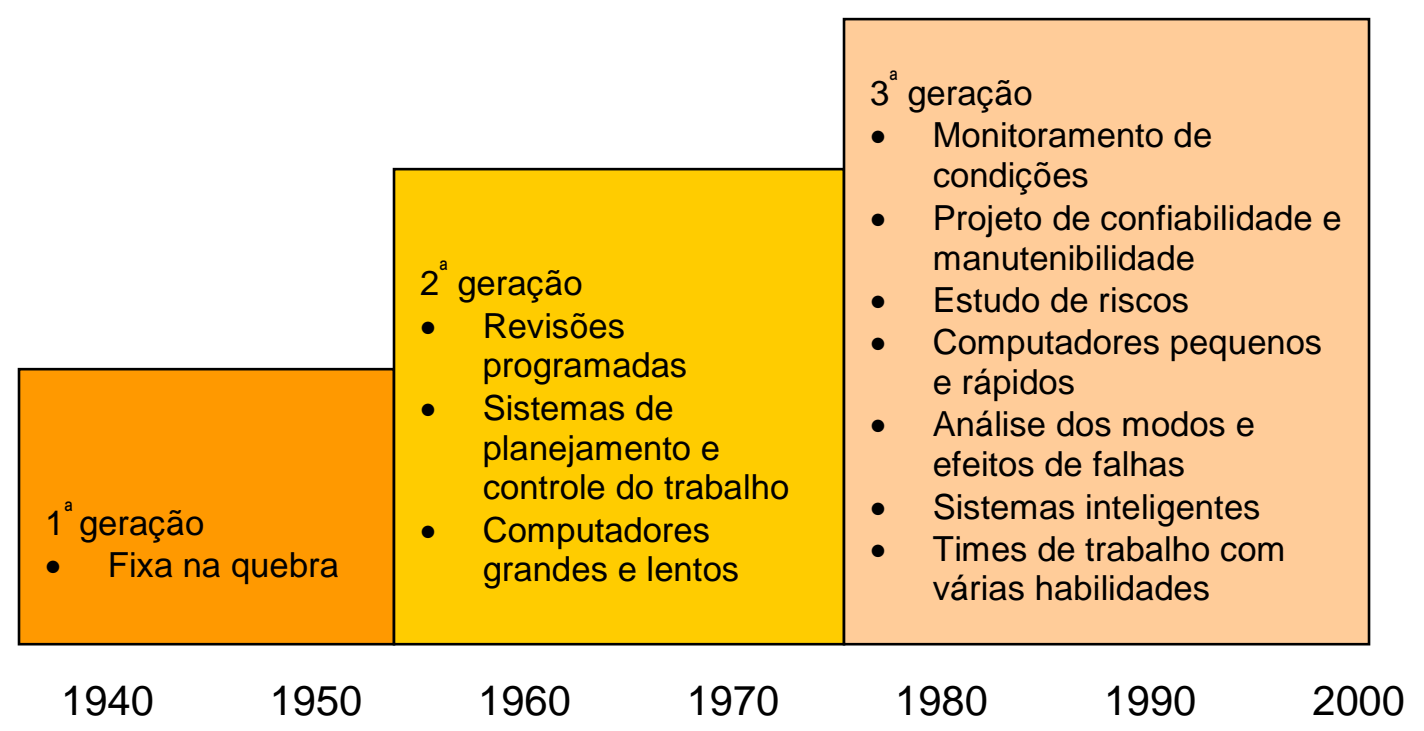

Figura 2. 1: Mudança nas técnicas de manutenção

Fonte: Moubray 1992, p.5. 


\section{3 A MISSÃO DA MANUTENÇÃO}

A missão da manutenção nos dias atuais, passa por uma quebra de paradigmas.

Para Pinto e Xavier (1999, p.12), a missão da manutenção é manter a "... disponibilidade da função dos equipamentos e instalações de modo a atender o processo produtivo, e a preservação do meio ambiente, com confiabilidade, segurança e custos adequados".

Xenos (1998) observa que as atividades de reparo são uma pequena parte das atribuições da manutenção, pois a maioria de suas ações deve ser direcionada no sentido de se evitar sistematicamente a ocorrência de falhas.

Pinto e Xavier (1999, p.12), comparando a manutenção com uma brigada de incêndio, descrevem, "quando ocorre à emergência a brigada deve atuar rapidamente, mas a principal atividade da brigada, a partir daí, é evitar a ocorrência de novos incêndios". Este conceito é observado na figura 2. 2, que mostra a mudança de paradigma da manutenção.

Paradigma do passado
Paradigma moderno

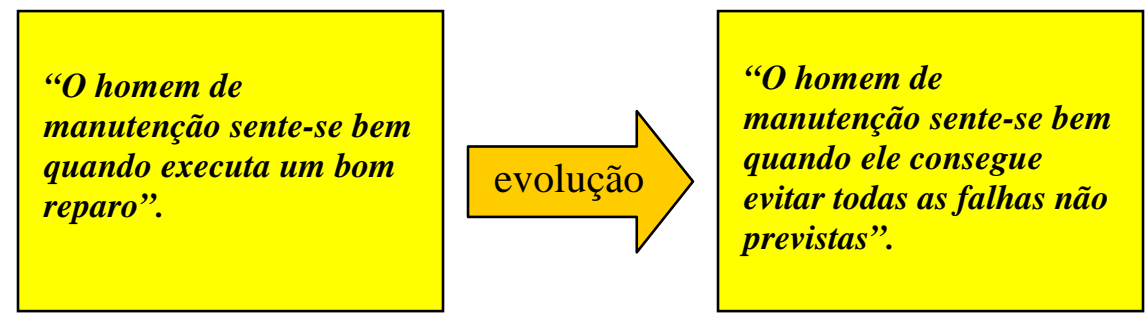

Figura 2. 2: Mudança dos paradigmas de manutenção

Fonte: Adaptado de Pinto e Xavier $^{4}$ (2001, p.17, apud RODRIGUES, 2003, p.30).

Sem essa mudança de paradigmas, será necessário um grande esforço para se conseguir uma melhoria pouco significativa, o que pode não ser

${ }^{4}$ PINTO, A.K. e XAVIER, J.A.N. (2001). Manutenção - Função estratégica. Rio de Janeiro: Qualitymark apud RODRIGUES, M. (2003). Manutenção industrial em Curitiba e cidades circunvizinhas: Um diagnóstico atual. 
suficiente para manter a competitividade da empresa (PINTO E XAVIER, 1999, p.13).

\section{4 IMPORTÂNCIA ESTRATÉGICA DA MANUTENÇÃO}

Historicamente, a manutenção foi considerada como um "mal necessário" por vários dirigentes das organizações. Entretanto, nos últimos anos, esta atitude está sendo alterada, dando a manutenção uma posição estratégica dentro das empresas. Os fatores que levaram a esta mudança foram: questões ambientais, razões de segurança, itens de garantia e responsabilidade com consumidores, matérias regulamentares, envelhecimento de plantas e equipamentos, direcionamento para reduções de custo e outros fatores competitivos como agilidade de entrega, confiabilidade de entrega e flexibilidade. Para atender as novas expectativas demandadas pelas atividades de manutenção, programas têm sido desenvolvidos para assegurar que os itens físicos continuem a cumprir integralmente sua função com custos e recursos mínimos. Está claro que funções de manutenção que não cumpram este papel devem ser eliminadas (TSANG, 1995, p.3).

Finch e Gilbert (1986, p.449) destacam que uma manutenção eficiente tem sido de grande importância para manter as plantas de manufatura rodando, e mais recentemente, esta importância tem aumentado em virtude de quatro fatores proeminentes: a redução de estoques intermediários nas plantas de manufatura (estoques de work-in-process); pressão das empresas para incrementar sua produtividade; aumento da automação das plantas, com incremento de robotização; avanço tecnológico dos equipamentos, necessitando de técnicos altamente especializados na manutenção.

Em razão de se posicionarem como empresas de classe mundial, muitas organizações têm realizado sistemas eficazes de manutenção para dar suporte a produção. Com o advento da produção enxuta, tornou-se vital a integração da gestão da manutenção na estratégia corporativa para assegurar a disponibilidade dos equipamentos, qualidade dos produtos, prazos de entrega e preços competitivos. Esta mudança necessária para a modernização das manufaturas levou a um re-exame do papel da gestão de manutenção a fim de 
se atingir vantagens competitivas (RIIS, LUXHOJ E THORSTEINSSON, 1997, p.349).

Tsang (2002, p.7-10) identifica quatro dimensões estratégicas para a gestão de manutenção. As três primeiras (mudanças devido à implantação do just in time, exigências ambientais e transformações tecnológicas) já foram comentadas. A quarta dimensão é a transformação das pessoas no sistema organizacional. De acordo com o autor, até tempos atrás, as organizações estavam preocupadas somente com a produção, deixando a dimensão de pessoal em segundo plano. Atualmente, em face de uma nova realidade, progressivamente as organizações estão se preocupando cada vez mais com a qualidade de vida de seus funcionários, introduzindo inovações para gerar alta satisfação dentro da organização. Dentre essas inovações pode-se citar: alto gereciamento, estruturas horizontais, times multidisciplinares, organizações virtuais e estratégia de alianças. Algumas dessas mudanças devem ser introduzidas na gestão da manutenção, a fim de levar a função manutenção a um nível de excelência para as empresas.

Ainda no que se refere à dimensão humana, Pinto e Xavier (1999, p.1112) citam que além de indicadores que meçam a Disponibilidade, a Confiabilidade, o Custo e a Qualidade do Atendimento, também é fundamental a utilização de indicadores que meçam o Moral, a Motivação e a Segurança do Grupo. Agindo dessa maneira, concluem os autores, “... é que a manutenção se torna uma FUNÇÃO ESTRATÉGICA".

A importância estratégica da manutenção pode também ser observada em função dos custos envolvidos nessa área de gestão.

Almeida (p.1), afirma que:

Os custos de manutenção correspondem à parte principal dos custos
operacionais totais de todas as plantas industriais de manufatura e de
produção. Dependendo da indústria específica, os custos de
manutenção podem representar entre $15 \%$ a $30 \%$ do custo dos bens
produzidos. Por exemplo, em indústrias alimentícias, os custos
médios de manutenção podem representar cerca de $15 \%$ do custo
dos bens produzidos; enquanto que nas indústrias siderúrgicas, de
papel e celulose, e outras indústrias pesadas, a manutenção pode
representar até $30 \%$ dos custos totais de produção.

Mais um dado que evidencia este argumento é dado por Almeida (p.1), segundo o autor a "Indústria Americana gasta mais de 200 bilhões de dólares todo ano com manutenção de equipamentos de fábricas e instalações”. 


\section{5 TIPOS DE MANUTENÇÃO}

A forma como se processa a intervenção em um equipamento define os vários tipos de manutenção existentes, e que muitas vezes recebem denominações diferentes. Por isso, é importante uma caracterização mais objetiva dos diversos tipos de manutenção, o que é feito a seguir.

\section{5. 1 MANUTENÇÃO CORRETIVA}

Manutenção corretiva consiste em reparar os equipamentos, ferramentas, máquinas depois que a quebra tenha ocorrido.

Para Monchy ${ }^{5}$ (1989 apud WYREBSKY, 1997, p.7) "a manutenção corretiva corresponde a uma atitude de defesa (submeter-se, sofrer) enquanto se espera uma próxima falha acidental (fortuita), atitude característica da conservação tradicional".

Segundo Viana6 ${ }^{6}$ (1991 apud WYREBSKY, 1997, p.7)

manutenção corretiva é a atividade que existe para corrigir falhas decorrentes
dos desgastes ou deterioração de máquinas ou equipamentos. São os
consertos das partes que sofreram a falha, podendo ser: reparos,
alinhamentos, balanceamentos, substituição de peças ou substituição do
próprio equipamento.

Segundo Harding7 (1981 apud WYREBSKY, 1997, p.8) "manutenção corretiva é o trabalho de restaurar um equipamento para um padrão aceitável". Manutenção corretiva, também conhecida como manutenção de avaria, é executada quando a ação é tomada para restaurar a capacidade funcional dos equipamentos ou sistemas avariados ou em mau funcionamento. Trata-se de uma atitude reativa, porque a ação de manutenção é disparada por um evento não programado ou falha do equipamento (TSANG, 1995, p.3). A principal vantagem da manutenção corretiva consiste em não exigir acompanhamentos e inspeções nas máquinas (WYREBSKI, 1997, p.8).

\footnotetext{
${ }^{5}$ MONCHY, F. (1989). A função manutenção - Formação para a gerência d manutenção industrial. São Paulo: Durban apud WYREBSKI, J. (1997). Manutenção produtiva total: Um modelo adaptado. p. 7.

${ }^{6}$ VIANA, L.P. (1991). III Semanário de manutenção - Trabalhos Técnicos - secção regional VII Paraná e Santa Catarina. Curitiba: ABRAMAN apud WYREBSKI, J. (1997). Manutenção produtiva total: Um modelo adaptado. p. 7.

HARDING, H.A. (1981). Administração de Produção. São Paulo: Atlas apud WYREBSKI, J. (1997). Manutenção produtiva total: Um modelo adaptado. p. 7.
} 
Muitos autores destacam que a manutenção corretiva é uma técnica de gerenciamento, em que os custos envolvidos são extremamente altos, quando comparados a outros tipos de gestão da manutenção.

Para Tsang (1995, p.3) com este tipo de manutenção em geral os custos são elevados pelos seguintes motivos:

- Alto custo de recuperação das condições de operação do equipamento em situação de crise.

- Danos secundários e riscos de segurança impostos pela falha.

- Penalidades associadas pela perda de produção.

Conforme Almeida (p.2),

Já que não há nenhuma tentativa de se antecipar os requisitos de manutenção, uma planta que utilize gerência por manutenção corretiva absoluta deve ser capaz de reagir a todas possíveis falhas dentro da fábrica. Este método reativo de gerência força 0 departamento de manutenção a manter caros estoques de peças sobressalentes que incluem máquinas reservas ou, pelo menos, todos os principais componentes para todos os equipamentos críticos da fábrica. A alternativa é fundar-se em vendedores de equipamentos que possam oferecer entrega imediata de todas as peças sobressalentes requisitadas.

Ainda conforme Almeida (p.2),

A análise dos custos da manutenção indica que um reparo realizado do modo corretivo-reativo terá em média um custo de cerca de três vezes maior que quando o mesmo reparo for feito dentro de um modo programado ou preventivo.

Nem todas as falhas podem ser previstas com exatidão, portanto falhas ocorrerão e assim deve-se ter a preocupação de se conhecer com precisão as tarefas de manutenção corretiva, afim de que se possa executá-la com a maior eficiência possível (FINCH E GILBERT, 1986, p.452).

Para Pinto e Xavier (1999, p.33)

Quando uma empresa tem a maior parte de sua manutenção corretiva na classe não planejada, seu departamento de manutenção é comandado pelos equipamentos e o desempenho empresarial da Organização, certamente, não está adequado às necessidades de competitividade atuais.

A necessidade de execução de tarefas de manutenção corretiva define o tipo de ação que deve ser tomada, e que em geral se resume a três tipos:

- Paliativa - ação de emergência para recolocar o equipamento em funcionamento.

- Curativa - repara em caráter definitivo. 
- Melhorativa - modificação ou troca de condições originais (RODRIGUES, 2003, p.32).

\section{5. 2 MANUTENÇÃO PREVENTIVA}

Existem várias definições de manutenção preventiva, em geral essas definições indicam que as tarefas de manutenção preventiva são disparadas pelo tempo. As tarefas de manutenção baseadas em condição ou monitoramento, para este trabalho serão consideradas tarefas de manutenção preditiva, e serão analisadas no item 2.5.3.

Para Slack et. al. (1999, p.492), "manutenção preventiva visa eliminar ou reduzir as probabilidades de falhas por manutenção (limpeza, lubrificação, substituição e verificação) das instalações em intervalos pré-planejados".

Segundo Viana ${ }^{8}$ (1991 apud WYREBSKY, 1997, p.8)

manutenção preventiva é uma filosofia, uma série de procedimentos, ações, atividades ou diretrizes que podem, ou não, ser adotados para se evitar, ou minimizar a necessidade de manutenção corretiva. Adotar a manutenção preventiva significa introduzir o fator qualidade no serviço de manutenção.

Harding $^{9}$ (1981 apud WYREBSKY, 1997, p.8) define manutenção preventiva como "trabalho destinado à prevenção da quebra de um equipamento".

Para Monchy"10 (1989 apud WYREBSKY, 1997, p.8) "manutenção preventiva é uma intervenção de manutenção prevista, preparada e programada antes da data provável do aparecimento de uma falha".

Para se programar os intervalos de tempo para a execução das tarefas de manutenção preventiva vários fatores são empregados.

De acordo com Motta (1999), até a década de 60, o principal fundamento da manutenção preventiva era a curva do tempo médio para falha, conhecida como "curva da banheira", mostrada na figura 2. 3:

\footnotetext{
${ }^{8}$ VIANA, L.P. (1991). III Semanário de manutenção - Trabalhos Técnicos - secção regional VII Paraná e Santa Catarina. Curitiba: ABRAMAN apud WYREBSKI, J. (1997). Manutenção produtiva total: Um modelo adaptado. p.8.

${ }^{9}$ HARDING, H.A. (1981). Administração de Produção. São Paulo: Atlas apud WYREBSKI, J. (1997). Manutenção produtiva total: Um modelo adaptado. p.8.

${ }^{10}$ MONCHY, F. (1989). A função manutenção - Formação para a gerência d manutenção industrial. São Paulo: Durban apud WYREBSKI, J. (1997). Manutenção produtiva total: Um modelo adaptado. p.8.
} 


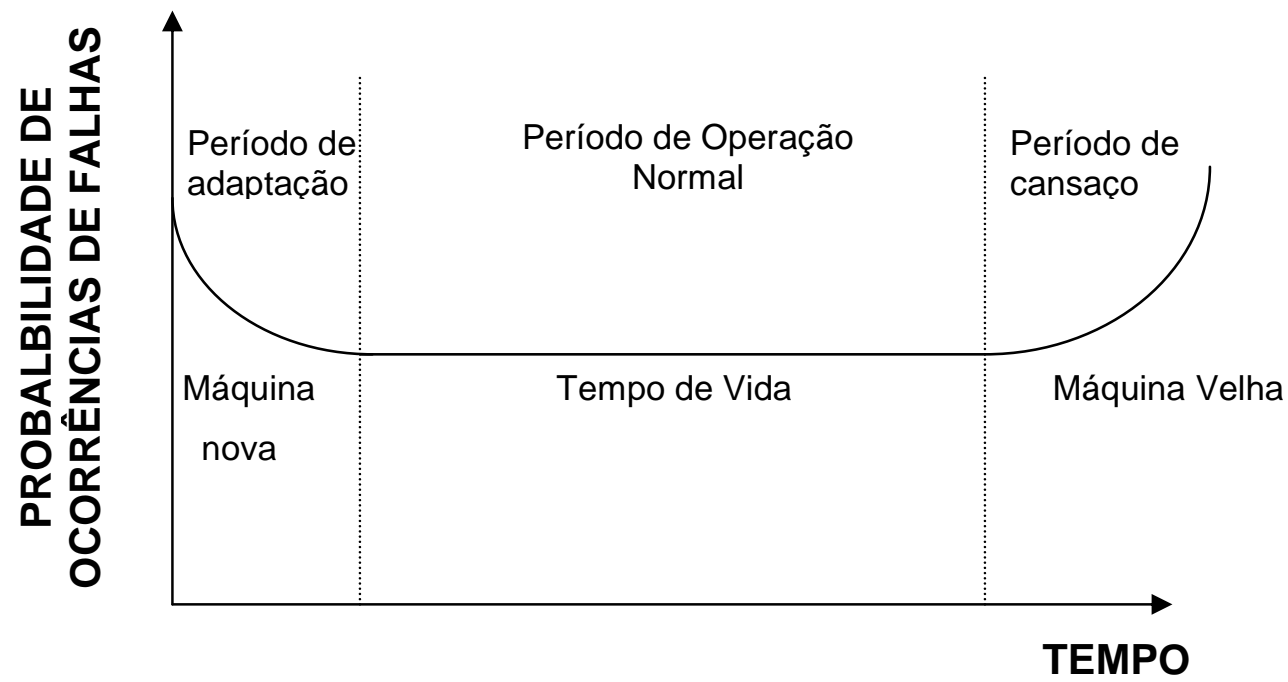

Figura 2. 3: Curva da Banheira

Fonte: Pasqua (1999, p.29)

Para Slack et al. (1999, p.481-482)

essa curva compreende três etapas distintas:

- a mortalidade "infantil" ou a etapa de "vida inicial", quando falhas iniciais ocorrem devido a peças defeituosas ou uso inadequado;

- a etapa de "vida normal", quando a taxa de falhas é normalmente baixa, razoavelmente constante e causada por fatores aleatórios normais;

- a etapa de "desgaste", quando a taxa de falhas aumenta à medida que a peça se aproxima do final de sua vida útil e as falhas são causadas por envelhecimento e deterioração das peças.

Wyder $^{11}$ (1977 apud FINCH E GILBERT, 1986, p.453) lista diversos fatores nos quais os intervalos de tempo podem ser baseados. Entre eles estão:

- Idade do equipamento.

- Condições do equipamento.

- Valor do equipamento.

- Condições de utilização do equipamento.

- Segurança requerida.

- Horas de operação.

- Suscetibilidade para desgaste.

- Suscetibilidade de risco.

- Suscetibilidade de perda de ajuste.

${ }^{11}$ WYDER, C.A. (1977). Preventive Maintenance - Maintenance Engineering Handbook. Nova York: McGraw-Hill apud FINCH, B.J. e GILBERT, J.P. (1986). Developing maintenance craft labor efficiency through an integrated planning and control system: A prescriptive model. 
Para Rodrigues (2003, p.33) a manutenção preventiva é adequada em "sistemas onde existam riscos ao meio ambiente e ao pessoal, sistemas complexos, sistemas de operação contínua, sistemas em que o custo da falha é muito elevado".

Para Finch e Gilbert (1986, p.452) os benefícios propiciados ao se adotar um sistema de manutenção preventiva são:

- Identificação dos itens com altos custos de manutenção, identificados principalmente por má utilização, abusos dos operadores e obsolescência.

- Adequar as vantagens de uma forma justa (excesso de valorização).

- Melhor relacionamento com os funcionários em virtude do menor afastamento de funcionários, e perda de incentivo.

- Menor custo de reparo, por se executar reparos mais simples antes da quebra.

- Declínio dos custos de manutenção em cada item do programa.

- Melhoria do controle de peças de reposição, diminuindo os estoques imobilizados.

- Menor rejeição de produtos, melhor controle de qualidade.

- Redução de pagamentos de horas extras no trabalho de manutenção

- Redução das paradas de produção

- Menor necessidade de equipamentos de reserva.

- Menor custo unitário de manutenção

- Menor escala de reparos.

- Maior segurança para os trabalhadores.

Como as tarefas de manutenção preventiva são programadas, baseando-se em tabelas de tempo, desenvolvidas pelos usuários dos equipamentos, ou por informações do fabricante dos mesmos, é essencial o planejamento detalhado deste sistema de manutenção.

Finch e Gilbert (1986, p.457) apresentam um diagrama de planejamento do sistema de manutenção preventiva integrado com manutenção corretiva, que é reproduzido na figura 2.4 . 


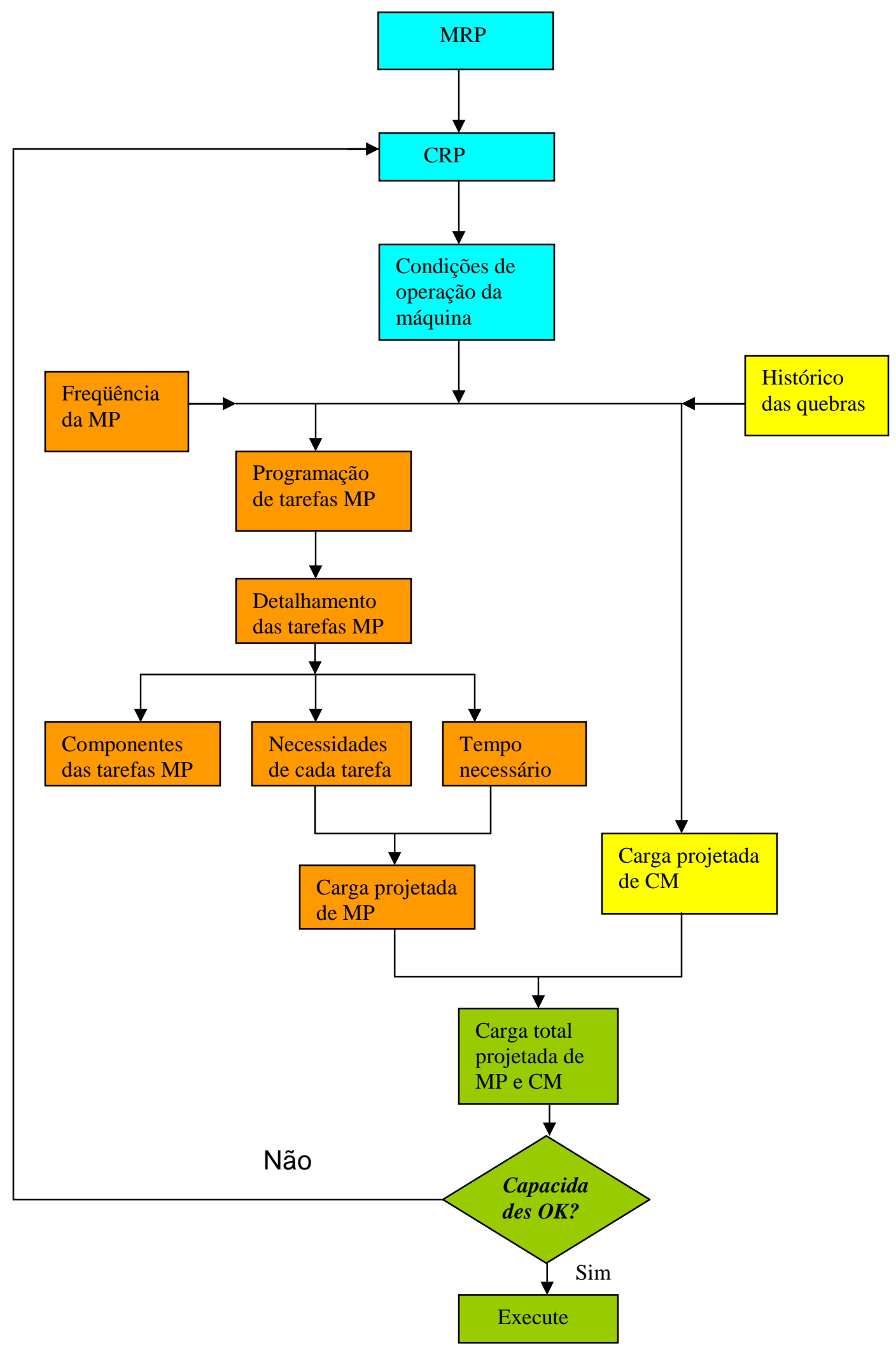

Figura 2. 4: Planejamento de Preventiva e Corretiva Integrado Fonte: Finch e Gilbert (1986, p.457)

Entre as desvantagens de se utilizar somente a manutenção preventiva como forma de gestão, os autores citam a possibilidade de gastos exagerados 
e desnecessários, que este tipo de gestão pode gerar, uma vez que podem ser realizadas intervenções antes da necessidade real das mesmas, ou que quebras ocorram antes do prazo previsto.

Há uma crença generalizada de que a manutenção preventiva é sempre mais econômica que a manutenção corretiva, e de que todas as falhas podem ser previstas. Em função desta crença, a manutenção baseada em tempo torna-se norma da manutenção preventiva, o que pode motivar gastos indiscriminados com os programas deste tipo de manutenção (TSANG, 1995, p.4).

Almeida (p.3) afirma "o resultado normal do uso da estatística do tempo médio entre falhas para programar a manutenção ou é um reparo desnecessário ou uma falha catastrófica".

O tempo médio entre falhas - TMEF ou MTBF como é mais conhecido (do inglês Mean Time Between Failures) - é uma medida alternativa de falhas de um componente ou sistema.

O MBTF é o inverso da taxa de falhas (em tempo). Ou seja:

MTBF = horas de operação / número de falhas

Pode-se medir a disponibilidade de um equipamento ou planta, como a não-operação em virtude da falha de um componente. Nesse caso a disponibilidade é dada por:

Disponibilidade $(\mathrm{D})=\mathrm{MTBF} / \mathrm{MTBF}+\mathrm{MTTR}$, onde :

MTBF é o tempo médio entre falhas

MTTR é o tempo médio para o reparo (do inglês Mean Time To Repair)

Dessa forma, percebe-se que uma estimativa otimista para o MTBF (intervalo de tempo maior que o real) pode ocasionar uma falha catastrófica por falta de manutenção, por outro lado uma estimativa pessimista (intervalo de tempo menor que o real) diminui a disponibilidade do equipamento ou da planta pelo excesso de manutenção.

Para Rodrigues (2003, p.33-34) o programa de manutenção preventiva se não for bem planejado e executado, causará prejuízos, ao invés de benefícios para a empresa.

Pinto e Xavier (1999, p.37) consideram ainda, como ponto negativo com relação à manutenção preventiva, a possível introdução de defeitos não existentes no equipamento devido a: 
- falha humana,

- falha de sobressalentes,

- contaminações introduzidas no sistema de óleo,

- danos durante partidas e paradas e

- falhas dos procedimentos de manutenção.

Concluindo, uma tarefa de "manutenção preventiva só deve ser aplicada em situações onde sua necessidade esteja perfeitamente identificada e justificada" (PINTO e XAVIER, 1999, p.112).

\section{5. 3 MANUTENÇÃO PREDITIVA}

A manutenção preditiva, também conhecida por manutenção condicionada, ou baseada na condição (CBM - Condition-based maintenance), é o tipo de prevenção de falhas que visa realizar a tarefa de manutenção quando ela for realmente necessária, ou em outras palavras tenta otimizar as tarefas da manutenção preventiva.

A manutenção baseada na condição (preditiva) e a manutenção baseada simplesmente no tempo (preventiva) são similares, entretanto, diferentemente da baseada em tempo, as tarefas de manutenção preditiva normalmente não envolvem intrusão no equipamento, e a ação preventiva só é tomada quando uma falha incipiente for detectada (TSANG, 1995, p.4).

Para Pinto e Xavier (1999, p.37) é "a atuação realizada com base em modificação de parâmetro de CONDIÇÃO ou DESEMPENHO, cujo acompanhamento obedece a uma sistemática".

Tavares (1999, p.126) destaca, "a determinação do ponto ótimo para execução da manutenção preventiva num equipamento, ou seja, o ponto a partir do qual a probabilidade de o equipamento falhar assume valores indesejáveis".

Monchy $^{12}$ (1989 apud WYREBSKY, 1997, p.9) afirma que a manutenção de condição é uma evolução da preventiva.

Mirshawka e Olmedo (1993, p.352), escrevem:

A manutenção preventiva baseada no conhecimento do estado/condição de um item, através de medições periódicas ou

\footnotetext{
${ }^{12}$ MONCHY, F. (1989). A função manutenção - Formação para a gerência d manutenção industrial. São Paulo: Durban apud WYREBSKI, J. (1997). Manutenção produtiva total: Um modelo adaptado. p.9.
} 
contínuas de um ou mais parâmetros significativos. A intervenção de manutenção preditiva busca a deteç̧ão precoce dos sintomas que precedem uma avaria. São denominações equivalentes: manutenção baseada na condição ou manutenção baseada no estado ou manutenção condicional.

Para Almeida (a, p.4), a definição de manutenção preditiva vai mais além, "a manutenção preditiva é uma filosofia ou atitude que usa a condição operacional real do equipamento e sistemas da planta industrial para otimizar a operação total da planta industrial".

Medeiros (p.1), afirma que:

A manutenção preditiva está sempre associada a um conjunto de monitoramento de condições, que permitem identificar características internas de funcionamento de uma máquina. Entretanto no planejamento global estas técnicas devem ser associadas a uma série de procedimentos, para garantir os objetivos principais de confiabilidade e redução de custos. Pode-se afirmar que 0 monitoramento envolve duas atividades básicas:

- Obter um grupo de características que possibilite definir a condição mecânica.

- Identificar e reconhecer mudanças da condição normal

Para Rodrigues (2003, p.36) a manutenção preditiva ganhou uma força surpreendente na década de 90 , com o aumento do nível de automação dos sistemas industriais, levando a função manutenção a ser vista como absolutamente necessária e que não precisa interferir no processo produtivo.

A manutenção preditiva é a primeira grande quebra de paradigma na função manutenção, e que com o desenvolvimento do conhecimento tecnológico, criando sistemas de monitoramento mais confiáveis, mais se intensifica (PINTO e XAVIER, 1999, p.37).

\section{QUANDO ADOTAR A MANUTENÇÃO PREDITIVA}

Tsang (1995, p.4), Pinto e Xavier (1999, p.38) enumeram que as condições básicas para se adotar a manutenção preditiva são:

- Possibilidade de algum tipo de monitoramento/medição no equipamento, no sistema, ou nas instalações.

- Os custos envolvidos com o equipamento, o sistema, ou as instalações mereçam esse tipo de ação.

- As falhas tenham origem em causas, cujo monitoramento seja possível e que a sua progressão possa ser monitorada. 
- Seja estabelecido um programa de acompanhamento, análise e diagnóstico sistematizado.

Finch (2003, p.127) enumera outras situações, a saber:

- O componente é crítico para o processo;

- O componente possui um histórico de falhas rápidas;

- O componente opera com falhas conhecidas; e.

- O componente opera de maneira diversa para a qual foi projetado.

Portanto, quando um componente crítico possuir um MTBF pequeno ou de difícil determinação, o monitoramento do mesmo é fundamental para que se atinja o nível de confiabilidade desejado.

As técnicas de monitoramento devem ser suficientemente sensíveis para detectarem falhas nas máquinas, quando elas ainda estão num estágio embrionário, serem aplicáveis numa grande faixa de tipos de equipamentos e ainda, preferencialmente serem fáceis e rápidas de serem avaliadas pelos funcionários (HOLROYD, a, p.1).

\section{A TOMADA DE DECISÃO NA MANUTENÇÃO PREDITIVA}

Há três tipos de decisão a serem tomadas num sistema de manutenção preditiva, segundo Tsang (1995, p.13):

1. Selecionar os parâmetros a serem monitorados.

2. Determinar a freqüência das inspeções.

3. Estabelecer os limites de alerta (gatilhos).

Selecionar o que monitorar depende de fatores como:

- tipo de planta,

- facilidades de cobertura,

- disponibilidade e confiabilidade das técnicas de monitoramento,

- investimento em instrumentação e treinamento,

- capacidade humana e

- custos de operação.

A medição de um parâmetro de controle é feita escolhendo-se uma grandeza que varie antes do equipamento apresentar falha, como por exemplo, vibração, temperatura, pressão, corrente elétrica, etc. (ANHESINE, 1999, p.42). 
A manutenção preditiva assume a hipótese de que a maioria das falhas fornece algum indício, de que elas estão ou irão ocorrer (falhas potenciais). Como o desenvolvimento desta falha pode ocorrer a qualquer tempo, a freqüência de acompanhamento deve ser tal que possibilite segurança sem provocar desperdício de recursos (PINTO E XAVIER, 1999, p.110). A esse respeito ainda, Finch (2003, p.127) acrescenta que a confiança na existência do tempo de retardo entre as primeiras indicações do problema e a propagação da falha é fundamental para o sucesso do monitoramento de condições.

Se o equipamento não é monitorado continuamente, os intervalos entre as inspeções devem ser determinados. Um intervalo muito curto provoca um excesso de verificações, já um período de inspeção muito longo, pode provocar paradas não planejadas do equipamento. Uma maneira de se estabelecer o intervalo de inspeção, é considerar o tempo entre o instante mais cedo em que um sintoma de falha é percebido, e o momento onde a falha realmente ocorre (MTBF). O intervalo de inspeção então, não deve exceder a metade do MTBF (TSANG, 1995, p.13).

Anhesine (1999, p.42) destaca a dificuldade de se definir o período de medição e os níveis de alarme. Quando o nível de alarme é atingido, o intervalo entre as inspeções deve diminuir.

Para Tsang (1995, p.13), os limites de alerta podem ser estáticos ou dinâmicos. Os estáticos são pré-selecionados no início da aquisição de dados. Os limites dinâmicos são usados para monitorar mudanças nos parâmetros medidos.

\section{MONITORAMENTO CONTÍNUO}

Como destacado no item anterior, a detecção prematura da falha é à base da manutenção preditiva. Se por ventura as ações de monitoramento não forem realizadas em intervalos adequados, corre-se o risco de se desperdiçar todo o investimento feito no sistema de manutenção preditiva. 0 monitoramento contínuo foi adotado primeiramente em situações onde 0 intervalo de tempo entre falhas era muito curto, e em equipamentos de alta responsabilidade, uma vez que os sistemas de monitoramento contínuo tinham um preço muito elevado (PINTO E XAVIER, 1999, p.185). 
Reyes $^{13}$ (1995 apud ANHESINE, 1999, p.40) afirma que o principal objetivo do monitoramento contínuo (detecção de condições de falha) pode ser alcançado definindo-se regiões de operação normal, de alerta e de emergência.

A figura 2. 5 apresenta uma hierarquia de monitoramento, onde o monitoramento de situação verifica se o sistema está funcionando.

O monitoramento de condição verifica se o funcionamento é adequado.

No monitoramento de desempenho acrescenta-se ao monitoramento de condição, as condições desejadas de funcionamento do sistema.

No quarto estágio, monitoramento de diagnóstico, compara-se os dados anteriores e atuais para se diagnosticar as condições operacionais do equipamento, checando-se a existência de algum erro na operação do mesmo.

No monitoramento de prognóstico busca-se predizer quando poderá ocorrer à falha do sistema, utilizando-se para isto as informações anteriores, histórico do equipamento e condições do equipamento.

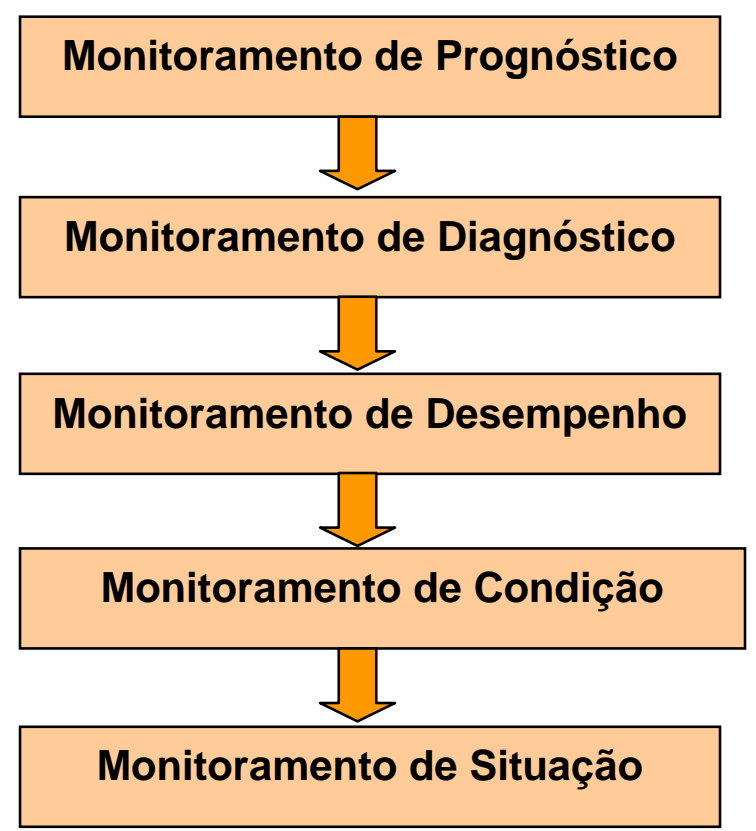

Figura 2. 5: Hierarquia do Monitoramento

Fonte: Cunha $^{14}$ (1996 apud ANHESINE, 1999, p.41).

\footnotetext{
13 REYES, (1995). apud ANHESINE, M.W. (1999). Uma abordagem sistêmica para diagnósticos em manutenção industrial.

14 CUNHA, (1996). apud ANHESINE, M.W. (1999). Uma abordagem sistêmica para diagnósticos em manutenção industrial.
} 
O desenvolvimento da eletrônica e de sistemas digitais propiciou um aumento da oferta de sistemas de monitoramento bem como ampliou as possibilidades de aplicação destes sistemas, levando também há uma redução de preços na utilização dos mesmos. Outra conseqüência do desenvolvimento citado foi à possibilidade do monitoramento ser acompanhado a distância (monitoramento remoto) (PINTO e XAVIER, 1999, p.185).

Outros aspectos importantes do monitoramento contínuo, segundo Pinto e Xavier (1999, p.186-189), são:

- Independe do pessoal.

- O monitoramento é constante, o que não é viável de ser obtido por instrumentos operados por pessoas.

- Envio de dados em tempo real.

- Pode ser customizada de acordo com as necessidades do cliente.

- Alguns fenômenos só podem ser detectados através de acompanhamento contínuo de certas variáveis, sobretudo em equipamentos rotativos.

- Alguns dados somente conseguem ser levantados em situação de parada ou partida das máquinas, o que impossibilita o levantamento manual de dados.

- É adequada para a verificação de transientes, o que não ocorre com coletores manuais.

- A existência de sistemas de monitoramento reduz os prêmios de seguro e tempo de campanha.

\section{TÉCNICAS PREDITIVAS}

Tsang (1995, p.8-10) apresenta que de uma forma geral os sistemas de monitoramento de manutenção preditiva visam:

- Determinar a existência de um problema num equipamento, quão sério é este problema, e quanto tempo o equipamento pode funcionar antes da falha.

- Detectar e identificar componentes específicos do equipamento que estão se degradando, ou seja, o modo de falha, e determinar as causas raízes do problema. 
Apesar do elevado número de técnicas e instrumentos disponíveis, as análises preditivas podem ser classificadas de acordo com o tipo de sintomas, que elas visam detectar. A classificação é a seguinte:

- Efeitos dinâmicos, como as vibrações e o nível de ruídos,

- partículas liberadas no ambiente,

- componentes químicos liberados no ambiente,

- efeitos físicos, como fissuras, trincas, desgaste e deformação,

- aumento de temperatura do equipamento, e

- efeitos elétricos, como tensão, corrente, isolação, condutividade, etc.

Existem cinco técnicas não-destrutivas que são usadas normalmente para gerência de manutenção preditiva: monitoramento de vibração, monitoramento de temperatura, monitoramento de parâmetro de processo, tribologia e inspeção visual. Estas técnicas preditivas são apresentadas a seguir:

\section{Monitoramento de Vibração}

Vibração ocorre naturalmente em qualquer sistema, à medida que este responde a uma excitação. $\mathrm{O}$ monitoramento e a análise de vibração são os métodos mais utilizados na manutenção preditiva.

Pinto e Xavier (1999, p.195-197) alertam que três aspectos devem ser levados em conta no momento em que se decide fazer a medição de vibração de uma máquina:

1. Qual é o tipo da máquina? Como é sua construção?

2. Qual o propósito da medição? O que se quer "ver"?

3. Qual a faixa de freqüência?

Essas questões permitem, que se faça a escolha adequada do sensor a ser utilizado, uma vez que para cada sensor, uma série de detalhes deve ser observada para dar confiabilidade nas medições realizadas.

O monitoramento de vibração para diagnóstico de defeitos possibilita a obtenção de uma grande riqueza de informações, que avaliam a condição de operação da máquina continua ou periodicamente. Quando se previr que níveis inaceitáveis de vibração serão atingidos, determina-se a época da revisão da máquina (NETO, p.1). 
Para Mazzei e Freitas Jr. (1997, p.137), o monitoramento de condições utilizando sinais de vibração é particularmente apropriado para máquinas rotativas, pois é capaz de identificar desbalanceamento, desalinhamento, falhas em rolamentos, falhas elétricas em motores, falhas de correias, etc.

De acordo com Tsang (1995, p.10), a vibração pode ser caracterizada por três parâmetros: amplitude, velocidade e aceleração. A sensibilidade dos sensores usados para a medição destes parâmetros varia com a freqüência de vibração. Em geral os manuais aconselham a utilização de sensores de amplitude em baixas freqüências, sensores de velocidade em faixas médias, e acelerômetros para altas freqüências.

Na prática, uma forma de se monitorar vibração é tomar todas as leituras de energia de vibração entre 10 e $10.000 \mathrm{~Hz}$, em pontos selecionados da máquina. Esses dados são então comparados com leituras realizadas em uma máquina nova, que serve como padrão, estabelecendo-se assim limites de alarme. Um diagnóstico de falha será disparado quando este limite for atingido.

Segundo Mazzei e Freitas Jr. (1997, p.143) pode-se optar por uma análise global, usando-se a medição do valor global de vibração. Este valor mostra as condições gerais da máquina, mas não é capaz de identificar o que e a quanto uma condição mecânica foi alterada. Esse procedimento é muito valioso para a avaliação de tendência com um valor pré-estabelecido. Nesse caso o fato do limite de alarme ter sido atingido não significa que a máquina necessita de intervenção, mas de uma análise de precisão.

A manutenção preditiva realizada com monitoramento de vibração é predicada em dois pontos básicos (ALMEIDA, p.5):

1. Todos os modos de falha comuns possuem componentes distintos de freqüência de vibração que podem ser isolados e identificados.

2. A amplitude de cada componente distinto de vibração permanecerá constante a menos que haja uma mudança na dinâmica operacional da máquina.

A figura 2. 6 apresenta uma visão da manutenção preditiva com ênfase na medição de vibrações. 


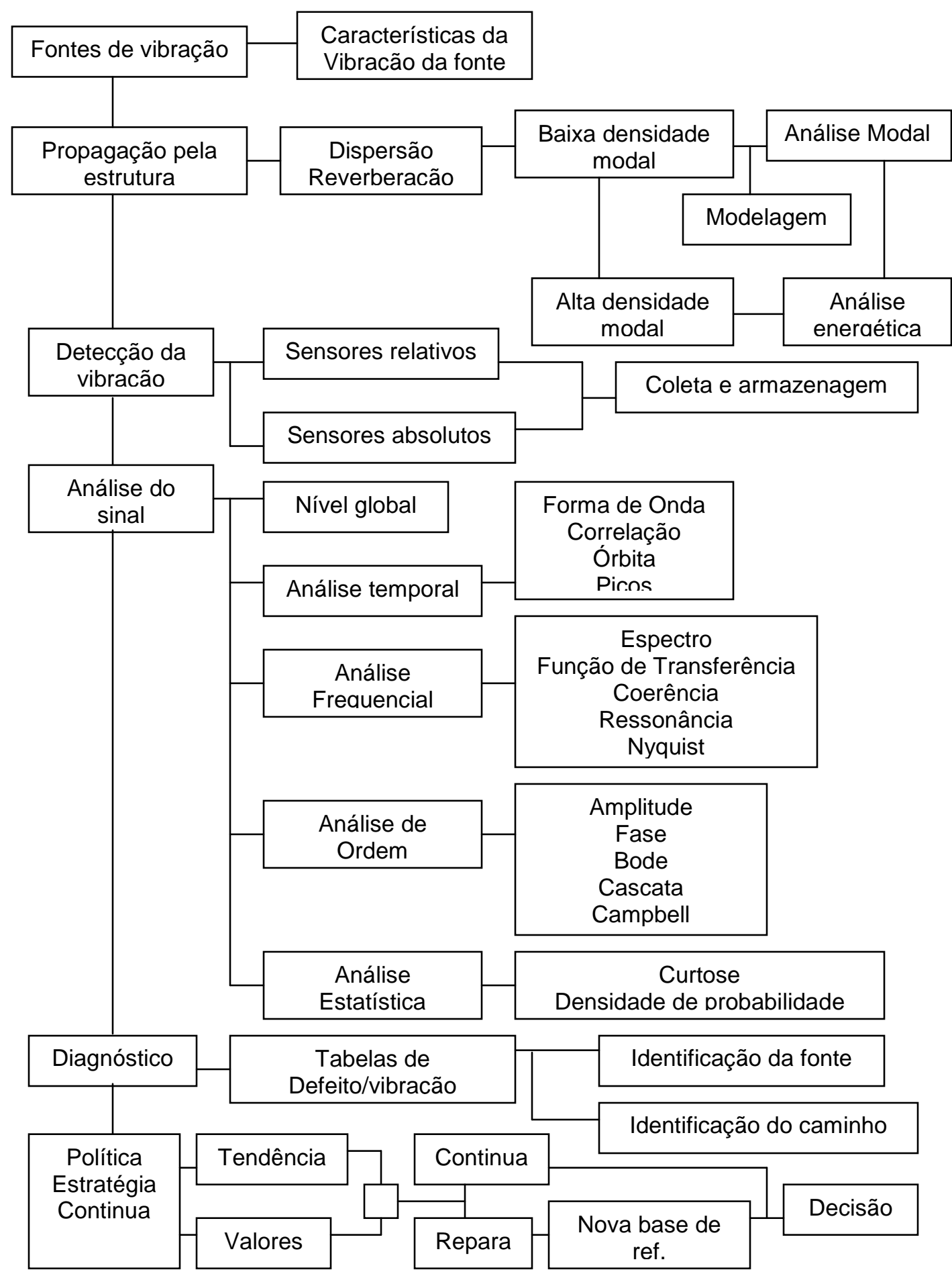

Figura 2. 6: Quadro de manutenção preditiva por monitoramento de vibrações Fonte: Neto (site www.microsyn.com.br, visitado em 10/11/03).

No modelo apresentado, uma fonte de vibração na máquina provoca uma perturbação, que se propaga pela estrutura, até que atinja o ponto de detecção. Uma vez tendo sido detectada pelos sensores, a perturbação na forma de sinal elétrico é coletada e armazenada. Através de técnicas de análise, processamento e apresentação do sinal, são fornecidos subsídios para 
se diagnosticar o defeito, que pode ser obtido por análise direta, ou com auxilio de sistema especialista. Juntamente com a análise de tendência e comparação com valores admissíveis, o diagnóstico do defeito possibilita a tomada de decisão quanto à continuidade de operação ou o planejamento de manutenção da máquina analisada (NETO, p.1).

Tsang (1995, p.11) alerta, como última recomendação, que se deve assegurar o não disparo de alarmes falsos, a fim de se preservar a confiabilidade do sistema de monitoramento.

\section{Monitoramento de Temperatura}

O acompanhamento da variação de temperatura possibilita a detecção de variação na condição do equipamento, bem como do próprio processo.

Pinto e Xavier (1999, p.210) listam alguns exemplos clássicos de acompanhamento de temperatura:

- Temperatura de mancais em máquinas rotativas.

- Temperatura da superfície de equipamentos estacionários.

- Temperatura em barramentos e equipamentos elétricos.

A termografia utiliza instrumentos projetados para medir a emissão de radiação infravermelha e assim, determinar as condições de operação da planta ou de algum componente. A imagem térmica foi utilizada primeiramente para monitorar os fornos nas siderúrgicas, e posteriormente teve seu uso disseminado para outras atividades da manutenção. A termografia é particularmente importante na manutenção, pois a geração excessiva de calor facilita a identificação de falha, por falta de lubrificação e de refrigeração, excesso de atrito entre componentes rotativos, etc. (EDWARDS, HOLT e HARRIS, 1998, p.32).

As técnicas termográficas são muito sensíveis às variações de condições do ambiente, assim como as partículas carregadas no ar, portanto essas variações devem ser compensadas quando dados térmicos são analisados (TSANG, 1995, p.11).

As principais aplicações industriais da termografia são:

- Verificação de componentes elétricos, onde não é possível o contato físico, como por exemplo, redes de distribuição e transmissão, barramentos, etc.

- Usinas siderúrgicas. 
- Fábricas de cimento.

- Indústria petroquímica.

Além da termografia, o monitoramento da temperatura pode ser executado por outros tipos de medidores, entre os quais Pinto e Xavier (1999, p.213) citam:

- Termômetros de contato;

- Fitas indicadoras de temperatura;

- Giz indicador de temperatura;

- Tinta termo-sensível;

- Pirômetro de radiação;

- Pirômetro ótico.

\section{Monitoramento de parâmetros de processos}

Monitoramento de parâmetros de processos cobre uma grande faixa de medidas, como por exemplo:

- Eficiência do processo;

- Perda de calor;

- Temperatura da máquina;

- Corrente do motor;

- Pressão de fluído; etc.

Os dados desses parâmetros são coletados normalmente como parte da rotina operacional, para monitoramento do desempenho da planta. Estes dados podem ser aproveitados para servir de indicadores das condições da planta, ou de componentes. Esse procedimento de monitoramento de condição é também aplicado em plantas não-mecânicas como trocadores de calor, unidades de filtragem, tubulações e caldeiras (TSANG, 1995, p.11).

\section{Tribologia}

A palavra tribos tem origem grega e significa atrito, portanto tribologia é o estudo do atrito.

Edwards, Holt e Harris (1998, p.28) e Tsang (1995, p.11) definem tribologia como sendo a observação de superfícies que interagem com movimento relativo entre elas. Tribologia engloba deslizamento entre superfícies e outras formas de interação entre as mesmas. Como 
conseqüência, os problemas de friç̧ão e desgaste são partes integrantes desses estudos.

Na manutenção preditiva utilizam-se três tipos de técnicas de tribologia:

1. análise de óleos lubrificantes;

2. análise das partículas de desgaste e

3. ferrografia.

A análise de óleos lubrificantes, como método de monitoramento de condições, já é utilizado há muito tempo. Amostras de lubrificante são retiradas em intervalos regulares, de modo que o acompanhamento das condições do mesmo seja feito. $\mathrm{Na}$ análise do óleo tradicional, duas técnicas são mais difundidas: a verificação das características físico-químicas do lubrificante e presença de partículas oriundas de desgaste. Entre as características físicoquímicas normalmente são analisados: viscosidade, número de acidez total TAN, número de basicidade total - TBN, conteúdo de sólidos, teor de água, corrosividade, oxidação, diluição por combustível e ponto de fulgor (TSANG, 1999, p.1; PINTO e XAVIER, 1999, p.230).

Já a ferrografia é usada particularmente para mensurar a qualidade da lubrificação no mecanismo mais fundamental que existe: a engrenagem (DAVIES $^{15}, 1995$ apud EDWARDS, HOLT e HARRIS, 1998, p.30). A ferrografia pode ser feita em óleos ou graxas e identifica, classifica e quantifica as partículas que estão presentes no lubrificante apontando ou não a existência de desgaste anormal, contaminação e perda das características do lubrificante (PINTO e XAVIER, 1999, p.231).

$\mathrm{Na}$ ferrografia, o laboratório prepara corpos de prova (ferrogramas), onde estão contidas todas as partículas em suspensão da amostra. Em seguida a partícula é analisada através de microscópio. Em função da morfologia, coloração, tamanho, acabamento superficial e quantidade de partículas, é possível a determinação da origem do desgaste sofrido (PINTO e XAVIER, 1999, p.231; EDWARDS, HOLT e HARRIS, 1998, p.30).

As limitações do emprego da tribologia na manutenção preditiva são:

- alto custo dos equipamentos,

15 DAVIES, R. (1995). Gearing up for effective maintenance - the plant engineer apud EDWARDS, D.J.; HOLT, G.D.; HARRIS, F.C. (1998). Predictive maintenance techniques and their relevance to construction plant. 
- procedimentos baseados em laboratório,

- confiança na retirada de amostra de óleos e

- habilidades específicas para a interpretação dos dados (TSANG, 1999, p.12).

\section{Inspeção visual}

A inspeção visual dos componentes da planta proporciona um método simples e barato de monitoramento de condição.

Pinto e Xavier (1999, p.218) alertam que embora a inspeção visual possa ser considerada uma técnica subjetiva, a mesma é fundamental na manutenção preditiva. A necessidade de realização de inspeção visual sem a desmontagem dos equipamentos, a dificuldade de acesso, além do conforto para o inspetor, levou ao aparecimento de diversos instrumentos/equipamentos de reflexão e ópticos.

Através da inspeção visual é possível a detecção de vazamentos, trincas, falhas estruturais, medições de espessuras, etc.

\section{BENEFÍCIOS DA MANUTENÇÃO PREDITIVA}

É consenso entre vários autores (PINTO e XAVIER, 1999, TSANG, 1995, ALMEIDA, 2003), que a manutenção preditiva é a que menos intervém na planta produtiva. A gestão da manutenção preditiva, sobretudo em equipamentos complexos e dispendiosos, leva a um aumento da vida útil dos equipamentos, além do controle da condição e atendimento do processo.

Almeida (b, p.1-5), citando um levantamento realizado pela "Plant Performance Group" (uma divisão da Technology for Energy Corporation) em 1988, com 500 fábricas dos Estados Unidos, Canadá, Grã-Bretanha, França e Austrália, que implementaram com sucesso métodos de manutenção preditiva, resume os benefícios desta gestão nos seguintes fatores:

- Redução dos custos de manutenção;

- Redução de falhas nas máquinas;

- Redução do tempo de parada para reparo;

- Redução no estoque de peças sobressalentes;

- Aumento da vida das peças;

- Aumento da produção; 
- Melhoria na segurança do operador;

- Aumento dos lucros.

A tabela 2. 1 apresenta os valores extraídos da pesquisa citada:

Tabela 2. 1: Benefícios da Manutenção Preditiva Fonte: Almeida (b, p.2).

\begin{tabular}{|l|l|}
\hline BENEFÍCIO & PERCENTUAL \\
\hline REDUÇÃO DOS CUSTOS DE MANUTENÇÃO & $50 \mathrm{~A} 80 \%$ \\
\hline REDUÇÃO DE FALHAS NAS MÁQUINAS & $50 \mathrm{~A} 60 \%$ \\
\hline REDUÇÃO DE ESTOQUE DE SOBRESSALENTES & $20 \mathrm{~A} 30 \%$ \\
\hline REDUÇÃO DE HORAS EXTRAS PARA MANUTENÇÃO & $20 \mathrm{~A} 50 \%$ \\
\hline REDUÇÃO DO TEMPO DE PARADA DAS MÁQUINAS & $50 \mathrm{~A} 80 \%$ \\
\hline AUMENTO NA VIDA DAS MÁQUINAS & $20 \mathrm{~A} 40 \%$ \\
\hline AUMENTO DA PRODUTIVIDADE & $20 \mathrm{~A} 30 \%$ \\
\hline AUMENTO DOS LUCROS & $25 \mathrm{~A} 60 \%$ \\
\hline
\end{tabular}

É importante observar, que existe um limite acima do qual o aumento da confiabilidade não traz benefícios e o lucro acaba por diminuir.

\section{5. 4 MANUTENÇÃO DETECTIVA}

A manutenção detectiva começou a ser mencionada na literatura a partir da década de 90.

Segundo Pinto e Xavier (1999, p.40), a definição de manutenção detectiva é: "... a atuação efetuada em sistemas de proteção buscando detectar FALHAS OCULTAS ou não perceptíveis ao pessoal de operação e manutenção".

A manutenção detectiva é aplicada aos dispositivos que não são adequadamente atendidos pelas outras três formas de manutenção já vistas anteriormente (corretiva, preventiva ou preditiva). Estes são dispositivos que somente necessitam trabalhar em condições especiais, e que não se consegue acompanhar e se perceber quando estão em um estado de falha. Geralmente estes componentes passam por verificações periódicas para se saber se ainda estão trabalhando, como exemplo pode-se mencionar sistema de alarme de incêndio (GERAGHETY). 
Pinto e Xavier (1999, p.40-41) resumem a necessidade de tarefas de manutenção detectiva, em virtude do aumento da utilização de computadores digitais em instrumentação e controle de processo nos mais diversos tipos de plantas industriais. As falhas nos sistemas de proteção podem acarretar dois problemas: não atuação ou atuação indevida. Concluem os autores que as conseqüências desses problemas levam a diminuição da confiabilidade afetando a disponibilidade das plantas. Na manutenção detectiva, especialistas fazem verificações no sistema, sem tirá-lo de operação, sendo capazes de detectar falhas ocultas, podendo corrigir a situação.

A principal diferença é o nível de automatização. Na manutenção preditiva, faz-se necessário o diagnóstico a partir da medição de parâmetros. Já na manutenção detectiva, o diagnóstico é obtido de forma direta a partir do processamento das informações colhidas junto à planta. Por exemplo, o botão de lâmpadas de sinalização e alarme em painéis deve ser testado periodicamente para se saber se a lâmpada não está queimada.

\section{5. 5 ENGENHARIA DE MANUTENÇÃO}

Engenharia de manutenção tem como filosofia deixar de fazer os consertos continuadamente, para procurar as causas básicas, modificar situações de constante mau desempenho, resolver problemas crônicos, melhorar padrões e sistemáticas, trabalhar conjuntamente com o Projeto, desenvolver a manutenibilidade, interferir tecnicamente nas compras ligadas à função manutenção (PINTO e XAVIER, 1999, p.42).

Para Fernandes (2003, p.6), a engenharia de manutenção reúne um conjunto de ações para corrigir deficiências anteriores, e que se constituem em importante banco de informações, para se atingir o objetivo principal da manutenção. A base das ações da engenharia de manutenção está diretamente ligada ao ciclo de gerenciamento de manutenção mostrado na figura 2. 7: 


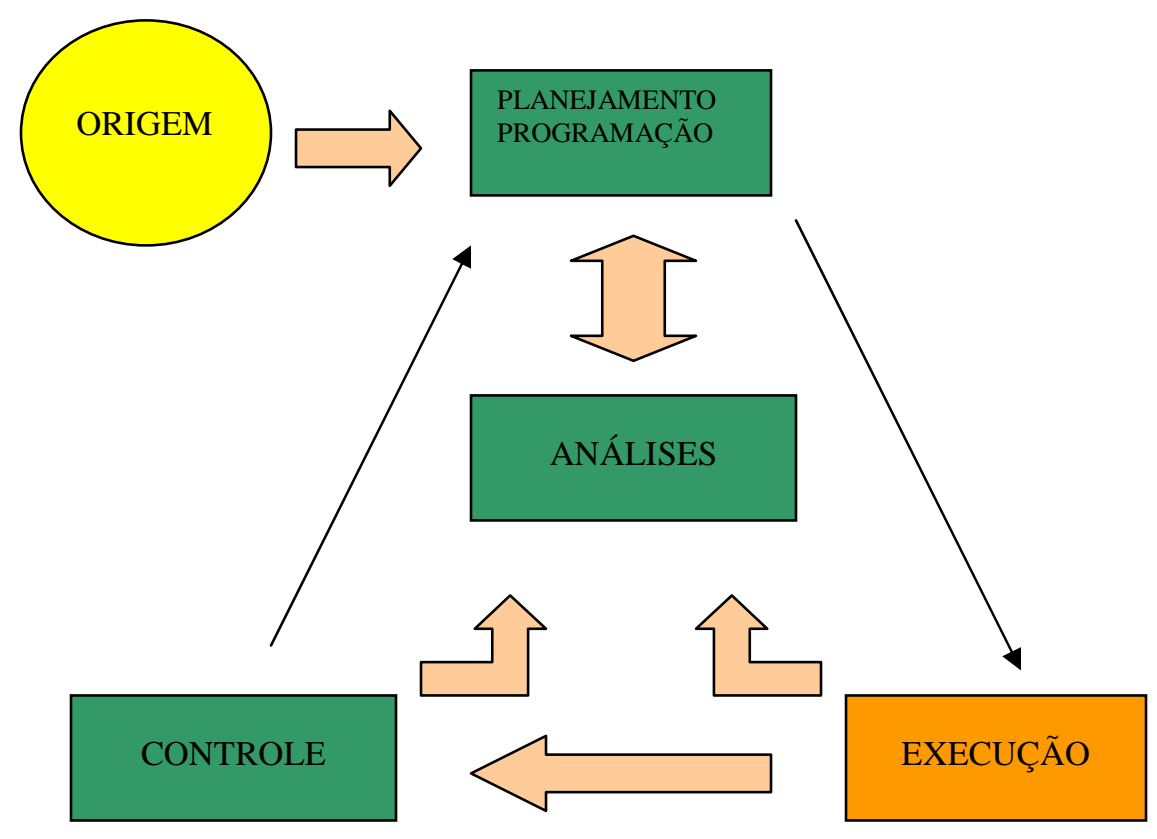

Figura 2. 7: Ciclo de Gerenciamento de Manutenção Fonte: Fernandes (2003, p.6, ano 3, no. 27).

A Origem refere-se de forma simplificada ao fluxo de informações dentro do departamento de manutenção, onde a operação e a manutenção definem a origem das necessidades da manutenção.

Uma vez estas necessidades identificadas, elas são encaminhadas ao Planejamento e Programação, que define as prioridades e formas de como as tarefas serão executadas.

$\mathrm{Na}$ etapa de Execução, os serviços são realizados e as informações são devidamente coletadas.

No Controle, estas informações são lançadas num sistema informatizado de gerenciamento, encerrando as ordens de serviço, atualizando os planos de manutenção e formando um histórico técnico e estruturado dos equipamentos.

O sucesso da política de manutenção é medido na fase de Análises, bem como são feitas às recomendações à equipe de manutenção a partir da avaliação de custos de manutenção, análise das paradas dos equipamentos e detecção de falhas repetitivas.

Pinto e Xavier (1999, p.42) consideram ainda que a engenharia de manutenção é a segunda quebra de paradigma na manutenção (a primeira é a adoção da manutenção preditiva). Praticar engenharia de manutenção significa uma mudança cultural nas empresas, significa perseguir benchmarks, aplicar técnicas modernas, compatíveis com a manutenção de classe mundial. 
Concluindo, no instante em que função manutenção estiver utilizando para análises, estudos e proposições de melhorias todos os dados que o sistema de preditiva colhe e armazena, a organização estará praticando engenharia de manutenção (PINTO e XAVIER, 1999, p.43).

\section{6 FERRAMENTAS E TÉCNICAS DE MANUTENÇÃO}

Existem várias ferramentas e técnicas para o aprimoramento da função manutenção. Essas ferramentas não são excludentes e, geralmente, têm utilização concomitante.

Considerando-se o objetivo e o escopo deste trabalho, será apresentada uma concepção básica de algumas destas metodologias/técnicas.

\section{6. 1 ANÁLISE DOS MODOS E EFEITOS DAS FALHAS - FMEA}

A técnica de Análise dos Modos e Efeitos das Falhas - FMEA (do inglês Failure Mode and Effect Analysis) procura, em princípio, evitar que ocorram falhas no projeto do produto ou do processo, através da análise das falhas potenciais e propostas de ações de melhoria. O objetivo básico é detectar falhas antes que se produza uma peça e/ou produto, ou seja, busca-se um aumento da confiabilidade (CAPALDO, GUERRERO e ROZENFELD, p.1).

Segundo Helman e Andery (1995, p.25 e 26), a FMEA é um técnica analítica padronizada para detectar e eliminar falhas potenciais de forma sistemática e completa. Na FMEA, procura-se determinar as falhas dos componentes mais simples, as suas causas e de que forma afetam os níveis superiores do sistema, é, portanto, um raciocínio de "baixo para cima".

Embora a FMEA tenha sido desenvolvida com enfoque no projeto/processos de novos produtos, devido a sua grande utilidade esta técnica passou a ser aplicada de diversas maneiras (CAPALDO, GUERRERO e ROZENFELD, p.1).

Atualmente existem diversos tipos de FMEAs, as etapas e a modo de realização da análise são as mesmas, a diferenciação entre os tipos se dá somente em relação ao objetivo. Segundo Kenneth (2002), estes tipos são:

- Sistema - focos em funções globais do sistema.

- Projeto - focos em componentes e em subsistemas. 
- Processo - focos em processos de manufatura e de conjunto.

- Serviço - focos em funções do serviço

- Software - focos em funções do software.

De acordo com Helman e Andery (1995, p.27), as perguntas básicas feitas em uma FMEA são:

- Que tipos de falhas são observados?

- Que partes do sistema são afetadas?

- Quais são os efeitos da falha sobre o sistema?

- Qual a importância da falha?

- Como preveni-la?

Para Capaldo, Guerrero e Rozenfeld (p.2), independentemente do tipo de FMEA e a aplicação, o princípio da técnica é o mesmo. A análise consiste basicamente na formação de um grupo de pessoas que identificam para o produto/processo em questão suas funções, os tipos de falhas, efeitos e possíveis causas desta falha. A seguir, são avaliados os riscos de cada causa de falha, e a partir desta avaliação tomam-se ações para minimizar estes riscos, aumentando a confiabilidade do produto/processo.

Para Pinto e Xavier (1999, p.92), a função manutenção está mais envolvida na FMEA de processo, já que nessa fase os equipamentos estão instalados e operando. Sugere-se que o grupo de FMEA seja multidisciplinar pela complementaridade de conhecimentos, além da vantagem de decisões colaborativas. Desta forma o grupo de FMEA de processo deve ter engenheiros e técnicos de manutenção.

Capaldo, Guerrero e Rozenfeld (p.2) mostram que a seqüência de etapas para a aplicação da FMEA é:

- Planejamento

- Análise de Falhas em Potencial

- Avaliação dos Riscos

- Melhoria

A fase de planejamento é realizada pelo responsável pela aplicação do FMEA e compreende:

- Descrição dos objetivos e abrangências da análise. 
- Formação das equipes de trabalho - o grupo preferencialmente deve ser pequeno e multidisciplinar.

- Planejamento das reuniões - essas devem ser agendadas com antecedência e aprovação de todos os membros, para se evitar interrupções.

- Preparação da documentação.

$\mathrm{Na}$ fase de Análise de Falha em Potencial o grupo de trabalho discute e preenche o formulário FMEA, como segue:

- Função e característica do produto/processo.

- Tipo de falha potencial para cada função.

- Efeito do tipo de falha.

- Causa possível da falha.

- Controles atuais.

$\mathrm{Na}$ etapa de Avaliação dos Riscos, o grupo de trabalho define os índices de severidade (S), ocorrência (O) e detecção (D) para cada causa de falha, de acordo com critérios previamente definidos. Embora existam exemplos de critérios que possam ser seguidos, o ideal é que a empresa tenha seus próprios critérios adaptados a sua realidade específica. Uma vez, tendo-se definidos os três índices, multiplicando-se os mesmos, calcula-se o coeficiente de prioridade de risco $(R)$.

$\mathrm{Na}$ fase de Melhoria, o grupo, utilizando os conhecimentos, criatividade, ou mesmo brainstorming, lista todas as ações que possibilitem a diminuição dos riscos. Estas medidas podem ser:

- Medidas de prevenção total ao tipo de falha.

- Medidas de prevenção total de uma causa de falha.

- Medidas que dificultam a ocorrência de falhas.

- Medidas que limitem o efeito do tipo de falha.

- Medidas que aumentam a probabilidade de detecção do tipo ou da causa de falha.

Uma vez analisadas as medidas quanto a sua viabilidade, definem-se quais medidas serão implantadas.

Um ponto onde vários autores concordam é o fato da necessidade de revisão contínua da análise realizada, confrontando-se as falhas potenciais 
imaginadas pela equipe de trabalho, com as falhas que realmente ocorrem no dia-a-dia, possibilitando a incorporação de falhas não previstas, bem como a reavaliação das falhas previstas pelo grupo.

Capaldo, Guerrero e Rozenfeld (p.5) destacam a importância da técnica FMEA, mostrada na figura 2. 8:

- UMA FORMA SISTEMÁTICA DE SE CATALOGAR INFORMAÇÕES SOBRE AS FALHAS DOS PRODUTOS/PROCESSOS;

- MELHOR CONHECIMENTO DOS PROBLEMASNOS PRODUTOS/PROCESSOS;

- AÇÕES DE MELHORIA NO PROJETO DO PRODUTO/PROCESSO, BASEADO EM DADOS E DEVIDAMENTE MONITORADAS (MELHORIA CONTÍNUA);

- DIMINUIÇÃo DE CUSTOS POR MEIO DA PREVENÇÃo DE FALHAS;

- O BENEFícIO DE INCORPORAR DENTRO DA ORGANIZAÇÃO A ATITUDE DE PREVENÇÃO DE FALHAS, A ATITUDE DE COOPERAÇÃO E TRABALHO EM EQUIPE E A PREOCUPAÇÃO COM A SATISFAÇÃO DOS CLIENTES;

Figura 2. 8: Importância que a FMEA pode proporcionar para a empresa Adaptado: Capaldo, Guerrero e Rozenfeld (www.numa.org.br/conhecimentos)

Helman e Andery (1995, p.43) apresentam os passos que habitualmente devem ser seguidos para a condução de uma análise via FMEA, e podem ser resumidos pela figura 2. 9: 


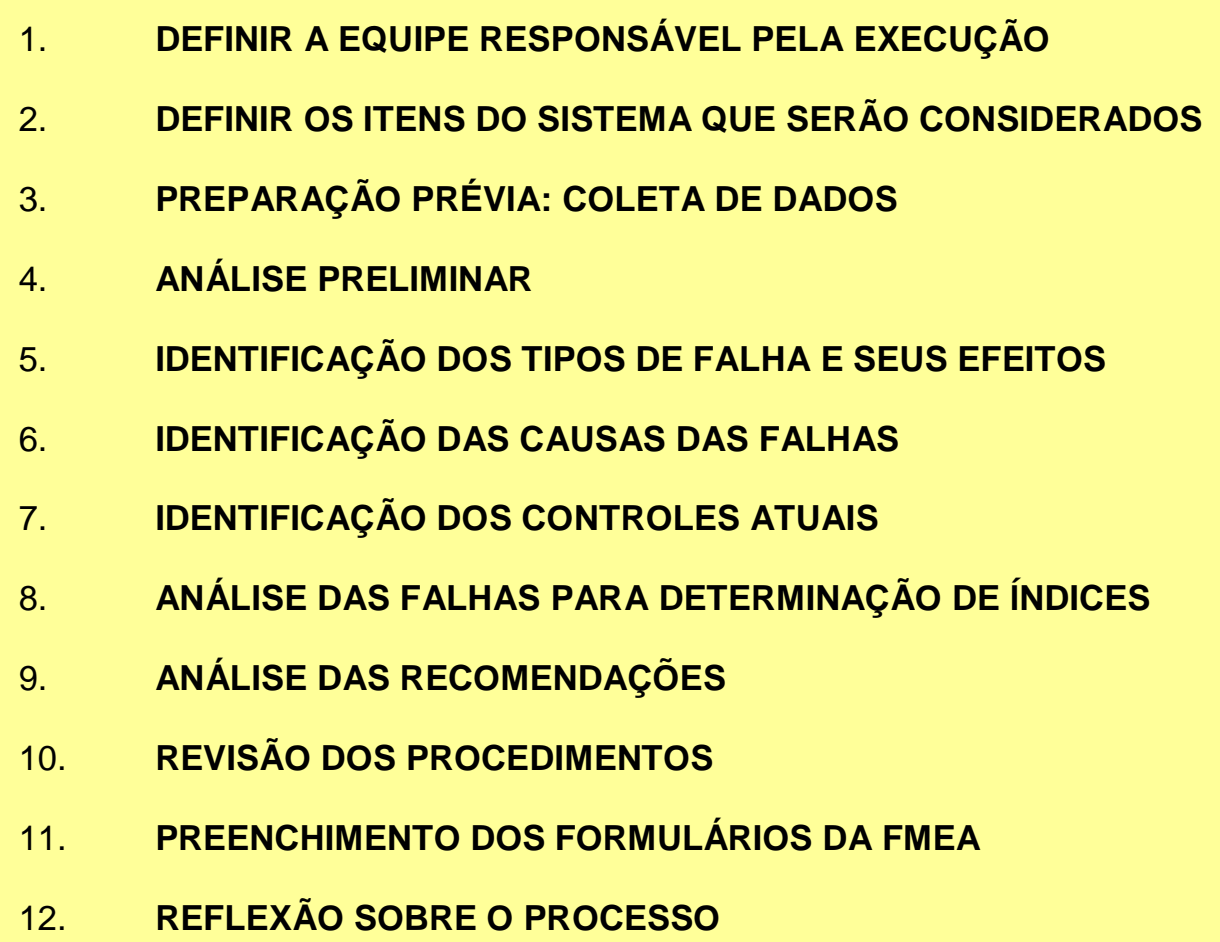

Figura 2. 9: Elaboração da FMEA Adaptado: Helman e Andery (1995, p.44).

Pinto e Xavier (1999, p.94) concluem que "a FMEA localiza falhas potenciais e suas causas. Desse modo, as ações necessárias podem ser tomadas com vista a evitar problemas futuros e prejuízos, antes que eles aconteçam".

\section{6. 2 ANÁLISE DA ÁRVORE DE FALHAS - FTA}

A Análise da Árvore de Falhas - FTA (do inglês Fault Tree Analysis) é uma técnica analítica usada em confiabilidade, manutenção e análise de segurança.

Para Guerrero e Rozenfeld (p.1), a busca crescente pela melhoria da qualidade de produtos, bem como a satisfação dos clientes tem popularizado técnicas e ferramentas que visam melhorar a confiabilidade de produtos e processos. Uma destas técnicas é a Análise da Árvore de Falhas - FTA, que busca, através da análise sistemática de possíveis falhas e suas conseqüências, alcançar estes objetivos. 
Para Helman e Andery (1995, p.63), a FTA é capaz de fornecer bases objetivas para funções diversas tais como a análise de modos comuns de falhas em sistemas.

Ainda segundo Helman e Andery (1995, p.64), a utilização da FTA é particularmente útil para:

- Auxiliar a identificação dedutiva de falhas do sistema.

- Definir a relevância de aspectos do sistema, em relação à ocorrência de uma falha em particular.

- Fornecer um maior entendimento do comportamento do sistema.

O Lewis Research Center da Nasa (p.2), define a FTA como um procedimento de "cima para baixo" (top-down), uma vez que se parte de um evento de topo, e procura-se determinar os caminhos que podem ter ocorrido para se atingir este evento. A análise procura determinar como eventos de topo podem ser causados por uma falha individual ou um conjunto de falhas, de níveis inferiores.

A FTA é um modelo gráfico, que mostra a relação hierárquica entre os modos de falhas identificados no FMEA ou eventos que podem resultar no evento de topo.

Helman e Andery (1995, p.64) destacam que a análise é conduzida até que se atinja eventos ou situações básicas cuja análise não se considera necessária aprofundar. Estes eventos são chamados de limite de resolução. Tendo se obtido o conjunto de eventos que constituem o limite da árvore e as causas básicas das falhas, deve-se elaborar um plano de ação a fim de se evitar ocorrência das mesmas.

A figura 2. 10 apresenta as finalidades de uma FTA: 


\section{FTA}

\section{FINALIDADES}

1. ESTABELECER UM MÉTODO PADRONIZADO DE ANÁLISE DE FALHAS OU PROBLEMAS, VERIFICANDO COMO OCORREM EM EQUIPAMENTO OU PROCESSO.

2. ANÁLISE DA CONFIABILIDADE DE UM PRODUTO OU PROCESSO.

3. COMPREENSÃO DOS MODOS DE FALHA DE UM SISTEMA, DE MANEIRA DEDUTIVA.

4. PRIORIZAÇÃO DAS AÇÕES CORRETIVAS QUE SERÃO TOMADAS.

5. ANÁLISE E PROJETO DE SISTEMAS DE SEGURANÇA OU SISTEMAS ALTERNATIVOS EM EQUIPAMENTOS

6. COMPILAÇÃO DE INFORMAÇÕES PARA A MANUTENÇÃO DE SISTEMAS E ELABORAÇÃO DE PROCEDIMENTOS DE MANUTENÇÃO.

7. INDICAÇÃO CLARA E PRECISA DE COMPONENTES MAIS CRÍTICOS OU CONDIÇÕES CRÍTICAS DE OPERAÇÃO.

8. COMPILAÇÃO DE INFORMAÇÕES PARA TREINAMENTO NA OPERAÇÃO DE EQUIPAMENTOS

9. COMPILAÇÃO DE INFORMAÇÕES PARA PLANEJAMENTO DE TESTES E INSPEÇÃO.

10. SIMPLIFICAÇÃO E OTIMIZAÇÃO DE EQUIPAMENTOS

Figura 2. 10: Aplicações da FTA

Fonte: Helman e Andery (1995, p.65).

A FTA é uma técnica que possui uma importante aplicação na função manutenção.

Helman e Andery (1995, p.17) destacam:

A facilidade de apresentar uma perfeita inter-relação funcional entre uma falha e suas possíveis causas permite a elaboração de uma árvore associada a cada uma das falhas principais (ou mais comuns) que podem acontecer em um dado equipamento. Na elaboração da árvore, a falha em questão será considerada como evento de topo. As árvores de falhas finalizam-se com as possíveis causas de cada problema, e se completam com um plano de ação para sua solução. Este plano de ação poderá incluir, além das contramedidas recomendadas para cada caso, informações tais como:

- Pessoal requerido para o trabalho e sua respectiva especialidade. 
- Ferramentas necessárias à tarefa a ser realizada.

- Tempo que demandará sua execução.

- Custo da operação.

- Peças sobressalentes.

- Etc.

A árvore de falhas correspondente a cada defeito será montada por uma equipe constituída pelo pessoal da manutenção mais apropriado para cada caso. Desta forma, uma pessoa menos experiente poderá beneficiar-se da análise realizada pelos seus colegas com maior conhecimento do assunto.

Pelas suas características, esta árvore poderá ser atualizada ou completada à medida que se disponha de novas informações sobre o problema.

Assim sendo, a árvore de falhas constitui um método simples de registrar a memória da empresa no tocante aos procedimentos de manutenção e uma forma muito conveniente para o treinamento das pessoas encarregadas de executá-los.

Para Guerrero e Rozenfeld (p.2) embora existam semelhanças entre FTA e FMEA, no que tange a finalidade, as duas técnicas apresentam várias diferenças quanto à aplicação e ao procedimento da análise, que podem ser vistas na tabela 2. 2:

Tabela 2. 2: Comparação entre FTA e FMEA

Fonte: Guerrero e Rozenfeld (p.2, www.numa.org.br/conhecimentos)

\begin{tabular}{|c|l|l|}
\hline & \multicolumn{1}{|c|}{ FTA } & \multicolumn{1}{|c|}{ FMEA } \\
\hline \multirow{2}{*}{ OBJETIVO } & $\begin{array}{l}\text { Identificação das causas } \\
\text { primárias das falhas }\end{array}$ & $\begin{array}{l}\text { Identificação das falhas } \\
\text { críticas em cada componente, } \\
\text { suas causas e conseqüências }\end{array}$ \\
\cline { 2 - 3 } & $\begin{array}{l}\text { Elaboração de uma relação } \\
\text { lógica entre falhas primárias e } \\
\text { falha final do produto }\end{array}$ & Hierarquizar \\
\hline \multirow{2}{*}{ PROCEDIMENTO } & $\begin{array}{l}\text { Identificação da falha que é } \\
\text { detectada pelo usuário do } \\
\text { produto }\end{array}$ & $\begin{array}{l}\text { Análise das falhas em } \\
\text { potencial de todos os } \\
\text { elementos do sistema, e } \\
\text { previsão das conseqüências }\end{array}$ \\
\cline { 2 - 4 } & $\begin{array}{l}\text { Relacionar essa falha com } \\
\text { falhas intermediárias e } \\
\text { eventos mais básicos por } \\
\text { meio de símbolos lógicos }\end{array}$ & $\begin{array}{l}\text { Relação de ações corretivas } \\
\text { (ou preventivas) a serem } \\
\text { tomadas }\end{array}$ \\
\hline
\end{tabular}




\begin{tabular}{|c|l|l|}
\hline \multirow{2}{*}{ APLICAÇÃO } & $\begin{array}{l}\text { Melhor método para análise } \\
\text { individual de uma falha } \\
\text { específica }\end{array}$ & $\begin{array}{l}\text { Pode ser utilizado na análise } \\
\text { de falhas simultâneas ou } \\
\text { correlacionadas }\end{array}$ \\
\cline { 2 - 3 } & $\begin{array}{l}\text { O enfoque é dado à falha final } \\
\text { do sistema }\end{array}$ & $\begin{array}{l}\text { Todos os componentes do } \\
\text { sistema são passíveis de } \\
\text { análise }\end{array}$ \\
\hline
\end{tabular}

\section{6. 3 MANUTENÇÃO CENTRADA EM CONFIABILIDADE - RCM}

Manutenção Centrada em Confiabilidade, mais conhecida por RCM, sua sigla em inglês (Reliability Centred Maintenance), teve sua origem no início dos anos 60, dentro da indústria aeronáutica comercial (DHILLON, 1999, p.161).

Manutenção Centrada em Confiabilidade - RCM é uma ferramenta usada para determinar o que deve ser feito para assegurar que os itens físicos continuem a cumprir o papel que os usuários desejam que esses itens cumpram, em outras palavras, preservar o contexto operacional (MOUBRAY, 1992, p.7).

No gerenciamento de qualquer item físico, dois pontos devem ser considerados:

- O item deve ser mantido.

- O item pode necessitar de modificações.

Manter um item significa preservar o estado desejado, ou seja, que ele continue a cumprir suas funções. Está claro para que isso seja possível, o equipamento deve ser capaz de executar tal necessidade, uma vez que a manutenção pode apenas recuperar a capacidade interna do item, e não aumentar sua capacidade. Embora, na prática, a maioria dos equipamentos seja capaz de ter o desempenho desejado, em alguns casos este fato não ocorre, daí a necessidade de modificá-los. A RCM é uma ferramenta que engloba a consideração sistemática das funções do sistema, o modo de falhas desse sistema, bem como a priorização, baseada em fatores econômicos e de segurança, para a aplicação de uma Política de Manutenção adequada e eficaz (ANHESINE, 1999, p.65). 


\section{AS SETE QUESTÕES BÁSICAS DA RCM}

Moubray (1992, p.7 e 8) apresenta as sete questões básicas que devem ser respondidas para se enquadrar qualquer item no processo de RCM:

1. Quais são as funções e padrões de desempenho associado ao item no contexto operacional atual?

2. De que forma ele falha em cumprir suas funções?

3. O que causa cada falha funcional?

4. O que acontece quando cada falha ocorre?

5. De que forma cada falha tem importância?

6. O que pode ser feito para prevenir cada falha?

7. O que deve ser feito, se não for encontrada uma tarefa preventiva apropriada?

A razão destas perguntas é mostrada a seguir:

Funções e padrões de desempenho

Se a Manutenção é responsável por assegurar que um item físico cumpra suas funções como desejado no contexto atual, então esses dados devem ser quantificados. Portanto, como regra geral, deve-se definir as funções e quantificar os padrões de desempenho de cada item, no que se refere a variáveis de produção, qualidade do produto, serviços ao consumidor, custos operacionais e implicações ambientais e de segurança. Em geral os usuários estão em melhor posição para identificar exatamente a contribuição de cada item, e por isso é essencial que sejam envolvidos no processo de RCM (MOUBRAY, 1999a, p.3).

\section{Falha Funcional}

A abordagem inicial da RCM para o gerenciamento da falhas ocorre em dois níveis:

- Como o item pode falhar.

- O que pode possibilitar a perda de função.

Para a RCM, se o equipamento tem uma função, como definido na questão anterior, falha funcional é a perda dessa função, em outras palavras, a incapacidade de um item físico atingir os padrões de desempenho desejados. Esta definição engloba as falhas parciais, pois os itens físicos podem ainda 
estar funcionando, mas num nível inaceitável de desempenho (MOUBRAY, 1999, p.3).

\section{Modos de Falha}

Moubray (1999b, p.3) apresenta que uma vez tendo sido identificados as falhas funcionais, o próximo passo é tentar identificar todos os eventos que podem levar a um estado de falha, e que são chamados de Modos de Falha.

Esta identificação do evento deve cobrir as ocorrências com equipamentos similares, operando em condições semelhantes ao do contexto em estudo, as falhas que são prevenidas pela existência de tarefas de manutenção, bem como as falhas que não ocorreram, mas que tenham possibilidades reais de ocorrerem no contexto em questão.

Tradicionalmente as listas de modos de falha incluem falhas causadas por deterioração, desgaste normal e fadiga, entretanto não devem ser esquecidas as falhas humanas, que podem ser causadas tanto pelos operadores, como pelo pessoal da manutenção (MOUBRAY 1999, p.3).

Moubray (1992, p.9) alerta que neste passo, não se pode desperdiçar tempo tentando tratar os sintomas em vez das causas.

Efeitos da Falha

Para Moubray (1999b, p.3) nesta questão devem ser listados os efeitos de cada falha, uma vez tendo ocorrido o modo de falha.

Esta descrição deve englobar todas as informações necessárias para apoiar a avaliação das conseqüências da falha como, por exemplo:

- As provas da ocorrência da falha (se existirem).

- De que forma a falha afeta a segurança e/ou o meio ambiente.

- De que maneira a falha afeta a produção ou operação.

- Os riscos físicos causados pela falha.

- O que fazer para reparar a falha.

Com o conhecimento dos efeitos da falha é possível se estabelecer ações de manutenção preventiva, preditiva e detectiva, em razão da importância de cada falha. Se o efeito provocado pela falha for de pouca importância, o grau de prevenção será pequeno, entretanto se os efeitos forem sérios, se justificam ações significativas na tentativa de se evitar sua ocorrência (PINTO e XAVIER, 1999, p.107). 


\section{Conseqüências da falha}

A análise detalhada de indústrias mostra a existência entre 3 e 10 mil possibilidades de modos de falha. Cada um desses modos afeta a organização de forma diferente e com efeitos diferentes. Eles afetam as operações, a qualidade do produto, o serviço ao consumidor, a segurança, o meio ambiente, e eles ainda tomam tempo e custam dinheiro para serem reparados (MOUBRAY, 1992, p.10).

Ainda de acordo com Moubray, o grande mérito da RCM é reconhecer que as conseqüências das falhas vão muito mais longe que suas características técnicas. De fato, este reconhecimento mostra que a razão de se realizar medidas de manutenção pró-ativa não visa simplesmente prevenir a falha em si, mas evitar ou pelo menos mitigar suas conseqüências.

A RCM além de reconhecer a importância das conseqüências das falhas, na tomada de decisão da manutenção, ainda classifica estas conseqüências em quatro grupos:

- Falhas ocultas - são aquelas não percebidas pelo pessoal da operação, mas que podem expor a organização a múltiplas falhas, com conseqüências, geralmente, catastróficas.

- Falhas com conseqüências de segurança e ambientais

- Falhas com conseqüências operacionais - afetam a produção, qualidade do produto e custos operacionais.

- Falhas com conseqüências não operacionais - falhas evidentes que não afetam a segurança nem o meio ambiente, e restringem-se ao custo direto do reparo.

A RCM utiliza esta categoria (conseqüências da falha), como base da estratégia de tomada de decisão da manutenção. Por forçar uma revisão estrutural, esta categoria acaba por integrar os objetivos da manutenção, com a operação, segurança e meio ambiente. A avaliação das conseqüências das falhas também dá ênfase contrária à idéia de que toda falha é má e deve ser prevenida. Isto demonstra que a manutenção deve focar suas atividades para gerenciar as falhas que afetam o desempenho da organização, ou seja, a manutenção deve ser encorajada a pensar formas diferentes de gerir as falhas, em vez de simplesmente se concentrar em prevení-las (MOUBRAY, 1999a, p.4). 


\section{Prevenção}

Muitos ainda acreditam que o aumento da disponibilidade de uma planta, é garantido por algum tipo de manutenção preventiva, ou que quanto mais revisado for um equipamento, menor a probabilidade de ele apresentar falhas, esta era a visão da " 2 a . geração da manutenção", mostrada no item 2. 2 deste trabalho, que utilizava como parâmetro à substituição de componentes baseada em intervalos de tempo (curva da banheira) (PINTO E XAVIER, 1999, p.109 e MOUBRAY, 1999a, p.4).

Este modelo é verdadeiro para certos tipos de equipamentos simples, e para alguns mais complexos onde um modo de falhas é dominante. Em particular, desgaste onde existe contato direto com o produto (por exemplo, em bombas, correias transportadoras e refratários), fadiga, corrosão, abrasão e evaporação (MOUBRAY, 1999a, p.5).

A RCM adota o modelo, onde seis tipos de curvas de falha são empregados para caracterizar a vida útil dos equipamentos, e não apenas a "curva da banheira", onde é representada a mortalidade infantil, a vida útil por um determinado intervalo de tempo e finalmente a área onde o desgaste é mais acentuado (PINTO E XAVIER, 1999, p.108).

A figura 2. 11 apresenta os seis tipos de curvas de falha, onde $o$ eixo $X$ representa o Tempo e o eixo $\mathrm{Y}$ representa a Ocorrências de falhas:

A

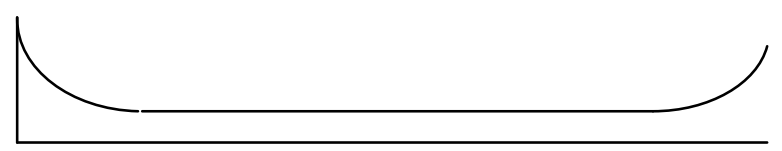

B

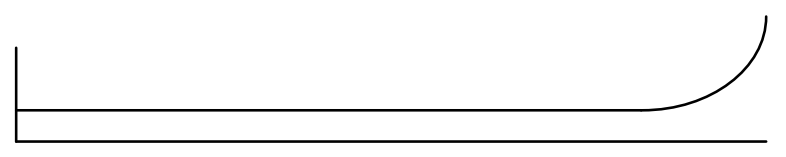

C

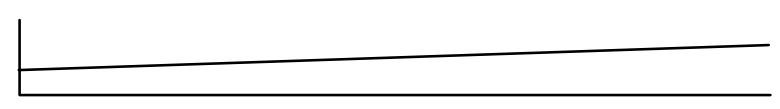

D

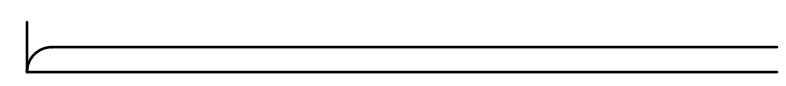


E

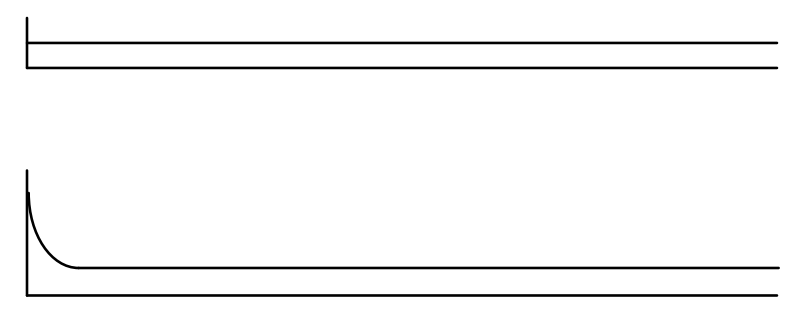

Figura 2. 11: Tipos de curvas de falhas - ocorrências de falhas $X$ tempo Fonte: Moubray (1999a, p.5).

Para Pinto e Xavier (1999, p.108), a figura 2.12 tem as seguintes implicações:

- A curva A representa a "curva da banheira", já explicada.

- A curva B mostra a probabilidade constante de falha, com um leve incremento de probabilidade de falhas no final da vida útil.

- A curva C mostra um aumento lento e gradual na probabilidade de falha, sem uma idade definida de desgaste.

- A curva D apresenta uma baixa probabilidade de falha, durante o início de operação de um equipamento novo, e um rápido aumento para um nível constante de probabilidade de falha.

- A curva $\mathbf{E}$ indica probabilidade constante de falha a qualquer tempo, ou seja, mostra falha aleatória.

- A curva F indica alta probabilidade no início (mortalidade infantil), que cai para uma situação de probabilidade constante para as demais idades.

Os padrões A, B, C representam falhas típicas por fadiga ou corrosão, enquanto que os padrões $\mathbf{D}, \mathbf{E}$ e $\mathbf{F}$ representam falhas típicas em equipamentos complexos, por exemplo, hidráulicos ou eletrônicos.

Pesquisas realizadas na aviação civil mostram a seguinte distribuição percentual por tipos de curvas de falha:

Tabela 2. 3: Distribuição percentual por tipos de falhas Fonte: Adaptado de Moubray (1999a, p.5).

\begin{tabular}{|c|c|}
\hline Padrão de falha & Percentual \\
\hline A & $4 \%$ \\
\hline B & $2 \%$ \\
\hline
\end{tabular}




\begin{tabular}{|c|c|}
\hline C & $5 \%$ \\
\hline$D$ & $7 \%$ \\
\hline$E$ & $14 \%$ \\
\hline$F$ & $68 \%$ \\
\hline
\end{tabular}

Moubray (1999a, p.5) destaca que embora as ocorrências da aviação civil não sejam necessariamente as mesmas da indústria, não há dúvida que com o aumento da complexidade dos componentes, há um aumento de ocorrências de padrão E F.

Pode-se concluir, portanto, que para equipamentos complexos, nem sempre é verdadeira a crença da ligação entre idade de operação e confiabilidade, e também que a adoção exagerada de revisões programadas pode introduzir defeitos (MOUBRAY, 1999a, p.5 e PINTO e XAVIER, 1999, p.109).

Moubray (1992, 1999a), Pinto e Xavier (1999) apresentam que, as conseqüências das falhas influem decisivamente na adoção ou não de ações de manutenção preventiva, têm-se três formas de atuação:

- Manutenção preditiva ou sob condição.

- Manutenção preventiva com tarefas programadas de restauração.

- Manutenção preventiva com tarefas programadas de descarte.

Nas tarefas de manutenção preditiva ou sob condição acredita-se que a maioria das falhas sinaliza quando ela estiver para ocorrer. Esta sinalização é conhecida por falha potencial, e é definida como condição física que indica que uma falha funcional está para ocorrer ou está ocorrendo.

As tarefas de manutenção preventiva quer sejam programadas de restauração, quer sejam programadas de descarte, são baseadas no tempo, independente da condição em que o item se encontre. No primeiro tipo pode-se incluir a reforma ou restauração de um item, seu retrabalho ou ainda uma revisão periódica. Já no segundo tipo, o item é descartado quando o mesmo atinge uma idade limite pré-definida, ação esta, muito adotada na aviação.

Ausência de tarefas de manutenção preventiva 
Moubray (1992, 1999a, 1999b), Pinto e Xavier (1999) listam as três providências que devem ser tomadas na ausência de tarefas de manutenção preventiva, que são:

- Descoberta de falhas - consiste em executar checagens para se saber se 0 item consegue cumprir suas funções, em oposição ao que é feito em tarefas sob condição, que verifica se algo está falhando.

- Reprojeto do item - se a tarefa de prevenir a falha envolver risco à segurança ou ao meio ambiente, ou ainda, se a falha tiver conseqüências operacionais e o custo da tarefa de prevenção for maior que o custo do reparo da falha, então o item ou componente deve ser reprojetado.

- Não programar manutenção - se uma falha de conseqüências não operacionais tiver seu custo de prevenção maior do que o custo do reparo desta falha, durante um período de tempo, então se deve deixar a falha ocorrer e se executar a manutenção corretiva planejada.

\section{IMPLEMENTAÇÃO DA RCM}

Vários autores, entre eles, Anhesine (1999, p.67), Pinto e Xavier (1999, p.112), Tsang (1995, p.8), destacam que para se responder as sete questões básicas da RCM, é necessário à formação de uma equipe multidisciplinar.

Somente um time multidisciplinar é capaz de analisar adequadamente equipamentos, sistemas unidades, ou própria planta.

Moubray (1999a, p.7), Pinto e Xavier (1999, p.113) mostram as características funcionais das equipes multidisciplinares:

- Grupos pequenos

- Habilidades complementares

- Propósito comum

- Conjunto de objetivos de desempenho, traduzidos por indicadores.

- Conjunto de princípios comuns a outros tipos de planta.

- Responsabilidade mútua

A figura 2. 12 representa o grupo multidisciplinar para a implementação de RCM. 


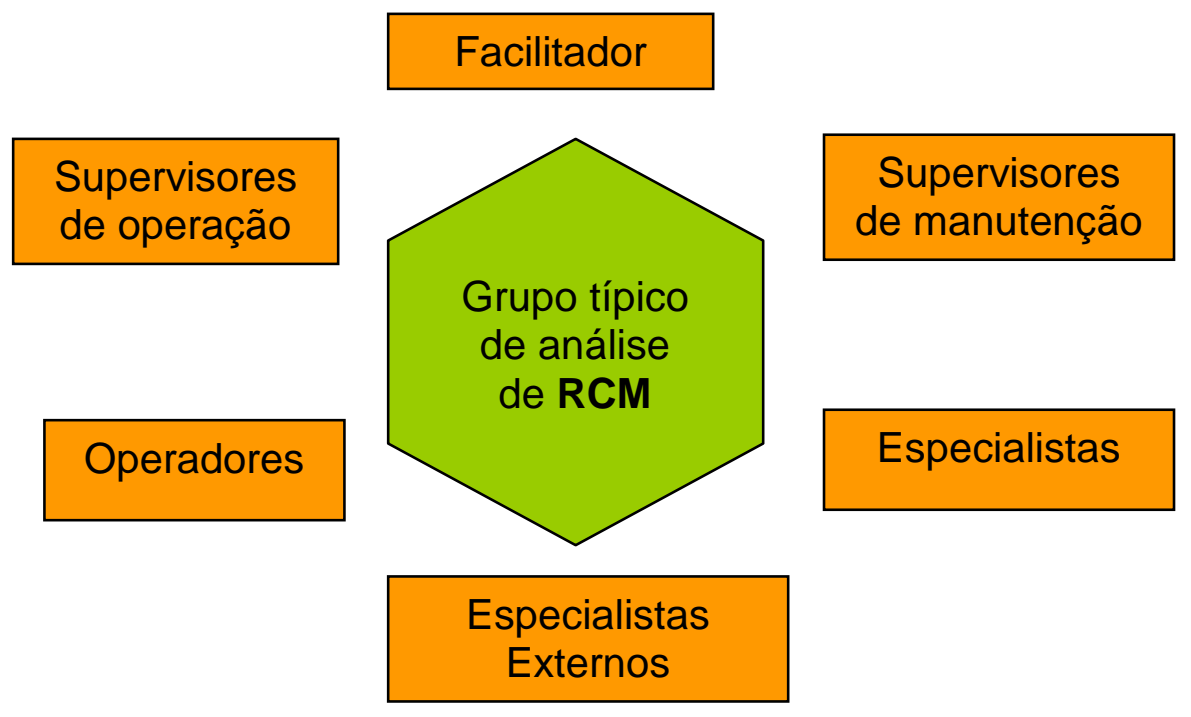

Figura 2. 12: Grupo típico de análise de RCM Fonte: Moubray (1999a, p.7).

O Facilitador é um especialista treinado em RCM, cujo papel é:

- assegurar o emprego correto da filosofia RCM,

- definir claramente as fronteiras do sistema,

- o correto entendimento de RCM por parte do grupo,

- buscar o consenso dentro deste grupo,

- garantir a eficácia da reunião e

- verificar que a documentação necessária seja feita.

Uma vez tendo sido concluída a revisão de cada componente, a gerência responsável pelo equipamento, deve ela mesma se certificar que a mesma é satisfatória e defensável (MOUBRAY, 1999a, p.7).

Após a aprovação final da revisão da $\mathrm{RCM}$, o último passo é a implementação.

As tarefas e procedimentos revisados devem ser desenhados de forma a assegurar que eles sejam claramente entendidos e seguramente aplicados pelas pessoas alocadas. As tarefas de manutenção são então, alimentadas de modo amigável, ao mesmo tempo em que os procedimentos operacionais são incorporados (MOUBRAY, 1999b, p.5). 


\section{RESULTADOS DA RCM}

Anhesine (1999, p.65) afirma que manutenibilidade e confiabilidade são indispensáveis para preservar a eficiência da produção, e resulta em maior disponibilidade dos equipamentos, propiciando assim produtos de alta qualidade, custos baixos e níveis elevados de produção, que são fundamentais para manter uma vantagem competitiva.

Para Moubray (1999a, p.8), Pinto e Xavier (1999, p.114 e 115), a prática da metodologia de RCM proporciona uma série de benefícios, que podem ser resumidos como segue:

- Melhorias das condições de segurança e ambientais - a RCM considera as implicações de segurança e ambientais provocadas pelas falhas, prioritárias em relação aos efeitos operacionais.

- Aumento do desempenho operacional - a RCM considera que todos os tipos de manutenção têm o seu valor, e possibilita o emprego do tipo mais eficaz de manutenção para máquina em cada situação.

- Melhoria do custo/benefício da manutenção - como adota a melhor solução de manutenção para cada tipo de máquina, a RCM propicia uma redução de custos entre $40 \%$ e $70 \%$ nas tarefas rotineiras de manutenção, além de garantir que o capital investido na manutenção se dará onde o efeito é maior.

- Aumento da vida útil dos equipamentos - focando enfaticamente a manutenção nas condições do equipamento, notadamente nos mais complexos e dispendiosos, é um fator de aumento da vida útil dos equipamentos.

- Banco de dados de manutenção - o processo de revisão realizado pelo time multidisciplinar de RCM, proporciona a obtenção de um banco de dados significativos para a manutenção e para a operação, disponibilizando uma memória a todos e a qualquer tempo, minimizando os efeitos de rotatividade de pessoal. Este banco de dados também favorece a decisão das peças que devem ser mantidas em estoque.

- Aumento da motivação individual - as reuniões dos times multifuncionais geram uma participação efetiva das pessoas envolvidas, o que sem dúvida leva a um aumento da satisfação pessoal. 
- Senso de equipe - a participação do pessoal nos grupos de trabalho, desenvolve o senso de equipe, propiciando resultados cada vez melhores.

Anhesine (1999, p.66), mostra a tabela 2. 4, que resume os benefícios da aplicação da RCM para usuários e fornecedores:

Tabela 2. 4: Benefícios da Confiabilidade e Manutenibilidade Fonte: Anhesine (1999, p.66).

\begin{tabular}{|l|l|}
\hline \multicolumn{1}{|c|}{ Benefícios do Usuário } & \multicolumn{1}{c|}{ Benefícios do Fornecedor } \\
\hline Maior disponibilidade de máquinas & Custos de garantia reduzidos \\
\hline Paradas não programadas reduzidas & Custos de construção reduzidos \\
\hline Custos de manutenção reduzidos & Custos de projeto reduzido \\
\hline Programa de trabalho estabilizado & Maior satisfação do usuário \\
\hline Aumento de desempenho J.I.T. & Maior vantagem competitiva \\
\hline Aumento da satisfação dos empregados & Ampliação das aplicações do produto \\
\hline Custo global de produção mais baixo & Melhor posicionamento no mercado \\
\hline Melhor e maior lucratividade & Aumento do volume de vendas \\
\hline
\end{tabular}

Moubray (1999a, p.5) afirma que a correta aplicação da RCM, fornece resultados positivos muito rapidamente, e se paga em questão de meses, ou mesmo de semanas. A maior característica da RCM é proporcionar um efetivo programa passo a passo de envolvimento de todas as pessoas ligadas aos equipamentos e ao processo.

Pinto e Xavier (1999, p.116) apresentam um diagrama mostrando a aplicação da RCM (Figura 2. 13). 


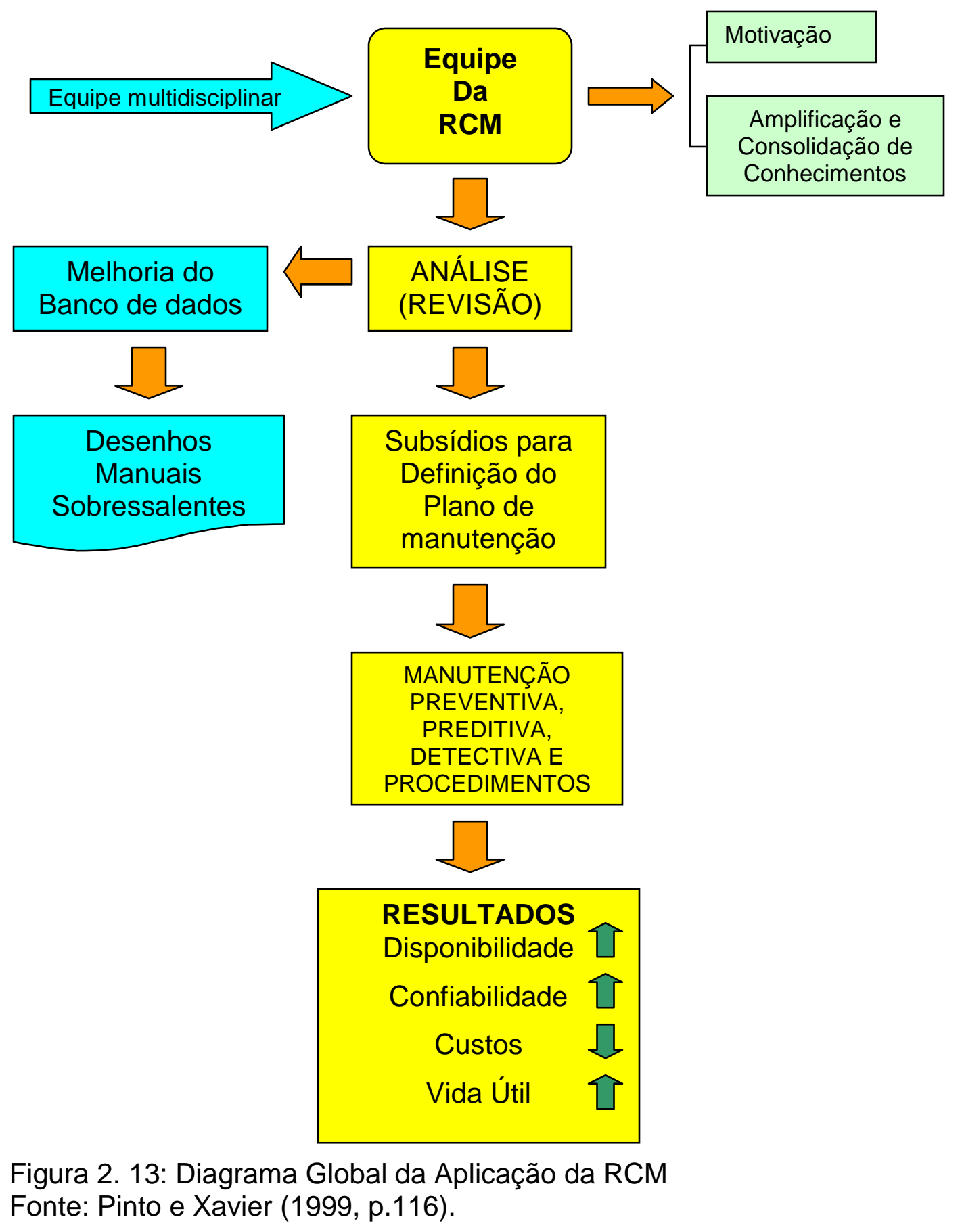

\section{7 DIMENSÕES ESTRATÉGICAS DA MANUTENÇÃO}

Tsang (2002, p.7-39) identifica quatro dimensões estratégicas para a gestão da manutenção, e indica os caminhos para alcançá-las.

As dimensões estratégicas identificadas pelo autor são:

1. Opções para realização das tarefas de manutenção - escolha entre execução interna dos serviços ou terceirização dos mesmos. 
2. Organização da função manutenção - estruturação das tarefas.

3. Técnicas e ferramentas da Manutenção - seleção da política de manutenção.

4. Sistemas de apoio - infra-estrutura de apoio à manutenção.

Para se atingir a primeira dimensão, o autor sugere que sejam respondidas três questões:

- O que não deve ser terceirizado?

- Que tipo de relacionamento deve ser adotado com o fornecedor externo?

- Como os riscos da terceirização devem ser gerenciados?

$\mathrm{Na}$ dimensão "Organização e estruturação das tarefas", o autor indica um planejamento e programação baseados em três níveis:

- Nível 1 - manutenção para manter a planta rodando.

- Nível 2 - atividades que produzem mudanças significativas nas condições da planta.

- Nível 3 - constitui-se de atividades como modificações na planta, recondicionamento ou revisão da mesma.

A dimensão estratégica "Técnicas e Ferramentas da manutenção", está diretamente ligada ao escopo do trabalho de mestrado, que está sendo realizado.

O autor enumera e comenta as políticas de manutenção utilizadas nas empresas, a saber:

- Trabalhar até a falha.

- Manutenção preventiva.

- Manutenção preditiva, ou baseada na condição (CBM).

- Projeto de melhorias ou engenharia de manutenção.

Na dimensão "Sistemas de apoio", o autor destaca que para se atingir as demais anteriores, são necessários vários tipos de apoio para a manutenção, tais como:

- Participação e envolvimento dos empregados.

- Hierarquia e comunicação.

- Educação e treinamento.

- Valorização e recompensa dos funcionários.

- Medidas de desempenho. 
- Sistemas de informação.

O autor conclui, apresentando a tabela 2. 5, que sintetiza as questões propostas pelo mesmo, bem como definindo que os fatores que permitem o alcance das dimensões estratégicas enumeradas são:

- O fator humano.

- O fluxo de informações.

Tabela 2. 5: Dimensões estratégicas de manutenção Fonte: Tsang (2002, p.36).

\begin{tabular}{|c|c|c|c|c|}
\hline Dimensão & Opções de serviço & Organização & Metodologia & Sistemas de apoio \\
\hline $\begin{array}{l}\text { Opções } \\
\text { Estratégicas }\end{array}$ & $\begin{array}{l}\text { Foco na manutenção } \\
\text { como vantagem } \\
\text { competitiva. } \\
\text { Terceirização de } \\
\text { serviços que não } \\
\text { constituem vantagem } \\
\text { competitiva }\end{array}$ & $\begin{array}{l}\text { Nivelamento } \\
\text { hierárquico } \\
\text { Flexibilização de } \\
\text { MO } \\
\text { Especialização de } \\
\text { MO }\end{array}$ & $\begin{array}{l}\text { Foco no } \\
\text { equipamento - } \\
\text { RCM } \\
\text { Foco nas pessoas - } \\
\text { TPM }\end{array}$ & $\begin{array}{l}\text { Autonomia } \\
\text { Cultura de times } \\
\text { E-maintenance: } \\
\text { e-CBM, } \\
\text { e-CMMS }\end{array}$ \\
\hline $\begin{array}{l}\text { Decisões } \\
\text { Chave }\end{array}$ & $\begin{array}{l}\text { Atividades realizadas } \\
\text { internamente. } \\
\text { Relacionamento com } \\
\text { fornecedores externos. } \\
\text { Gerenciamento de riscos } \\
\text { da terceirização }\end{array}$ & $\begin{array}{l}\text { Especialização da } \\
\text { planta. } \\
\text { Locação de MO } \\
\text { Especialização de } \\
\text { MO } \\
\text { Estruturação de } \\
\text { tarefas } \\
\text { Interação com } \\
\text { operação }\end{array}$ & $\begin{array}{l}\text { RCM: Definição } \\
\text { dos itens a serem } \\
\text { cobertos. } \\
\text { Envolvimento das } \\
\text { pessoas nas } \\
\text { análises e projeto } \\
\text { das tarefas } \\
\text { TPM: } \\
\text { Escopo de } \\
\text { aplicação } \\
\text { Redefinição do } \\
\text { papel dos } \\
\text { operadores e } \\
\text { mantenedores }\end{array}$ & $\begin{array}{l}\text { Alinhar as } \\
\text { seguintes práticas e } \\
\text { sistemas de apoio: } \\
\text { Participação e } \\
\text { autonomia. } \\
\text { Hierarquia e } \\
\text { comunicação. } \\
\text { Educação e } \\
\text { treinamento. } \\
\text { Recompensa e } \\
\text { reconhecimento } \\
\text { Medidas de } \\
\text { desempenho } \\
\text { Sistemas de } \\
\text { informação } \\
\text { E-maintenance: } \\
\text { Arquitetura Web }\end{array}$ \\
\hline $\begin{array}{l}\text { Elementos } \\
\text { chave do } \\
\text { processo de } \\
\text { mudança }\end{array}$ & \multicolumn{4}{|c|}{$\begin{array}{l}\text { Comunicar a necessidade de mudanças } \\
\text { Educar funcionários para adquirir novas habilidades e executar novos papéis } \\
\text { Acalmar a ansiedade dos funcionários } \\
\text { Desenvolver plano de implementação } \\
\text { Rever o progresso e tomar ações corretivas }\end{array}$} \\
\hline
\end{tabular}




\section{CONCEITOS E TECNOLOGIAS ENVOLVIDOS}

Neste capítulo são apresentados os conceitos e as tecnologias sobre o monitoramento por emissão acústica e noções básicas para a compreensão da comunicação entre micro computadores.

\section{1 EMISSÃO ACÚSTICA}

Emissão acústica pode ser definida como ondas elásticas geradas durante processos dinâmicos nos materiais. De forma simplificada se pode entender emissão acústica como os sons ou ruídos provenientes dos materiais quando sujeitos a esforços. Estes sons e ruídos nem sempre podem ser audíveis para o ser humano em virtudes das freqüências em que os mesmos ocorrem.

Embora o surgimento de sons e ruídos provenientes de materiais sujeitos a carga sempre tenham despertado apreensão por parte das pessoas, a utilização de emissão acústica como parâmetro para caracterizar o uso desses materiais foi negligenciado por muito tempo pela comunidade acadêmica.

Segundo Liptai, Harris e Tatro (1972) os primeiros estudos para a utilização de emissão acústica com fins acadêmicos relacionados com metais são creditados a Joseph Kaiser e seus colaboradores. No começo dos anos 50, na Alemanha, eles realizaram pesquisas utilizando instrumentos eletrônicos para detectar sons audíveis durante a transformação dos metais. Kaiser constatou que todos os metais pesquisados exibiam o fenômeno da emissão acústica e também que esta emissão era irreversível, isto é, a emissão acústica não é gerada pela recarga do material até que um determinado nível de tensão seja atingido. Este fenômeno é conhecido como "Efeito Kaiser" .

Durante a década de 60 muitos pesquisadores se interessaram por trabalhos utilizando a emissão acústica, principalmente, em relação à deformação plástica dos metais. Nessa época, os pesquisadores tinham muitas dificuldades com os ruídos e sons ambientes, por isso eles eram obrigados a trabalhar em laboratórios localizados em áreas isoladas. Estas dificuldades foram eliminadas, ou pelo menos minimizadas, com a utilização de 
instrumentos que operavam em faixas de freqüências acima da faixa de audição (LIPTAI, HARRIS e TATRO, 1972).

A emissão acústica é muito empregada em estudos de deformação de materiais e estudos de fadiga de estruturas ou equipamentos mecânicos estacionários, principalmente vasos de pressão, para a análise da integridade do material.

Uma maneira de se realizar esta verificação é provocar um estímulo numa região onde exista concentração de tensões (região que possui defeitos), com o estímulo ocorre uma redistribuição de tensões formando ondas mecânicas transientes. Transdutores piezelétricos, colocados na superfície, estimulados pelas ondas mecânicas transientes, transformam essa energia em energia elétrica. Esses sinais elétricos, por sua vez, são digitalizados e gravados para análise (PINTO e XAVIER, 1999).

A emissão acústica também é gerada durante a formação ou transformação de compostos químicos, tratamento térmico de metais, etc.

Em se tratando de equipamentos rotativos, mais especificamente em relação aos mancais, uma forma de energia acústica aparece quando um mecanismo começa a dar sinais de pequenas falhas, como por exemplo uma massa rotativa passando sobre um defeito, como uma esfera de rolamento que começa a se degradar, quer seja por corrosão, desgaste ou qualquer outro tipo de anomalia (BALDERSTON, 1972).

A partir dessa constatação, o monitoramento de máquinas rotativas utilizando a emissão acústica parece propiciar um caminho promissor na detecção prematura da degradação de componentes. Esta proposição vem de encontro com as expectativas da manutenção preditiva que busca a identificação de falhas nos estágios mais iniciais possíveis do processo de deterioração dos componentes.

Processos que geram atrito e impacto naturalmente são grandes fontes de ondas elásticas, que variam desde decibéis até $\mathrm{MHz}$. Estas ondas se propagam por toda a estrutura das máquinas. Como resultado desta propagação, existem vários esquemas de detecção das freqüências geradas, como por exemplo o monitoramento de vibração, que se utiliza de altos níveis de sinal de baixas freqüências. Entretanto esses sinais sofrem várias contaminações de outros ruídos, o que leva a necessidade de um complexo 
sistema de análise de sinais. Já a emissão acústica, por tratar com níveis mais elevados de freqüência, está menos sujeita a estas interferências.

De fato, a emissão acústica é fortemente influenciada por processos de falhas, porém, ela é muito pouco sensível quando os componentes estão rodando dentro da normalidade, ou seja, equipamentos em bom estado são muito silenciosos principalmente até $100 \mathrm{kHz}$ (HOLROYD, b).

O sistema de aquisição de dados é composto pela coleta de dados, que, neste trabalho, é realizada a partir dos sensores de emissão acústica e pela comunicação (MEIRELES, 2000, p.3-4).

A seguir destacam-se as tecnologias envolvidas com a comunicação.

\section{2 A COMUNICAÇÃO NAS EMPRESAS}

As empresas possuem vários computadores e equipamentos eletrônicos inteligentes em seus departamentos que precisam se comunicar entre si e com outros equipamentos similares da cadeia de suprimentos

Stand alone é quando um micro ou alguns micros estão colocados em um mesmo espaço físico e não estão em contato uns com os outros e as tarefas da empresa são realizadas por cada unidade sem nenhum compartilhamento quer seja de hardware, quer seja de software. Nesta fase o simples compartilhamento de arquivos se torna uma odisséia.

O micro padrão usado nesta fase possui componentes importantes para o enfoque em comunicações:

a) Placa de rede: nos modelos atuais, os micros já vêm prontos para serem ligados em rede. Normalmente é uma placa de rede padrão 10BaseT (suporta transferências de dados de 10 Mbps por segundo - 10 mega bits por segundo - IEEE 802.3) ou 100BasesT (100Mbps - a chamada fast ethetnet IEEE 802.3u). 


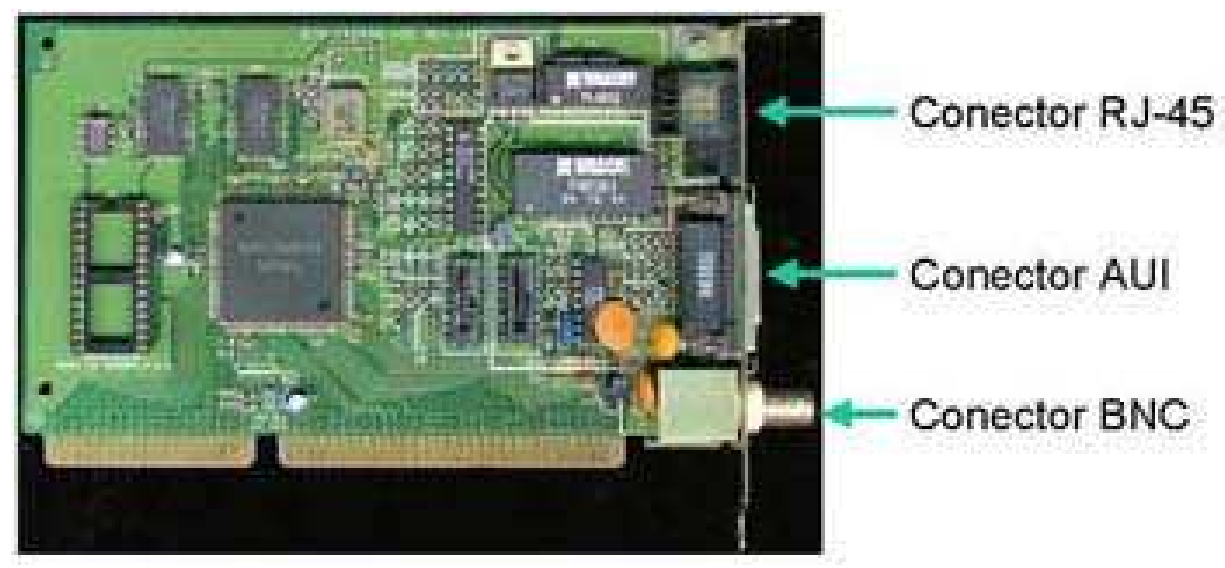

Figura 3. 1: Placa de rede

b) Modem: o modem é um dispositivo que permite ao micro transmitir e receber dados. A palavra MoDem é uma abreviação de modulatordemodulator, as operações que este componente realiza, ou seja, na modulação os dados digitais são transformados em sons e são transportados pela linha telefônica. A demodulação é o processo inverso, onde os sons transmitidos pela linha telefônica são novamente transformados em sinais digitais. Os modens instalados vêm com capacidade de transmissão de 56 kbps (56 kilobits por segundo). As conexões via modem para a internet são feitas por intermédio dos provedores de acesso à internet ou ISP - internet service provider.

Rede é qualquer aglomerado de peças funcionando em conjunto em uma ordem previsível. Em termos de informática, um grupo de computadores interligados por uma topologia em comum, que permite a transmissão dos dados (HAYDEN, 1999).

Qualquer que seja a rede que se queira montar (fast food, farmácias, computadores, etc), os motivos para essa montagem, segundo Hayden, podem ser resumidos basicamente nos seguintes pontos:

- as redes podem aumentar a eficiência

- as redes podem ajudar a padronizar políticas, procedimentos e práticas entre os usuários da rede 
- as redes podem reunir idéias e temas diversos em um fórum comum, onde eles podem ser tratados de maneira global, ao invés da ineficiente maneira individual

- as redes ajudam a garantir que as informações sejam redundantes - em outras palavras, que existam em mais de uma mente (ou computador) em um dado momento.

A partir dessas premissas, em se tratando de computadores, nota-se que se houver a necessidade de comunicação, de compartilhamento de dados, de aplicativos e de periféricos, a montagem de uma rede será bastante benéfica.

Em função da distância, quantidade e velocidade de transmissão de dados, vários tipos de meios físicos podem ser usados para a conexão de uma rede, como por exemplo par de fios trançados, fibra ótica, cabo coaxial, etc.

$\mathrm{Na}$ implementação de uma rede várias topologias, arranjos geométricos físico da rede de computadores, podem ser usadas, sendo as mais comuns, a de estrela, a de barramento, a de anel, a de ponto a ponto e a de multiconexão.

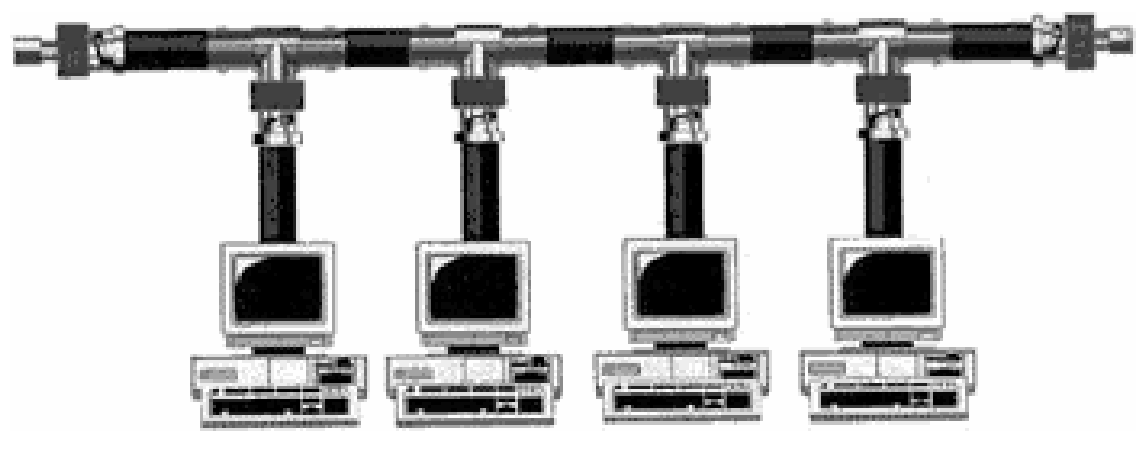

Figura 3. 2: Topologia em barramento 


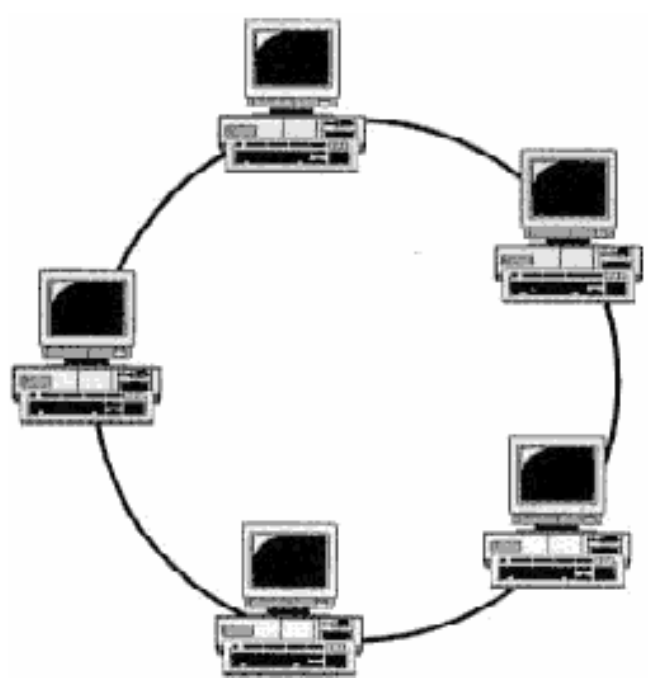

Figura 3. 3: Topologia em anel

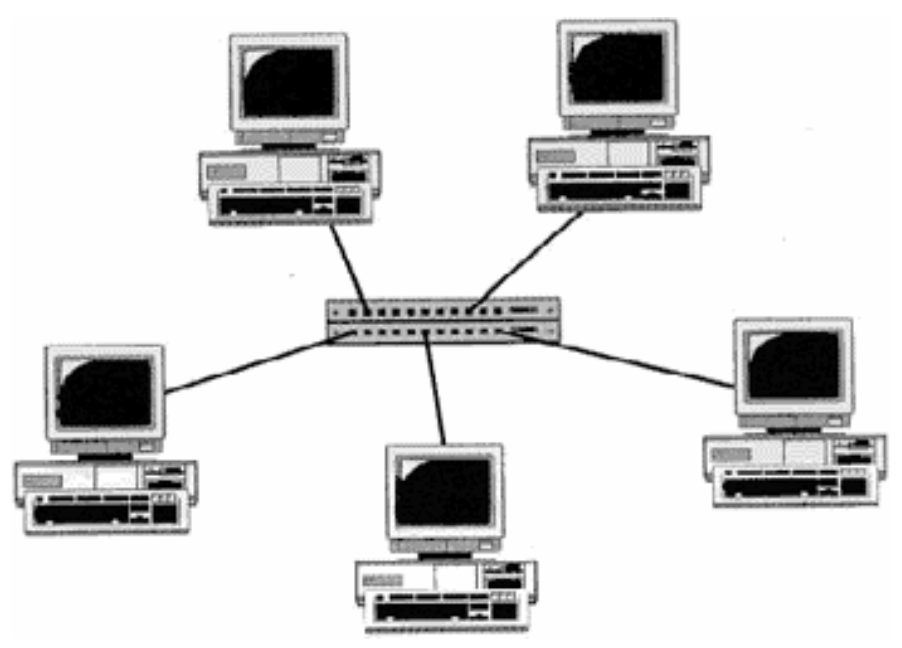

Figura 3. 4: Topologia em estrela

Além dos meios físicos e das topologias, as redes também são caracterizadas pelos seus tipos, que basicamente podem ser LANs e WANs.

A LAN (Local Area Network) é uma rede de computadores particular que utiliza transmissão serial e que estão todos no mesmo local físico. Ela possui um bom custo-benefício, pois a interligação dos componentes pode ser feita por um par de fios, cabo coaxial ou fibra ótica, apresentam taxas elevadas de transmissão de dados. Embora as LANs sejam as redes mais simples, elas podem se tornar bem grandes e complexas e compostas por até milhares de usuários. 


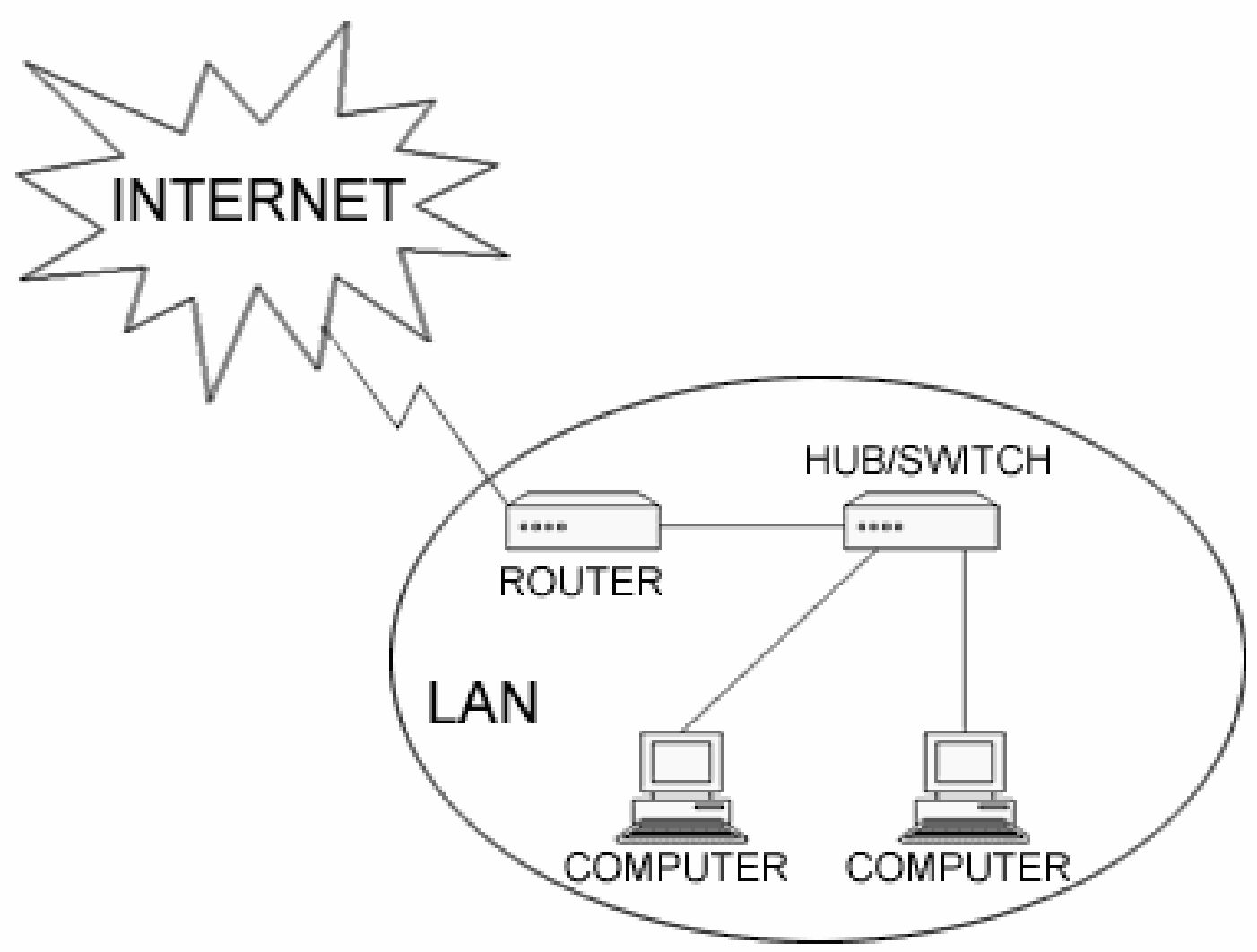

Figura 3. 5: Esquema de rede LAN

A WAN (Wide Area Network) é uma rede remota. As redes remotas são LANs espalhadas geograficamente. As taxas de transmissão são baixas, pois são limitadas pela velocidade da linha telefônica, essas restrições das linhas telefônicas são conhecidas por problemas de largura de banda. Geralmente as WANs são montadas quando todos os usuários necessitam ter acesso a um conjunto de informações. 


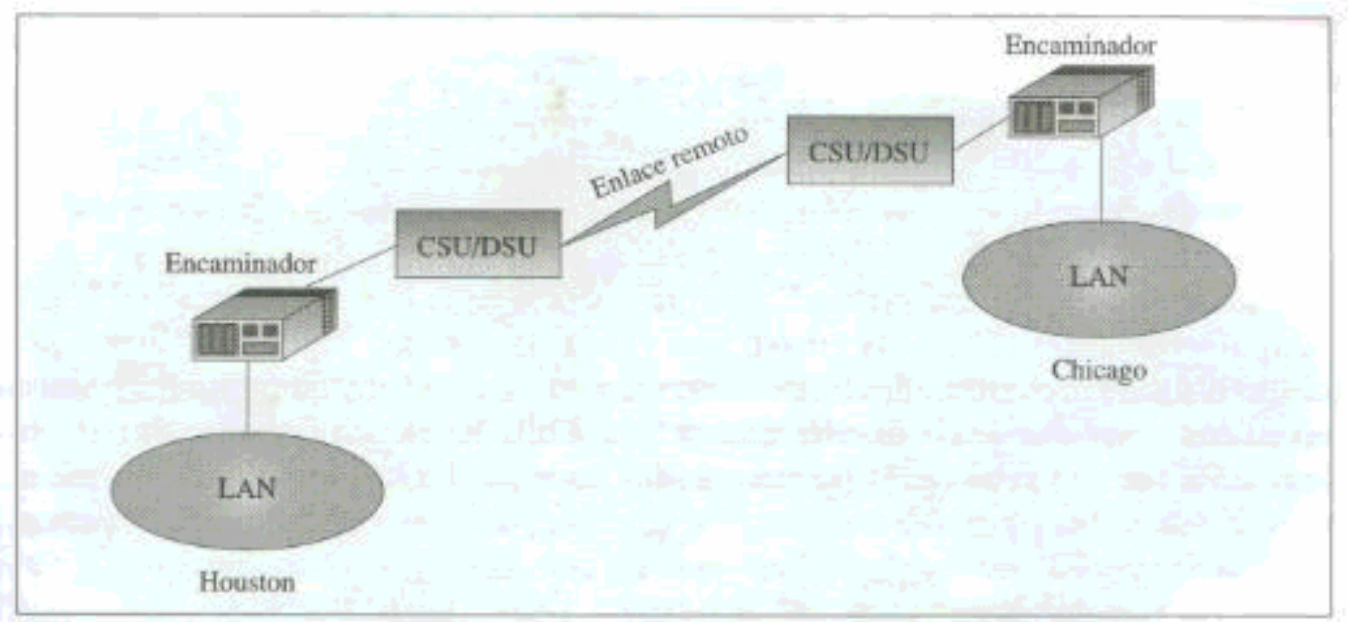

Figura 3. 6: Esquema de rede WAN

Quando se constrói uma rede privada (LAN ou WAN), utilizando-se dos mesmos softwares e dos mesmos protocolos da Internet, cria-se uma Intranet. Conectando-se a intranet com a Internet, oferecendo recursos para clientes e parceiros comerciais realizarem negócios, cria-se uma Extranet.

As pequenas empresas podem operar com poucos recursos em termos da informatização inicial para poderem efetivar sistemas de comunicação entre os seus decisores e as informações/dados que necessitam. Existe um investimento inicial que passa pela compra dos micros e softwares para cada colaborador da empresa, mas este investimento não é objeto de discussão, por se tratar de um gasto pré-operacional.

Para que a empresa saia de um sistema em que suas máquinas estão desconectadas umas das outras para um sistema integrado ou em rede tem-se que proceder alguns passos. Primeiramente entender que em cada máquina é instalado (roda) um sistema operacional (SO) que responde pelo gerenciamento desta máquina local. Como exemplo destes sistemas operacionais pode-se citar:

- Microsoft (MS) com os produtos da família Windows;

- Conectiva (empresa brasileira) e outros distribuidores do software livre Linux;

- Apple com a família Mac OS, para os micros Macintosh. 
Geralmente estes softwares já vêm distribuídos juntamente com os micros com a compra do hardware. Cada máquina é chamada de estação de trabalho ou desktop, pois é utilizada individualmente por cada colaborador.

Para o gerenciamento de um grupo de computadores ligados entre si, exige-se que se tenha um computador central chamado de servidor e que este opere um sistema operacional à parte dos SOs instalados nas estações para que faça o gerenciamento da rede constituída e integrada. Esta rede local é também chamada de LAN (local area network).

A ligação de cada estação de trabalho com o servidor é feita através de cabos. A arquitetura mais utilizada nas empresas é a que foi citada acima com um servidor gerenciando a rede e as estações de trabalho como clientes de serviços deste servidor, sendo chamada esta arquitetura de cliente/servidor (client/server architecture).

Nos servidores rodam os SOs de rede, sendo os mais comuns:

- Microsoft representada pelos Windows NT e os Windows 2000 Server.

- Novell, da família NetWare.

- Linux, versão para servidores, as mais variadas versões de cada distribuidor.

Nas pequenas empresas a disponibilidade de $\mathrm{SO}$ de rede pode-se resumir a estas três opções, outros SOs utilizados são os Unix das versões da IBM, HP e Sun.

Um ponto importante a discutir aqui é que as decisões que a empresa tomar na escolha dos softwares das estações e dos servidores de rede impactarão todos os sistemas futuros, dispositivos de redes, outros softwares colaborativos, e toda gama de produtos informacionais que a empresa for comprar no futuro. Por exemplo, quando a empresa decide comprar os produtos da Microsoft, esta decisão dirigirá a compra de vários produtos no futuro ligados à própria MS, isto ocorre com o pacote Office e com o Project e muito mais crítico com os softwares de Groupware, como o Exchange e agregados como o NetMeeting.

O papel fundamental do SO de rede é prover as estações quanto aos serviços impressão, compartilhamento de arquivos, aplicativos, internet e segurança. É importante salientar que este mesmo SO será a base para todos os softwares de GroupWare que a empresa vier a instalar. 


\section{Softwares base para o sistema colaborativo}

Com os recursos apresentados, a empresa já pode ativar o processo de comunicação interna eletrônica através de e-mail e/ou documentação compartilhada. Para tanto se deve atentar para alguns softwares que fazem 0 gerenciamento de contas de e-mail, pois no futuro também serão clientes de outros softwares que serão utilizados para a comunicação entre os decisores:

- MS Outlook: vem junto com o Office. Importante quando se utilizam as ferramentas e softwares da Microsoft, como por exemplo na aplicação do Exchange, algumas aplicações não abrirão em outros gerenciadores. No caso do Project a implicação é ainda maior devido à falta de aderência do Project com outros gerenciadores. O MS Outlook Express vem junto com o SO.

- Eudora: um gerenciador muito bom de e-mail, mas não se integra com o Exchange e nem com o Project. Muito bom para as soluções da Oracle (Collaboration Suíte) e Lotus-Notes.

- Outro software importante para a colaboração com os sistemas de apoio à decisão são os browsers:

- MS Internet Explorer: o browser da Microsoft é o mais largamente utilizado pela empresas, mas pode ser uma fonte de problemas se utilizados para softwares não Microsoft, como por exemplo o Primavera (concorrente do Project) e appelets Java.

- Netscape: não é compatível com o NetMeeting, ferramenta da Microsoft para reuniões virtuais. Problemas com exposição de programação web realizada com ASP, VB Script e dot.Net. Problemas com o Exchange e com o Project (Project Central).

A empresa deverá ainda se preocupar com a escolha do banco de dados, como por exemplo:

- Oracle:

- SQL Server:

- Access: 


\section{3 SENSORES}

Há muitos anos, que os técnicos de manutenção se utilizam de seus sentidos (tato, olfato, audição, visão) para diagnosticar condições de máquinas e componentes. Estes procedimentos são mais confiáveis quanto mais experientes são os técnicos envolvidos na manutenção.

Para que se execute um monitoramento objetivo são necessários instrumentos adequados, tais como: sensores, transdutores, leitores, etc (PINTO e XAVIER, 1999, p.184-189).

Em função do monitoramento a ser realizado pode-se escolher entre vários tipos de sensores.

A tabela 3. 1 relaciona alguns sistemas de monitoramento com seus respectivos sensores.

Tabela 3. 1: Sistemas de monitoramento e sensores utilizados Fonte: Pinto e Xavier, 1999, p.190.

\begin{tabular}{|c|c|c|}
\hline Equipamento/Instalação & Variável & Sensor \\
\hline Máquinas Rotativas & $\begin{array}{ll} & \text { Vibração } \\
\text { - } & \text { Deslocamento } \\
\text { axial } & \\
\text { - } \quad \text { Temperatura de } \\
\text { mancais } \\
\text { - } \quad \text { Rotação } \\
\text { - } \quad \text { Alinhamento }\end{array}$ & $\begin{array}{l}\text { Probe sem contato } \\
\text { Acelerômetro } \\
\text { piezelétrico } \\
\text { Pick up magnético } \\
\text { Probe sem contato } \\
\\
\text { RTD (Resistance } \\
\text { Temperature Detector) } \\
\text { Termopar } \\
\text { Probe sem contato } \\
\text { Sensores óticos a laser } \\
\text { Dodi-bars-probe sem } \\
\text { contato }\end{array}$ \\
\hline $\begin{array}{l}\text { Equipamentos } \\
\text { estacionários e estruturas }\end{array}$ & $\begin{array}{ll}\cdot & \text { Corrosão } \\
- & \text { Temperatura }\end{array}$ & $\begin{array}{l}\text { Sondas } \\
\text { Termopar }\end{array}$ \\
\hline Equipamentos elétricos & $\begin{array}{ll}- & \text { Temperatura } \\
\text { - } & \text { Corrente } \\
\text { - } & \text { Tensão } \\
\text { - } & \text { Resistência } \\
& \text { Capacitância }\end{array}$ & $\begin{array}{l}\text { RTD } \\
\text { Termopar } \\
\text { Infravermelho } \\
\text { Voltímetro, } \\
\text { Amperímetro } \\
\text { Ohmímetro } \\
\text { Registrador de tensão } \\
\text { e corrente } \\
\text { Mega }\end{array}$ \\
\hline
\end{tabular}


Os sensores utilizados para captar sinais de emissão acústica são do tipo piezelétrico. Estes sensores são constituídos por um cristal, montado em uma carcaça, que tem seu interior preenchido com resina, como mostrado na figura 3. 7 .

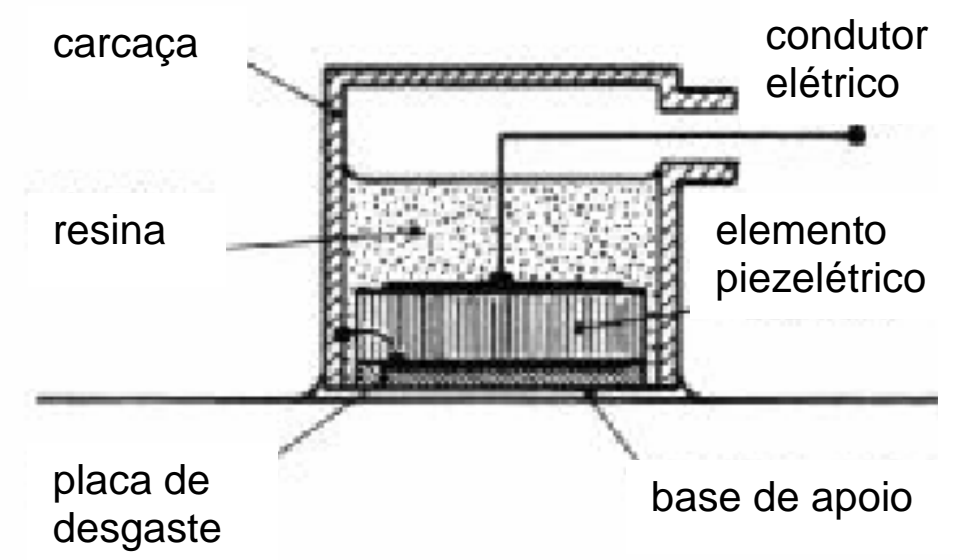

Figura 3. 7: Anatomia de um sensor piezelétrico

Quando uma onda elástica se propaga pela superfície, onde está fixado o sensor de EA, o cristal piezelétrico é pressionado produzindo um sinal elétrico, que é captado pelo transdutor.

Para serem empregados no monitoramento de componentes para manutenção os sensores devem atender especificações que lhes garantam robustez, uma vez que serão normalmente utilizados em condições bastante agressivas.

Os sensores de EA são de fácil instalação e pouco intrusivos, assim, ficam justificados a utilização dos mesmos num sistema de monitoramento para manutenção. 


\section{PROPOSIÇÃO DO SISTEMA DE MONITORAMENTO INTEGRADO PARA MANUTENÇÃO}

A atitude de se parar um equipamento para inspecioná-lo ou aguardar que o mesmo venha a falhar pode provocar grandes distúrbios na produção. Dessa forma, e considerando-se os aspectos de segurança, confiabilidade, desempenho e disponibilidade, conclui-se que a utilização de técnicas de manutenção preditiva são imprescindíveis para a otimização da produção nas empresas (ALMEIDA e ALMEIDA, p.10).

\section{1 DESCRIÇÃO GERAL}

Como já foi visto na Revisão Bibliográfica, a manutenção preditiva baseia-se no monitoramento das condições do equipamento, que é executada com a coleta e análise de dados.

O sistema proposto visa identificar variações de sinal de emissão acústica em componentes de máquinas rotativas, que possibilitem ao departamento de manutenção tomar iniciativas pró-ativas, que levem a uma diminuição do risco da ocorrência de falhas.

A escolha do sinal de emissão acústica para ser monitorado deve-se ao fato de que a interpretação do mesmo é bastante simples quando comparado à análise de vibração, método este, que é mais costumeiramente utilizado neste tipo de procedimento.

O sistema de monitoramento propicia um acompanhamento das condições de trabalho do componente em que o mesmo esteja instalado. A mudança dessas condições ocasiona uma variação na emissão acústica proveniente do componente. Assim alterações nas condições de lubrificação, desalinhamento de eixos, ocorrências de desgaste em rolamentos, folgas em mancais, etc., podem ser diagnosticadas pelo simples monitoramento do sinal de emissão acústica.

O sistema de monitoramento apresentado é composto por um sensor de emissão acústica, uma unidade de tratamento de sinais, um bloco de conexão, uma placa de aquisição de dados, um software de aquisição de dados e um micro-computador. Todos esses componentes serão descritos com mais detalhes a seguir. 
O sensor de EA utilizado é fabricado pela Empresa Sensis e sua função é transformar o sinal físico (ondas elásticas provenientes do choque das esferas do mancal com falhas nas pistas dos rolamentos) em um sinal elétrico.

A unidade de tratamento de sinal, também conhecida por condicionador de EA , também é de fabricação da Sensis, o modelo utilizado é o DM 42, cuja função é de amplificar, filtrar e retificar o sinal elétrico transmitido pelo sensor. A figura 4. 1 apresenta o sensor de EA e o condicionador de EA fabricados pela Sensis e que foram utilizados na pesquisa.

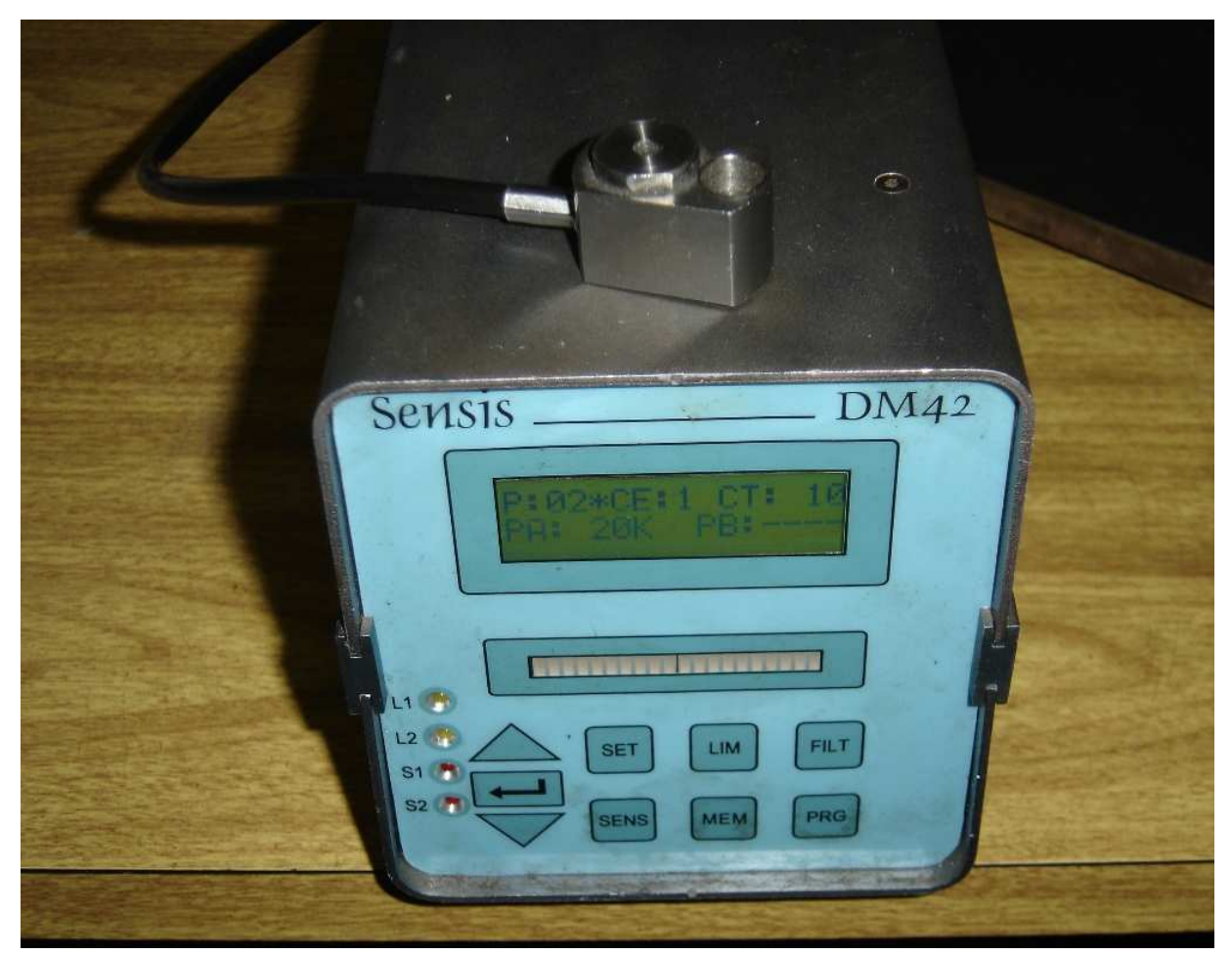

Figura 4. 1: Sensor e condicionador de EA DM 42 fabricados pela Sensis

O bloco de conexão utilizado é o modelo NI SBC-68, fabricado pela National Instruments, que tem por função conectar a saída do condicionador de EA, feita por um par de fios, em uma entrada de 64 pinos compatível com a placa de aquisição de dados.

A placa de aquisição de dados utilizada é fabricada pela National Instruments, seu modelo é $\mathrm{PCl}$ MIO-16E-4, com freqüência máxima de aquisição de $250 \mathrm{kHz}$, resolução da conversão de 12 Bits no fundo de escala, 16 canais analógicos e 8 canais digitais, e sua função é de digitalizar o sinal 
analógico recebido do condicionador de EA. A placa é acompanhada pelo driver NI - DAQ 6-9-1, também da National Instruments.

O software utilizado foi programado na linguagem Labview 6.1. Este que faz a interface entre o driver de aquisição de dados e o usuário do sistema de monitoramento.

Além da utilização de técnicas preditivas, outro procedimento que pode levar uma empresa a possuir uma vantagem competitiva, no que se refere à função manutenção, é a adoção da Engenharia de Manutenção.

Praticar Engenharia de Manutenção é utilizar todos os dados que o sistema de monitoramento colhe e armazena para análises, estudos e proposições de melhorias (PINTO e XAVIER, 1999, p.43).

Isto posto, surge à necessidade da implementação de um banco de dados, onde todas as informações provenientes do sistema de monitoramento possam ser armazenadas.

O banco de dados deve ainda possuir uma descrição detalhada de todas as tarefas da manutenção, a fim de que as mesmas possam ser planejadas e programadas.

A figura 4. 2 ilustra o sistema proposto:

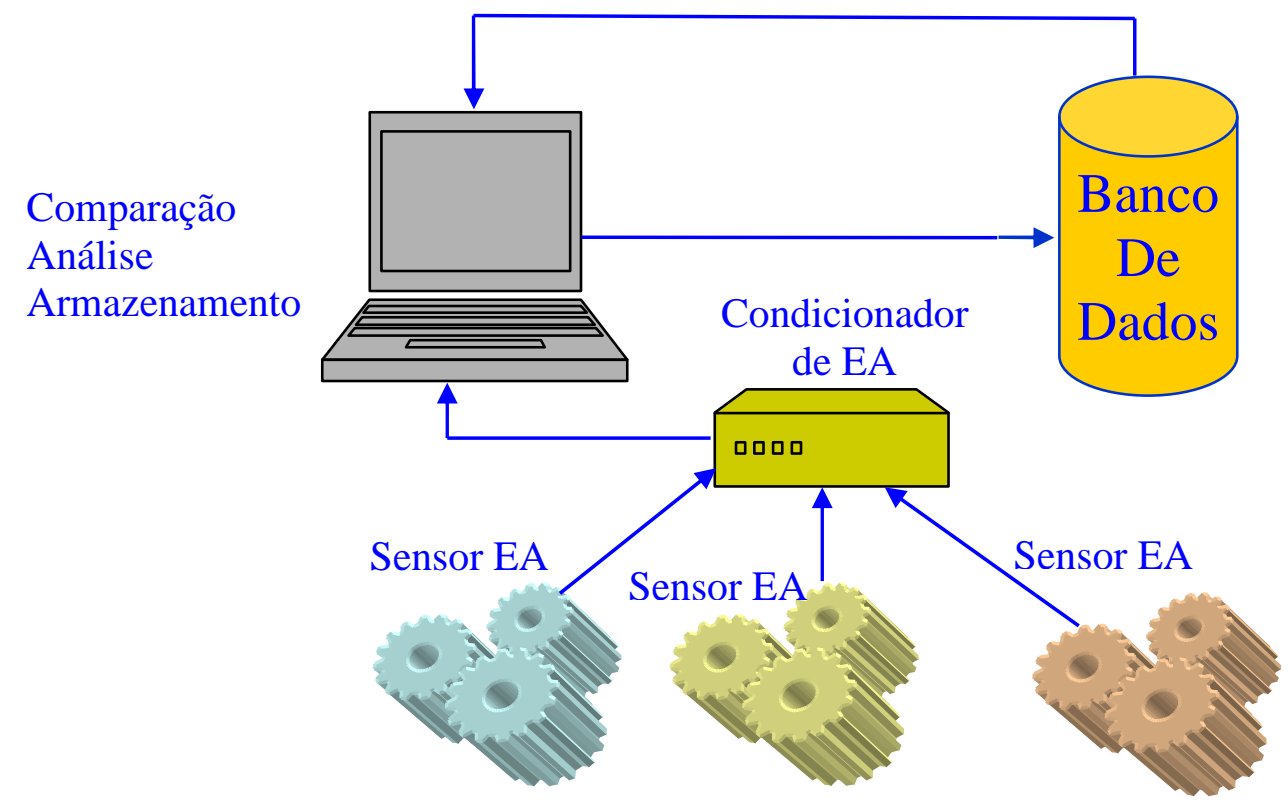

Figura 4. 2: Esquema do sistema de monitoramento e gestão da manutenção proposto. 


\section{2 INTEGRAÇÃO DO SISTEMA DE MONITORAMENTO}

Uma vez, tendo sido montado o sistema de monitoramento no ambiente de trabalho, é possível disponibilizar as informações obtidas pelo mesmo na rede interna da empresa, bastando para isso a conexão do micro utilizado no sistema de monitoramento à rede local da empresa (LAN).

A conexão do sistema de monitoramento à rede local permite que o mesmo se torne integrado, possibilitando assim uma sinergia maior entre os departamentos envolvidos direta ou indiretamente com a manutenção.

A integração do sistema permite que o planejamento e programação das tarefas de manutenção sejam disponibilizados na rede local. Assim, quando um nível de alerta for atingido e detectado pelo sistema de monitoramento, a partir do sinal de emissão acústica, é possível que todas as atividades ligadas a uma determinada tarefa de manutenção sejam disparadas pelos departamentos envolvidos.

Os departamentos de manutenção e produção podem, em conjunto, determinar a ocasião mais propícia para a execução dos serviços. O departamento de suprimentos terá todas as informações para que disponibilize os materiais requeridos no momento adequado, evitando, assim, o acúmulo de estoques desnecessários.

Esta integração interdepartamental favorece a implementação de boas práticas de manutenção tornando-se uma vantagem competitiva para a empresa.

A integração do sistema proposto à rede local é apresentada na figura 4.3:

O sistema proposto no presente trabalho, chamado aqui simplesmente sistema de monitoramento, pode também ser conectado à Internet (figura 4. 4) Este fato possibilita que o controle do sistema possa ser feito de modo remoto. 


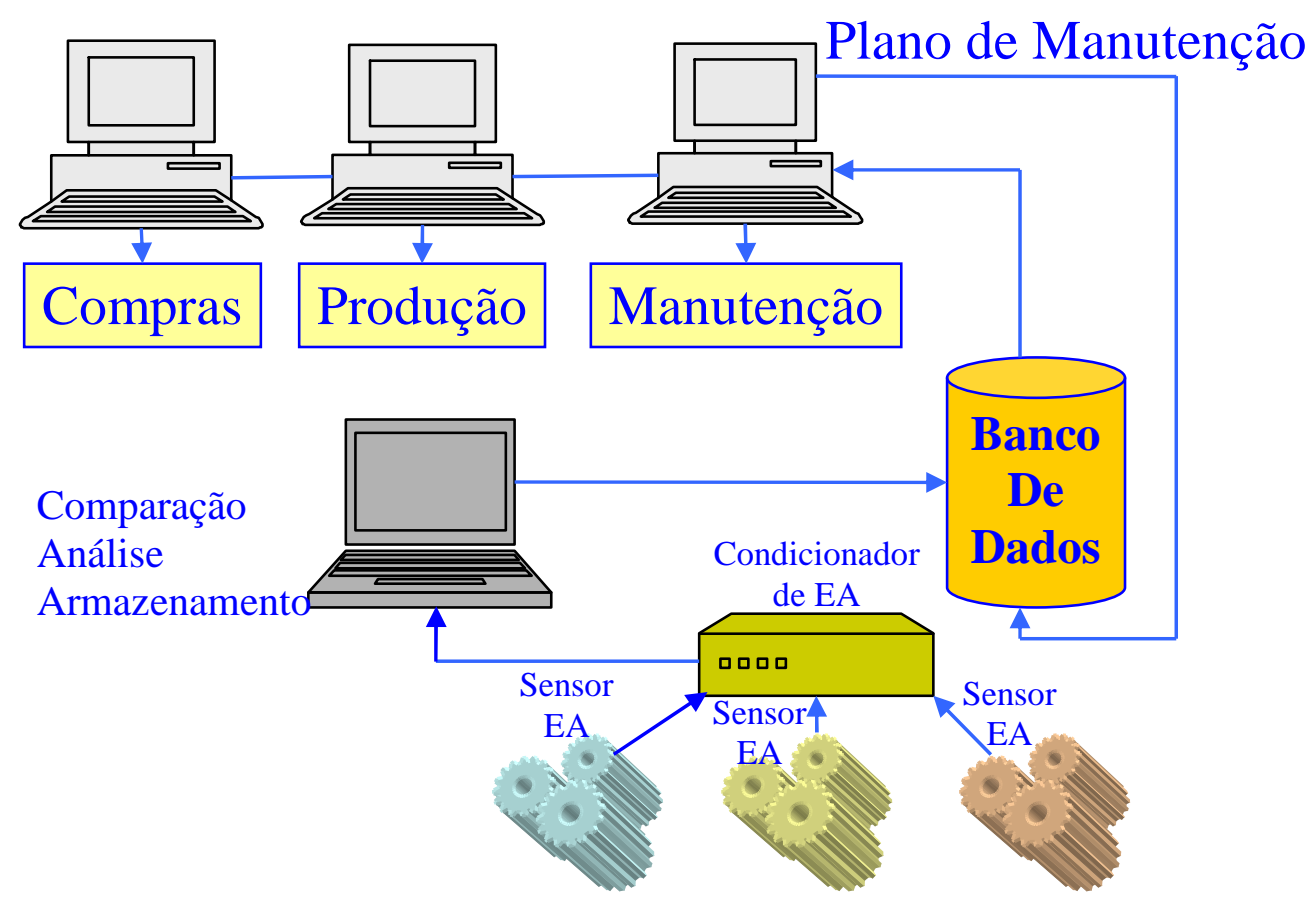

Figura 4. 3: Integração do sistema proposto à rede local

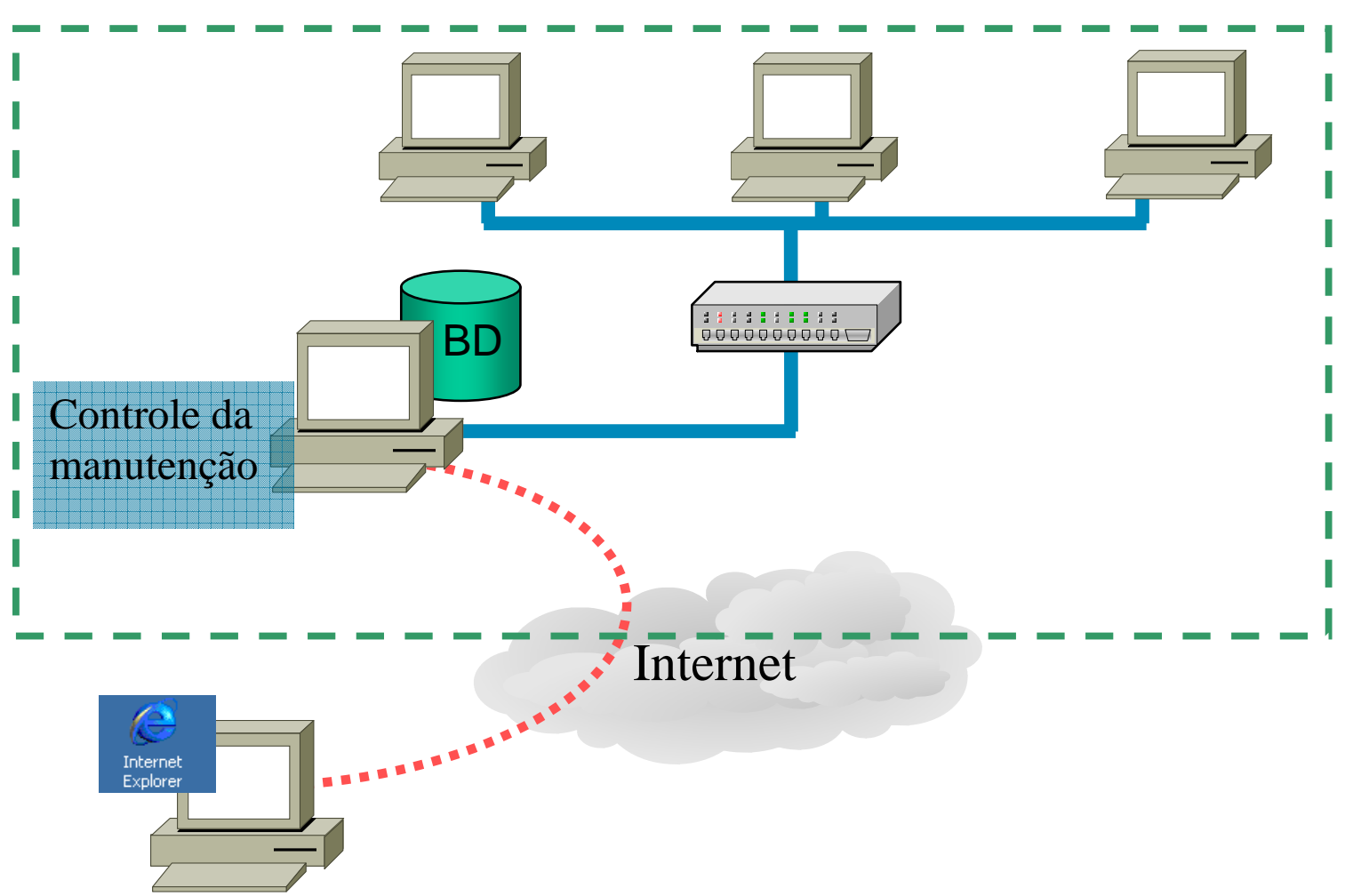

Figura 4. 4: Sistema de monitoramento conectado à Internet 
Um aspecto importante da gestão da manutenção é a otimização na tomada de decisões. Esta otimização depende da qualidade e da atualidade dos dados adquiridos pelos sistemas de controle de manutenção. $O$ volume de dados disponíveis para o gestor da manutenção se expande rapidamente. Este problema é ainda maior quando se trata de organizações com plantas (ou obras) dispostas em áreas geográficas muito dispersas como é o caso de empreiteiras e mineradoras. E-manutenção é um conceito que emerge para explorar o potencial da tecnologia de informação oferecendo novas opções para resolver estes problemas.

A disponibilização dos dados adquiridos pelo sistema de monitoramento via Web gera novas oportunidades de negócios. Os serviços de monitoramento podem ser terceirizados para empresas especializadas com uma intrusão mínima dentro da organização.

A definição correta entre a realização interna de serviços de manutenção ou a terceirização dos mesmos é uma das dimensões estratégicas da manutenção (TSANG, 2002).

\section{3 MODELO PARA ENSAIOS}

Para se testar o sistema proposto, foi montado no Núcleo de Manufatura Avançada da Escola de Engenharia de São Carlos - USP (NUMA) um modelo para ensaios.

O modelo é constituído por um eixo suportado por dois mancais de rolamentos acionado por um motor elétrico através de um acoplamento elástico apoiados sobre uma base de chapa de aço (figura 4. 5).

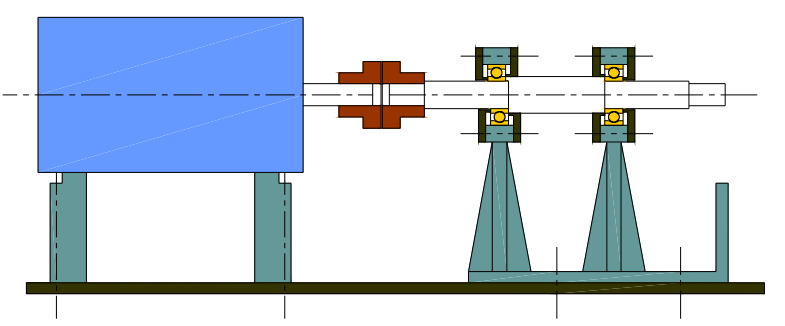

Figura 4. 5: Esquema do modelo utilizado nos ensaios 
Os ensaios foram realizados procurando-se identificar alterações nos níveis de emissão acústica a partir de um sensor localizado nos mancais. As condições de desgaste dos rolamentos, de lubrificação dos mancais, de alinhamento dos eixos e desgaste do acoplamento foram variadas e os respectivos níveis de emissão acústica foram coletados, filtrados, armazenados e analisados.

O objetivo dos ensaios foi determinar patamares de emissão acústica a partir dos quais as atividades de manutenção devem ser executadas, seguindose uma hierarquia e um procedimento previamente determinados pelo departamento de manutenção.

O diagrama da figura 4. 6 define a hierarquia das tarefas que devem ser executadas quando um gatilho for disparado assim que um determinado patamar de emissão acústica for atingido.

O sistema automaticamente lista a tarefa a ser executada, bem como os procedimentos, materiais, ferramentas, equipamentos e mão-de-obra necessários para a realização da mesma.

O programa para a coleta e análise de dados, bem como para a realização das atividades de manutenção, foi executado no software Labview, e está detalhado no item 4. 4. 


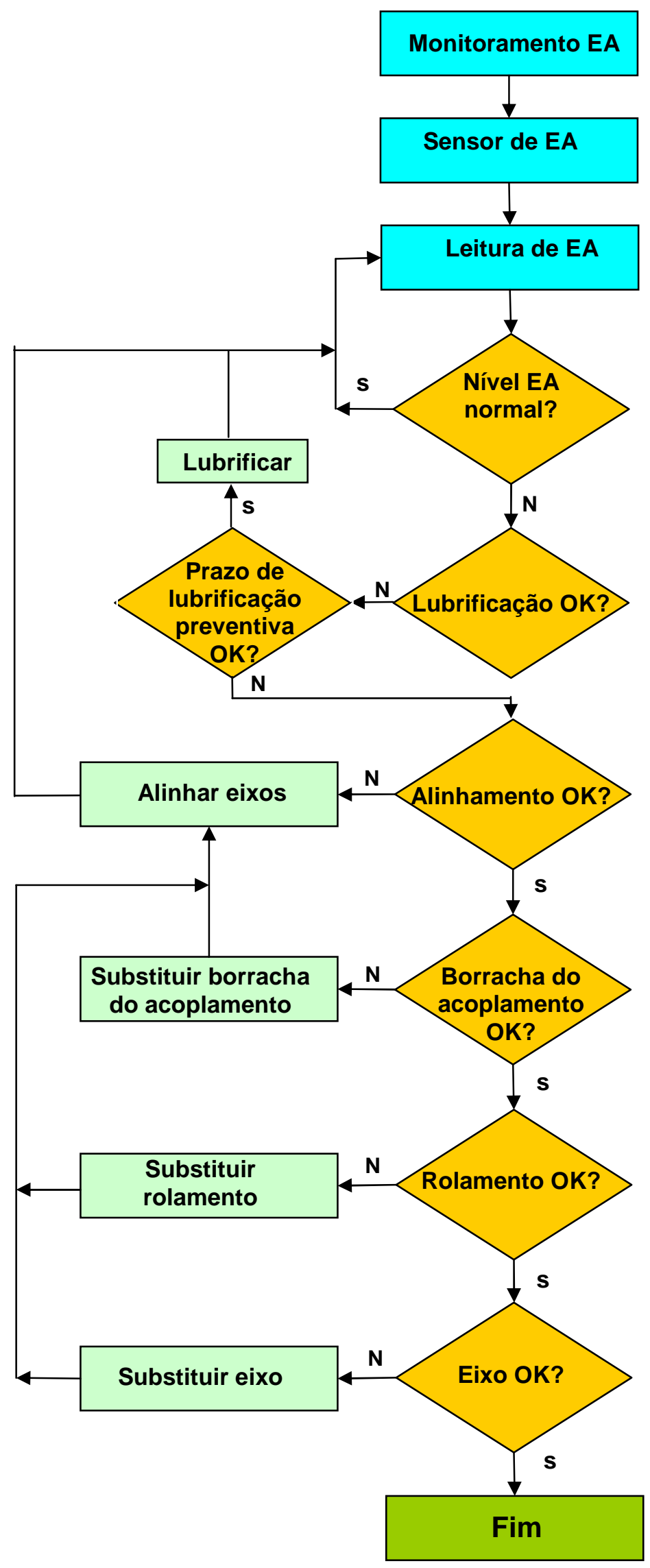

Figura 4. 6: Diagrama das atividades de manutenção para o modelo 


\section{4 DESCRIÇÃO DO PROGRAMA MANUTENÇÃO PREDITIVA}

O programa tem como objetivo coletar o sinal proveniente de uma placa de aquisição e transformá-lo em dados relativos à freqüência sonora e verificar quando esse sinal se apresenta acima de um limite pré-estabelecido, acionando instruções para que seja possível a realização das tarefas necessárias para a manutenção do componente monitorado.

O programa consiste em dois subprogramas. O primeiro deles coleta 0 sinal proveniente do sensor, e salva esses dados em um banco de dados. $O$ segundo é responsável por transformar o sinal em dados de freqüência e, a partir desses, verificar se o limite de freqüência pré-estabelecido foi ultrapassado, acionando as instruções para a realização das tarefas de manutenção.

- Subprograma 1

O primeiro subprograma é o responsável pela aquisição de dados propriamente dita e pelo armazenamento dos mesmos em um arquivo de texto com o objetivo de uma análise posterior (Figura 4. 7).

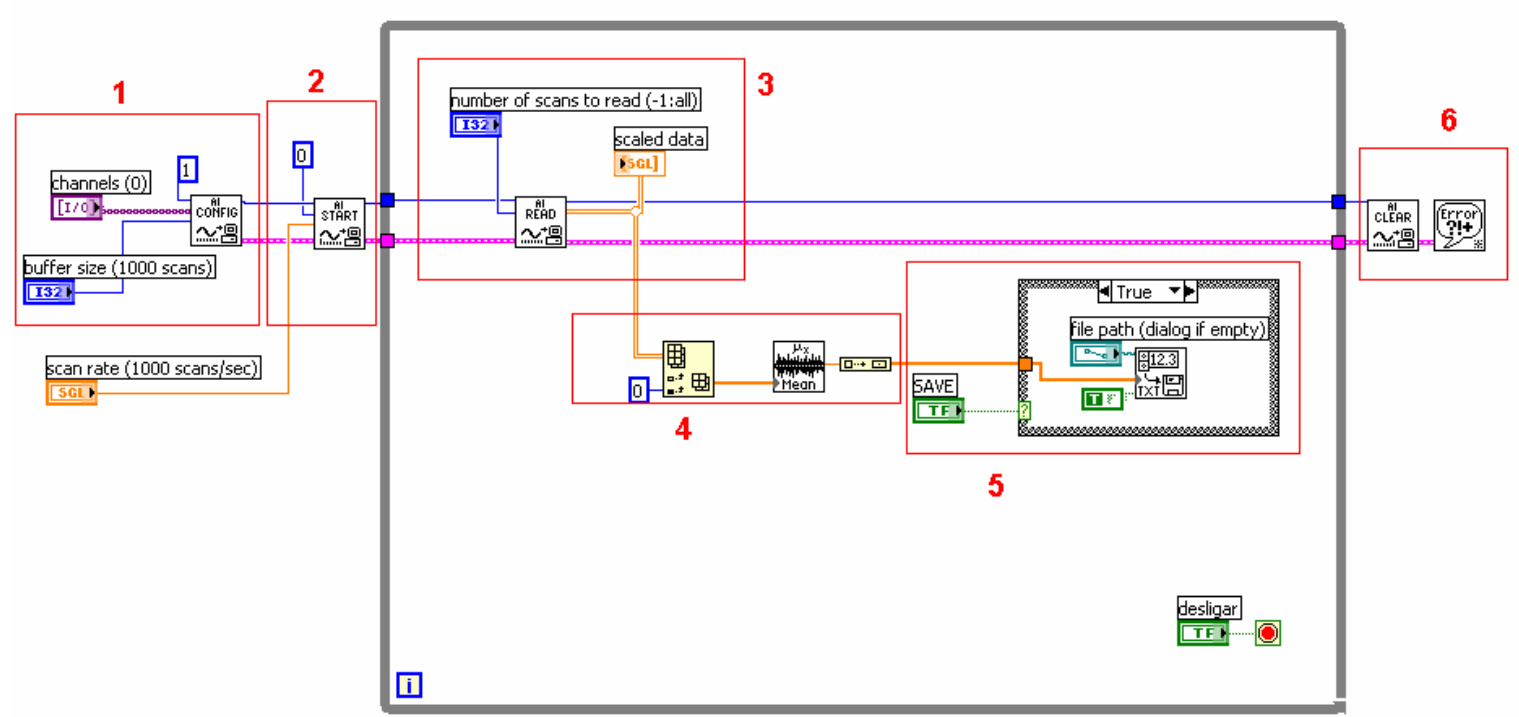

Figura 4. 7: Diagrama do subprograma de aquisição de dados

A Secção 1 consiste, em conjunto com as secções 2, 3 e 6, na parte do programa responsável por obter os dados da placa de aquisição. A sub-rotina AI CONFIG tem como entradas o número do canal de recepção, o número do device (geralmente 1) e o número de leituras que cada buffer vai armazenar. 
Na secção 2 a sub-rotina AI START tem como entradas o número de leituras feitas por segundo, e a quantidade de leituras que o programa vai fazer antes de finalizar (que está configurado como 0 para que o programa faça leituras até que o usuário finalize o programa manualmente).

A secção 3 apresenta a sub-rotina Al READ que tem como entrada 0 número de leituras que o programa vai fazer (configurado para -1 para que 0 programa faça todas as leituras). Como saída tem-se o sinal proveniente da placa de aquisição.

A secção 4 é responsável por calcular uma média dos pontos adquiridos em cada leitura através da sub-rotina MEAN.

A secção 5 é responsável por receber a informação calculada pela subrotina MEAN e enviá-la a um arquivo de texto cujo usuário fornecer o nome. Além disso, há uma estrutura de comparação que só é acionada quando o botão 'Save?' está ligado e que é responsável por salvar o arquivo de texto quando o botão estiver ligado.

$\mathrm{Na}$ secção 6 a sub-rotina Al CLEAR é responsável por finalizar a aquisição de dados. Já a sub-rotina GENERAL ERROR HANDLER, que é ligada a todas as sub-rotinas $\mathrm{Al}$, é a responsável, caso exista algum erro durante a aquisição, pelo relato do mesmo para uma possível correção

- Subprograma 2

Esse subprograma tem por objetivo comparar os dados coletados no subprograma 1 com um parâmetro pré-estabelecido e caso o mesmo seja ultrapassado, informar ao usuário qual medida de manutenção deve ser executada.

A primeira tela inicia-se com uma estrutura de seqüência, necessária para que a variável que controla a quantidade de vezes que o sinal passou do limite seja zerada, garantindo que o programa, toda vez que iniciado, não seja influenciado por aquisições anteriores (figura 4. 8).

A segunda tela dessa estrutura de case apresenta o programa em si, e será analisada por partes, conforme a legenda mostrada na figura 4. 9. 


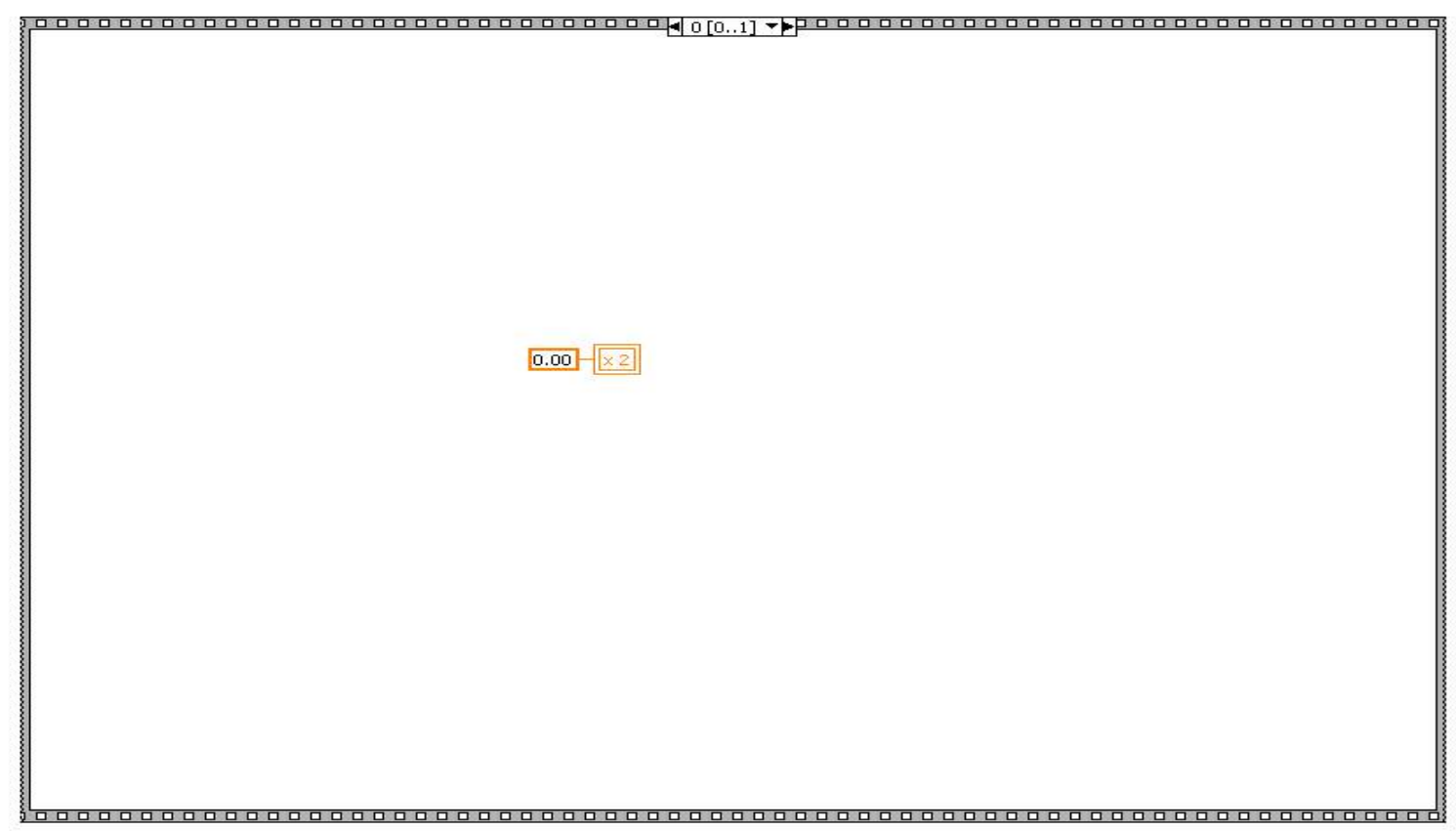

Figura 4. 8: Primeira tela - Estrutura de seqüência que zera o contador do programa

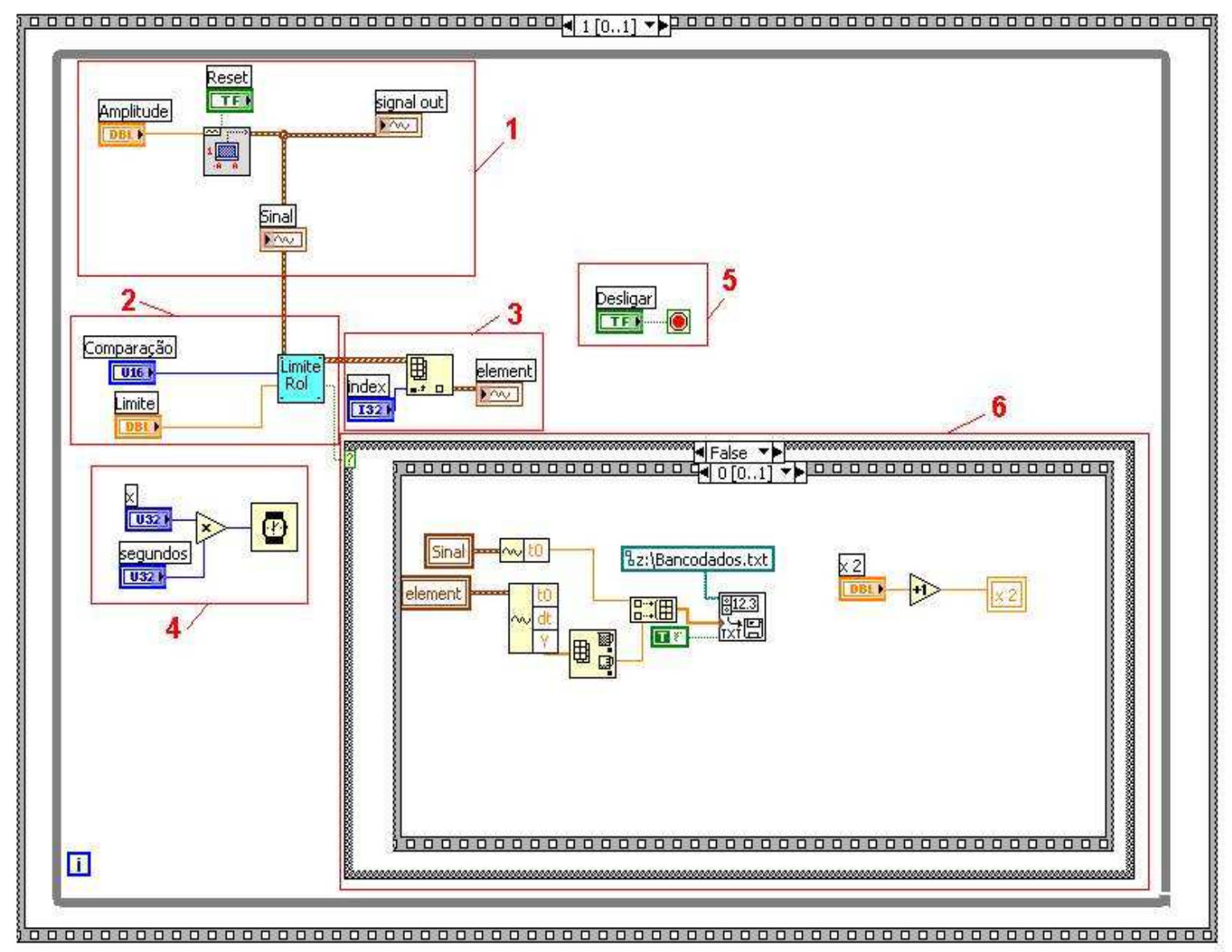

Figura 4. 9: Diagrama do programa 
Na secção 1 gera-se um sinal aleatório, já na forma de freqüência, para que seja possível se ter um controle sobre o sinal, durante a fase de teste. Como entrada, tem-se a amplitude do sinal desejado, e um botão que pode ser usado para limpar a área do gráfico. Como saída tem-se o sinal aleatório gerado. Esta secção realiza uma simulação do que é executado pelo subprograma 1 e tem efeito simplesmente de teste, quando os dois subprogramas estiverem rodando em conjunto esta secção é anulada.

As secções 2 e 3 apresentam a sub-rotina que verifica o limite da curva do sinal, que é o ponto chave do sistema de monitoramento, uma vez que, este parâmetro é o responsável por disparar as ações que deverão ser tomadas pelo departamento de manutenção. Trata-se de uma variação de uma subrotina pré-existente no Labview chamada Waveform Scalar Limit Comparison.

Essa sub-rotina fornece, a partir de uma curva de sinal, um limite e a forma de comparação (se é maior ou menor que o sinal) como entrada, uma resposta booleana que é verdadeira se o sinal tem todos os pontos dentro do limite, e falsa se o sinal tem algum ponto que ultrapassou o limite. Além disso, também fornece um vetor contendo o sinal original na primeira coluna, e os pontos que ultrapassaram o limite na segunda. A sub-rotina foi modificada de forma que a verificação dos pontos que estão acima do limite ocorresse separadamente nos intervalos de aquisição, e não para o sinal inteiro, fazendo com que o gatilho para a estrutura de comparação só fosse acionado quando o sinal do intervalo ultrapassasse o limite.

A secção 4 trata da geração de um atraso no looping, simulando 0 tempo de aquisição normal. Tem como entrada os segundos que se deseja atrasar o programa, sendo também útil na fase de teste como controle.

A secção 5 mostra a variável booleana responsável por manter o programa em constante repetição até que o botão desligar seja pressionado, quando então o programa é finalizado.

Na secção 6 é apresentada a estrutura de comparação, acionada a partir dos pontos acima do limite provenientes do sinal, é responsável tanto pela aquisição dos dados acima do limite com suas respectivas datas, como também, pelas telas de diálogo com o usuário. Para maior entendimento a secção 6 é subdividida a seguir (figura 4. 10): 


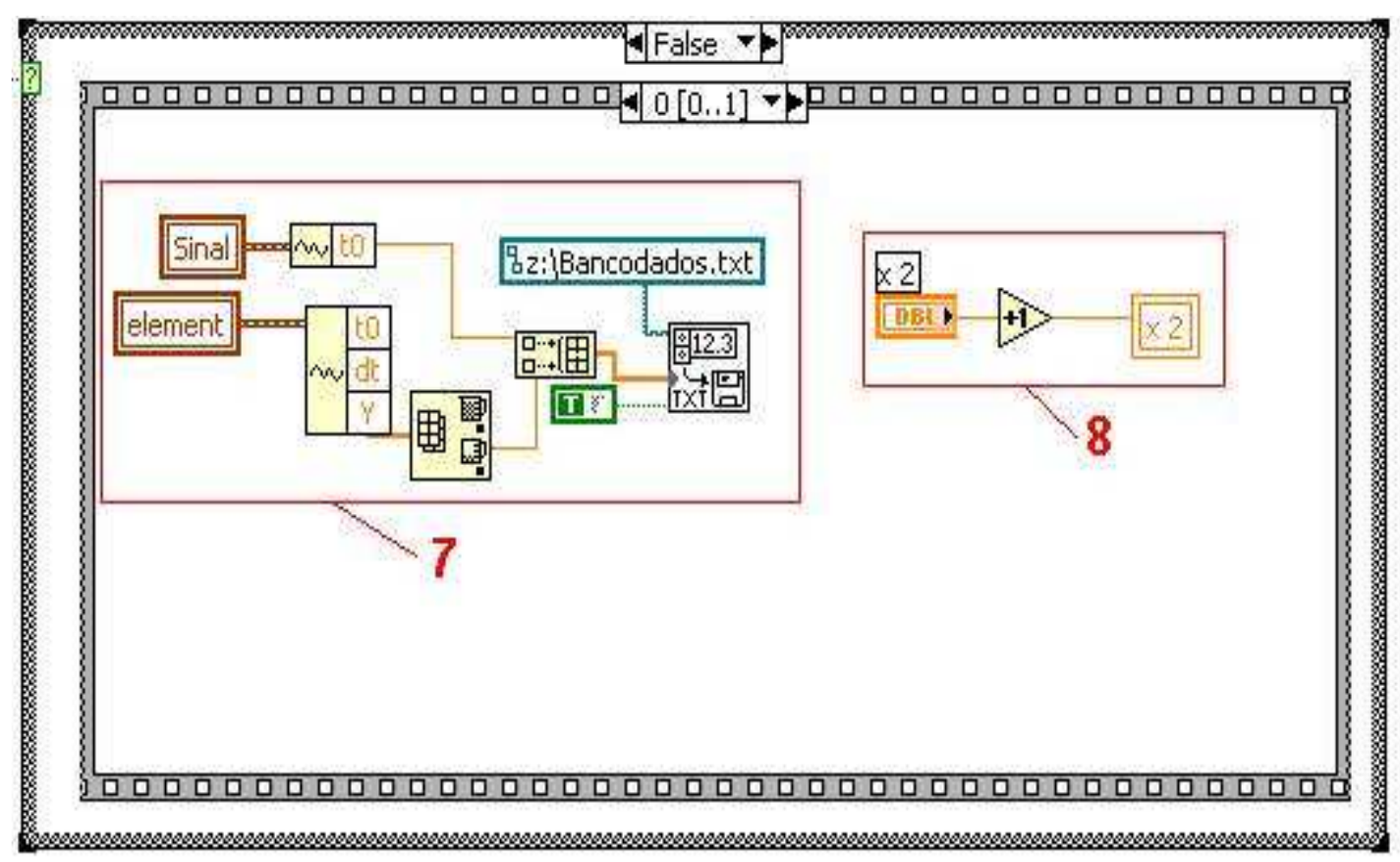

Figura 4. 10: Subdivisão da secção 6 do diagrama do programa

O sinal ao disparar a estrutura de comparação, dispara também uma estrutura de seqüência. Na secção 7 , obtém-se, a partir do sinal, a data e hora em que ocorreu a transgressão do limite, e obtém-se, dos dados que ultrapassaram o limite, aquele que foi o maior, indexando esses valores em uma tabela e enviando essas informações para um banco de dados, localizado no arquivo "bancodados.txt".

A secção 8 apresenta um contador que, ao ser acionado toda vez que o sinal ultrapassa o limite, contém um histórico desse número de vezes.

Para que a sub-rotina não seja influenciada por limites anteriores também é necessário que o histórico do sinal seja zerado toda vez que a comparação é acionada. A secção 9 é responsável por esse procedimento.

A figura 4.11 apresenta as secções 9 e 10 que executam os passos relativos a execução das tarefas de manutenção necessárias. 


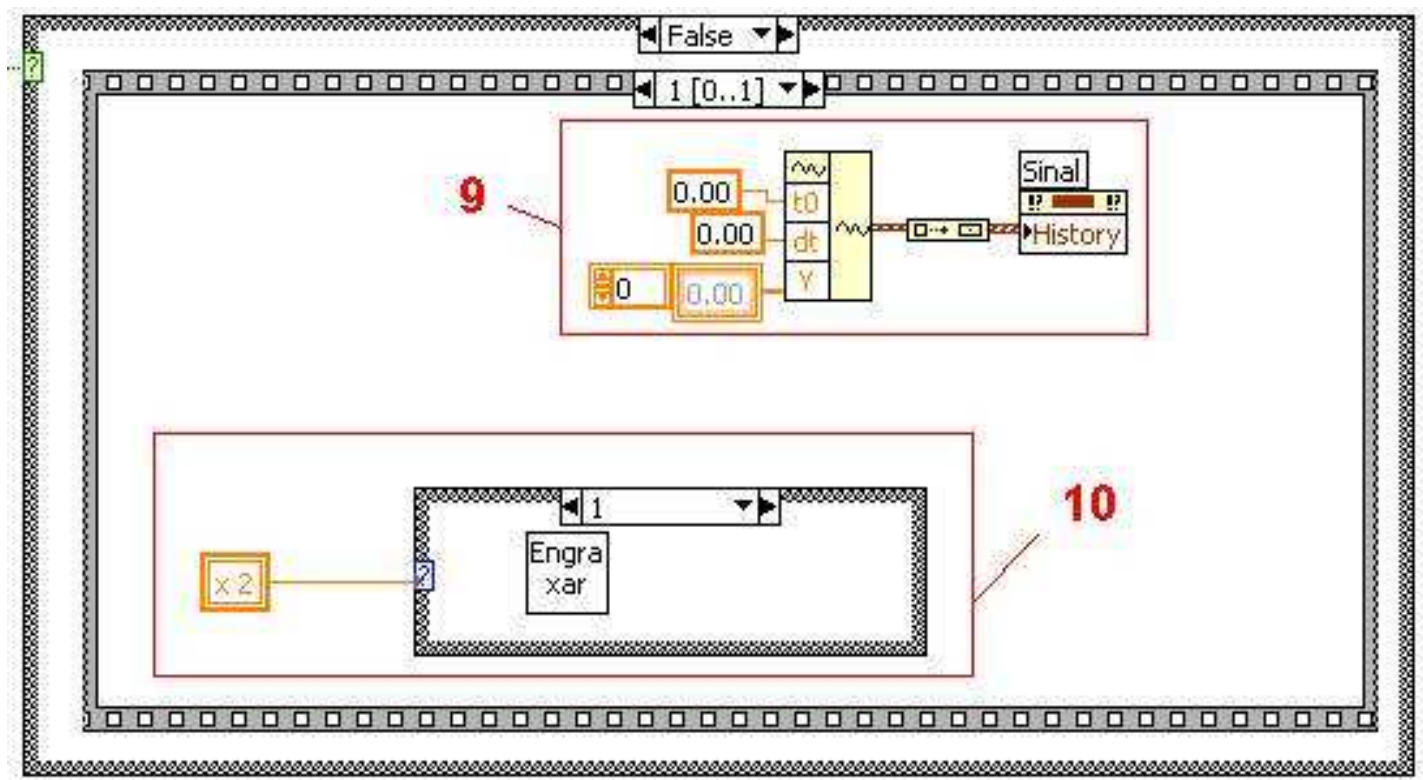

Figura 4. 11: Secções 9 e 10 do programa de manutenção

A secção 10 apresenta a estrutura de diálogo para com o usuário. Consiste em uma estrutura de comparação de quatro condições de diálogo programadas em subprogramas diferentes que apresentam basicamente à mesma seguinte estrutura (Figura 4.12):

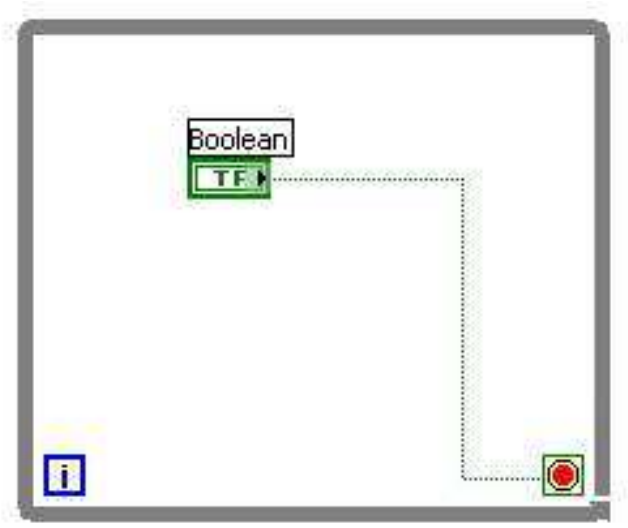

Figura 4. 12: Estrutura básica dos subprogramas da secção 10

Assim quando acionados, na tela de entrada eles fornecem as instruções do que o usuário deve fazer. Depois de realizá-las, o usuário deve pressionar OK, o que fará que a sub-rotina feche e o programa original retorne.

Cada uma dessas sub-rotinas será detalhada a seguir (Figuras $4.13 \mathrm{e}$ 4. 14): 


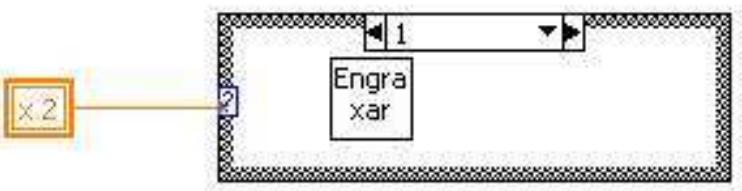

Figura 4. 13: Sub-rotina que dispara a atividade de manutenção "engraxar os rolamentos"

A primeira delas ocorre quando o sinal ultrapassa o limite pela primeira vez. Dispara as instruções de como engraxar o mancal.

\section{Engraxar os rolamentos}

Tempo de execução: 20 minutos

Material necessário: Graxa

Ferramentas necessárias: 1 chave de fenda de 6"

1 chave fixa/estrela $9 \mathrm{~mm}$

Mão de obra: 1 lubrificador

Execução:

Remova todas as tampas dos rolamentos.

Aplique a graxa.

Recoloque as tampas dos rolamentos.

\section{OK}

Figura 4. 14: Tela que apresenta a atividade de manutenção "engraxar"

A segunda condição ocorre quando, mesmo após lubrificar o mancal, a taxa de emissão acústica continua em níveis não aceitáveis, disparando as instruções sobre como alinhar os rolamentos (Figura 4.15 e 4. 16).

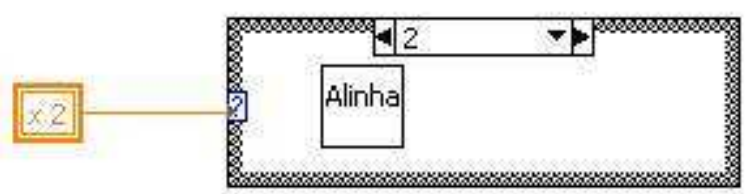

Figura 4. 15: Sub-rotina que dispara a atividade "alinhamento dos eixos" 


\section{* Alinhamento dos eixos}

Tempo de execução: 30 minutos

Material necessário: Jogo de calços de $0,1 \mathrm{~mm}$

Ferramentas necessárias: 2 chaves fixa/estrela $18 \mathrm{~mm}$

2 chaves fixalestrela $13 \mathrm{~mm}$

Mã̃o de obra: 1 mecânico

Execução:

Faça o alinhamento dos componentes com o auxilio dos calços necessários

Aperte e solte os parafusos em forma cruzada.

A tolerância permitida é de (verificar no manual do motor elétrico ou do acoplamento elástico)

\section{OK}

Figura 4. 16:Tela que apresenta a atividade "alinhamento dos eixos"

A terceira condição ocorre quando o alinhamento não foi suficiente para solucionar o problema, disparando as instruções sobre como substituir a borracha do acoplamento (Figuras 4.17 e 4. 18).

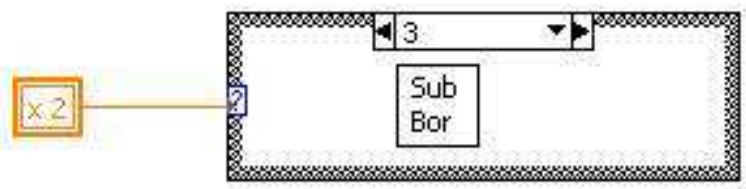

Figura 4. 17: Sub-rotina que dispara a atividade "substituição da borracha do acoplamento"

\section{* Substituição da borracha do acoplamento}

Tempo de execução: 35 minutos

Material necessário: Borracha do acoplamento elástico modelo (verificar Modelo).

Jogo de calços de $0,1 \mathrm{~mm}$

Ferramentas necessárias: 2 chaves fixalestrela $18 \mathrm{~mm}$

2 chaves fixa/estrela $13 \mathrm{~mm}$

Mão de Obra: 1 mecânico

Execução:

Remova os parafusos de fixação do mancal.

Afaste o mancal da base.

Substitua a borracha do acoplamento.

Posicione o mancal na base

Aperte os parafusos de fixação do mancal.

Alinhe as eixos como descrito na tarefa 2.

Figura 4. 18: Tela que apresenta a atividade "substituição da borracha do acoplamento" 
Se o sinal de emissão acústica ainda apresentar níveis altos de freqüência, a quarta e última condição é acionada, troca dos rolamentos do mancal (Figuras 4. 19 e 4. 20).

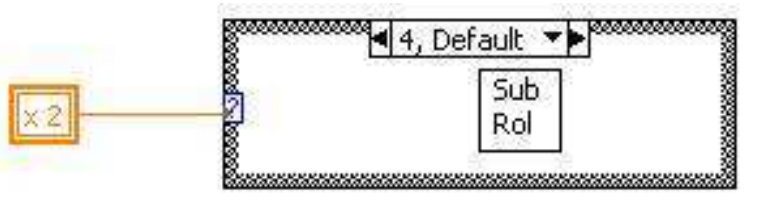

Figura 4. 19: Sub-rotina que dispara a atividade "substituição dos rolamentos"

\section{* Substituição dos rolamentos}

Tempo de execução: 3 horas

Material necessário: 2 rolamentos 6205

Ferramentas necessárias: 2 chaves fixa/estrela $18 \mathrm{~mm}$

2 chaves fixa/estrela $13 \mathrm{~mm}$

1 chave fixa/estrela $9 \mathrm{~mm}$

1 chave de fenda $6^{\prime \prime}$

1 chave fixa/estrela $8 \mathrm{~mm}$

1 jogo de calcos de $0,1 \mathrm{~mm}$

1 prensa de 1 ton

Mão de Obra: 1 mecânico e 1 ajudante

Execução:

Remova o sensor de emissão acústica.

Solte os parafusos de fixação do mancal

Remova o mancal da base.

Remova o acoplamento elástico do eixo da bomba.

OK

Figura 4. 20: Tela que apresenta a atividade "substituição dos rolamentos" O programa deve, então, ser reinicializado. 


\section{TESTES E AVALIAÇÃO DOS RESULTADOS}

Para se verificar a operacionalidade do sistema de monitoramento proposto, foram realizados testes com o modelo para ensaios.

Como já mencionado, no item 4.4, o ponto chave do sistema é o parâmetro que dispara as atividades da manutenção. Com o objetivo de se determinar este fator, foram testadas várias possibilidades de montagens com rolamentos novos e desgastados, com e sem lubrificação.

Como só foi possível a utilização de um único sensor de $E A$, a cada montagem media-se os níveis de EA no mancal 1 (do lado do acoplamento elástico), empregando-se o filtro de Passa Alta do condicionador de EA para as freqüências de $75 \mathrm{kHz}$ e $100 \mathrm{kHz}$. O filtro passa alta foi utilizado para que ruídos provenientes de vibrações e do motor elétrico não fossem considerados. Essas medidas foram armazenadas no banco de dados para análises posteriores.

Em seguida, deslocava-se o sensor para o mancal 2 (lado oposto ao acoplamento elástico) e repetia-se o mesmo procedimento.

Notou-se ao longo dos ensaios, que para uma mesma condição de montagem, os níveis de EA variavam quando os mesmos eram realizados em datas distintas.

Chegou-se a conclusão que este fato ocorria em virtude de não se conseguir a garantia de que as condições de montagem tinham sido rigorosamente mantidas.

Dessa forma, e tendo em vista que em ambiente industrial esse tipo de problema não deve ocorrer (pois o sensor estaria sempre montado no mancal) optou-se por executar todas as montagens e ensaios possíveis em uma única rodada de testes.

A princípio foram montados rolamentos novos nos dois mancais e foram variadas as condições de lubrificação. As possibilidades ensaiadas foram:

- Mancal $1 \mathrm{com}$ rolamento bom com graxa e mancal 2 com rolamento bom com graxa, que para efeito de legenda foi denominado de RBCRBC.

- Mancal $1 \mathrm{com}$ rolamento bom com graxa e mancal 2 com rolamento bom sem graxa - RBCRBS. 
- Mancal 1 com rolamento bom sem graxa e mancal 2 com rolamento bom com graxa - RBSRBC.

- Mancal 1 com rolamento bom sem graxa e mancal 2 com rolamento bom sem graxa - RBSRBS.

Para essas condições os resultados obtidos com o sensor de EA posicionado no mancal 1 são resumidos nos gráficos das figuras 5.1 e 5.2 , para as duas freqüências de emissão acústica avaliadas:

mancal 1

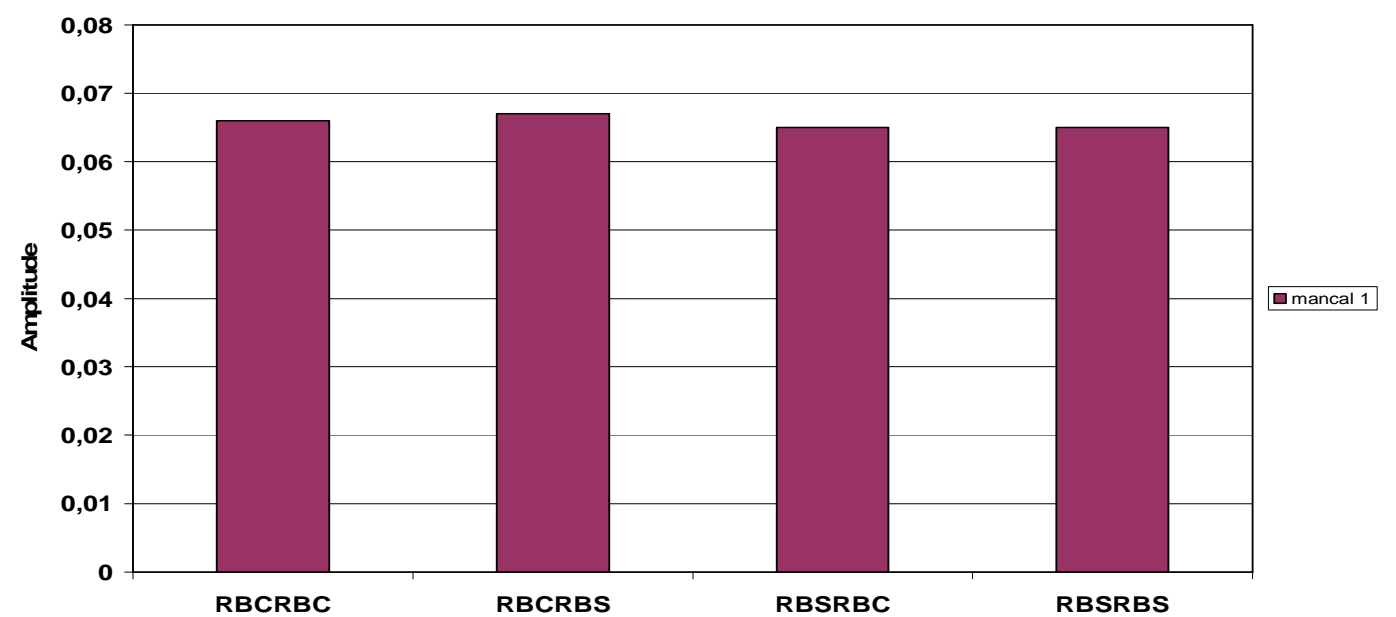

Figura 5. 1: Resultados para o mancal 1 e 2 com rolamentos bons e o sensor de EA posicionado no mancal $1-75 \mathrm{kHz}$

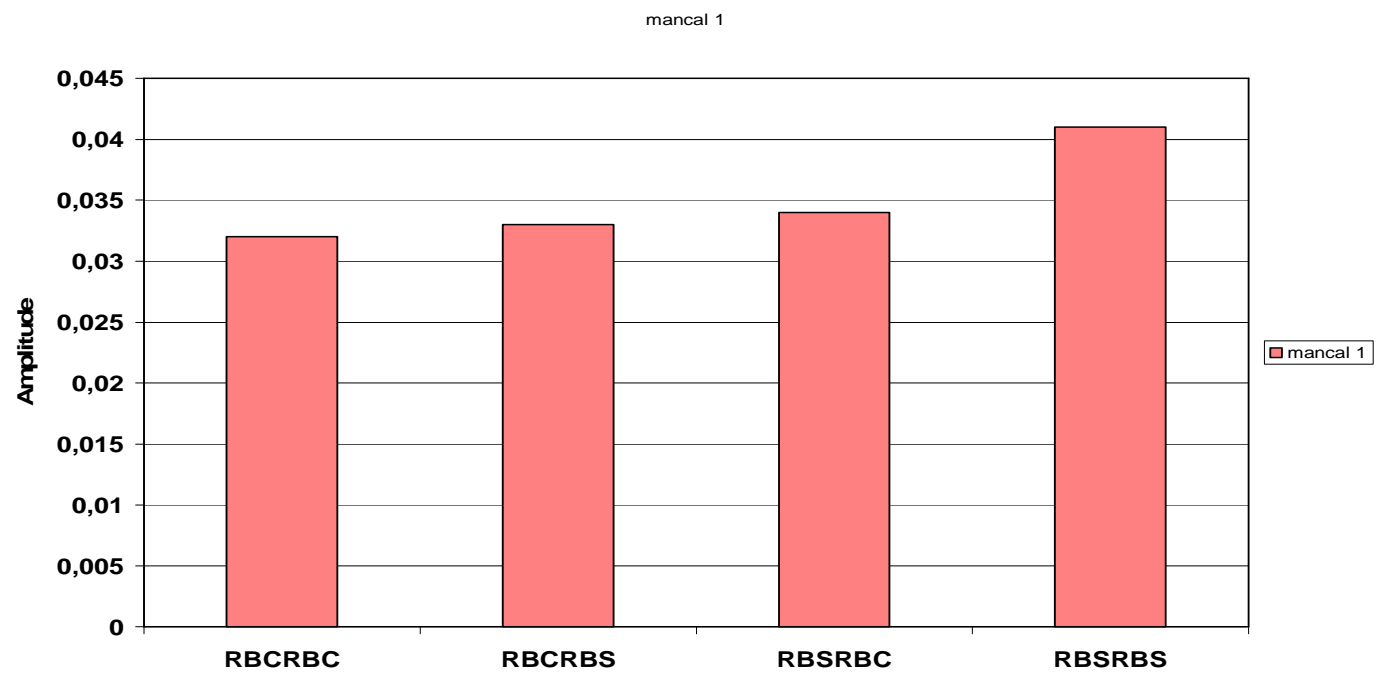

Figura 5. 2: Resultados para o mancal 1 e 2 com rolamentos bons e o sensor de EA posicionado no mancal $1-100 \mathrm{kHz}$

A seguir foi montado no mancal 2 um rolamento comprovadamente danificado, as condições de lubrificação foram variadas nos dois mancais. As 
possibilidades testadas e as medidas obtidas com o sensor posicionado no mancal 1 foram as seguintes:

- Mancal 1 com rolamento bom com graxa e mancal 2 com rolamento ruim com graxa - RBCRRC.

- Mancal 1 com rolamento bom com graxa e mancal 2 com rolamento ruim sem graxa - RBCRRS.

- Mancal $1 \mathrm{com}$ rolamento bom sem graxa e mancal 2 com rolamento ruim com graxa - RBSRRC.

- Mancal $1 \mathrm{com}$ rolamento bom sem graxa e mancal 2 com rolamento ruim sem graxa - RBSRRS.

As figuras 5.3 e 5.4 mostram os resultados obtidos.

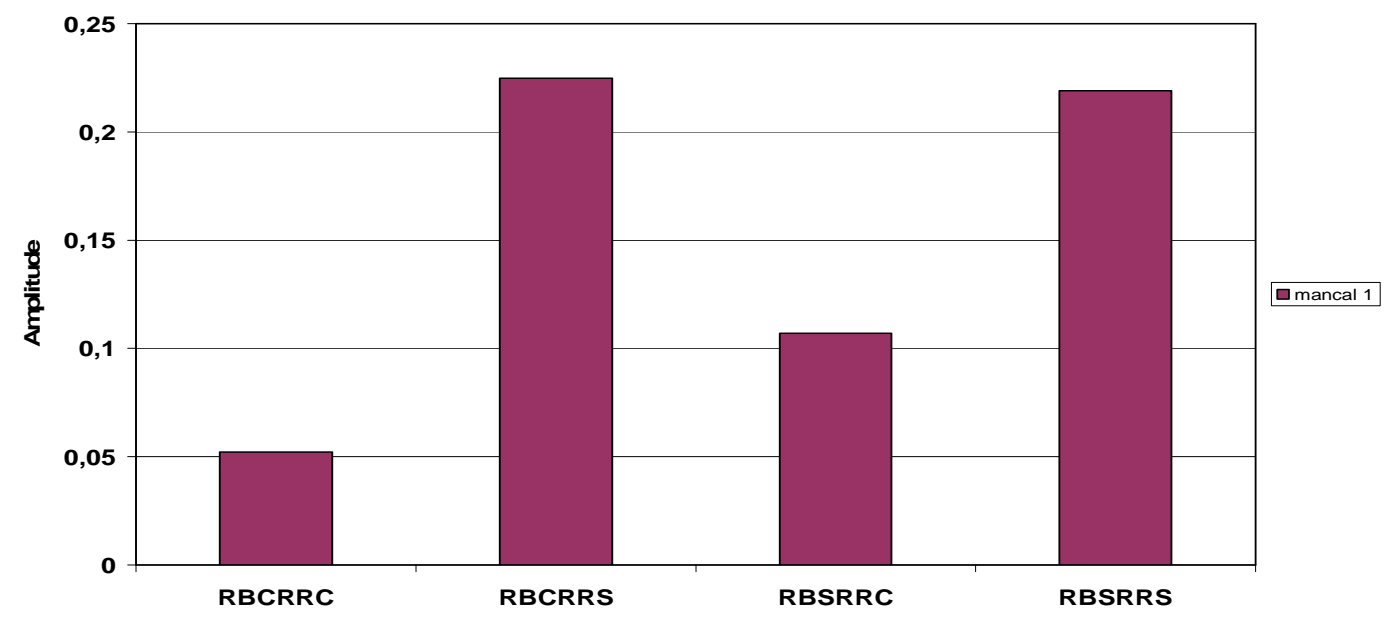

Figura 5. 3: Resultados para o mancal 1 com rolamento bom e mancal 2 com rolamento ruim e o sensor de EA posicionado no mancal 1 - $75 \mathrm{kHz}$

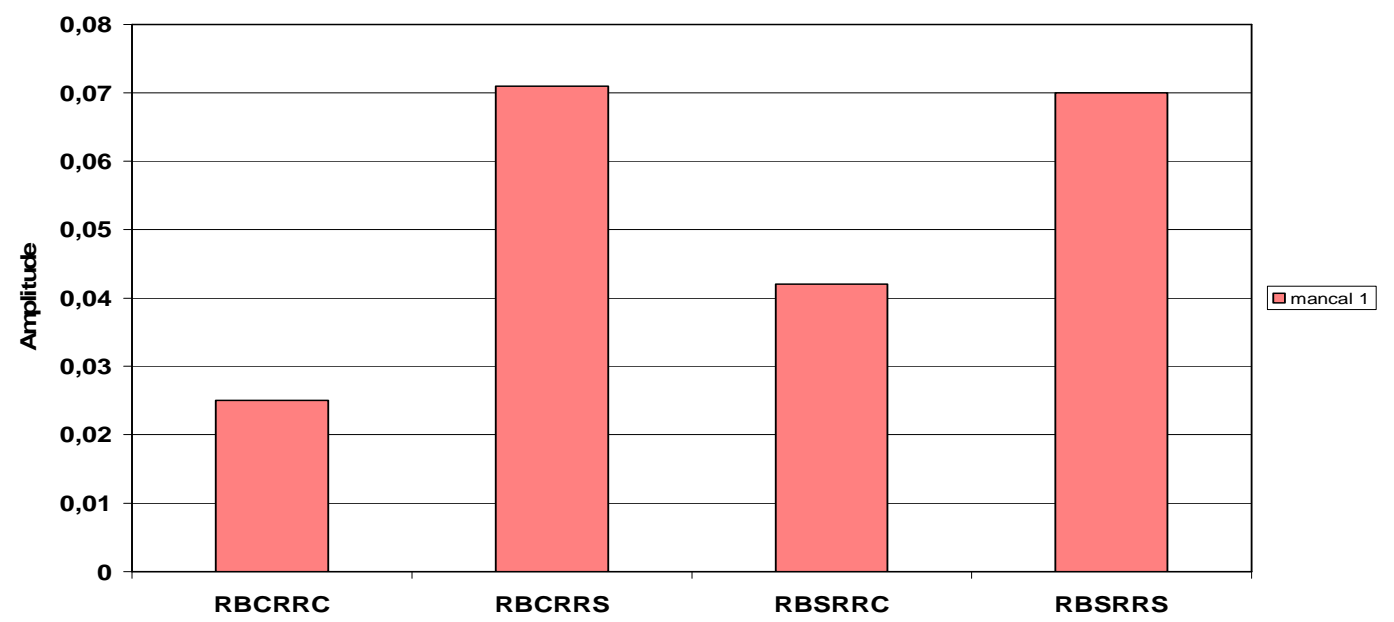

Figura 5. 4: Resultados para o mancal 1 com rolamento bom e mancal 2 com rolamento ruim e o sensor de EA posicionado no mancal $1-100 \mathrm{kHz}$ 
$\mathrm{Na}$ seqüência, substituiu-se o rolamento bom do mancal 1 por outro comprovadamente danificado, ficando portanto os dois mancais com rolamentos comprovadamente ruins. Foram variadas as condições de lubrificação dos dois mancais. Os testes realizados e os resultados obtidos com o sensor de EA posicionado no mancal 1 são os seguintes:

- Mancal 1 com rolamento ruim com graxa e mancal 2 com rolamento ruim com graxa - RRCRRC.

- Mancal 1 com rolamento ruim com graxa e mancal 2 com rolamento ruim sem graxa - RRCRRS.

- Mancal 1 com rolamento ruim sem graxa e mancal 2 com rolamento ruim com graxa - RRSRRC.

- Mancal 1 com rolamento ruim sem graxa e mancal 2 com rolamento ruim sem graxa - RRSRRS.

Os resultados são apresentados nas figuras 5.5 e 5.6 .

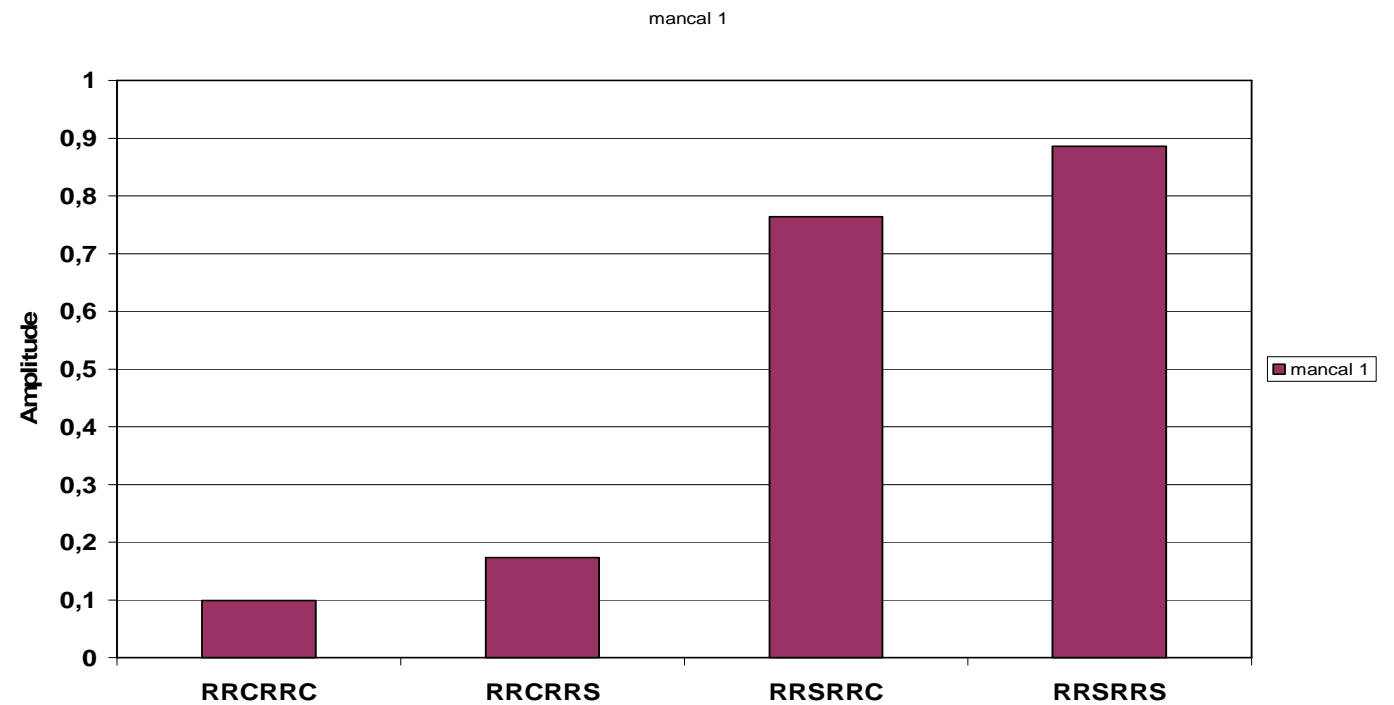

Figura 5. 5: Resultados para os mancais 1 e 2 com rolamentos ruins e o sensor de EA posicionado no mancal $1-75 \mathrm{kHz}$ 


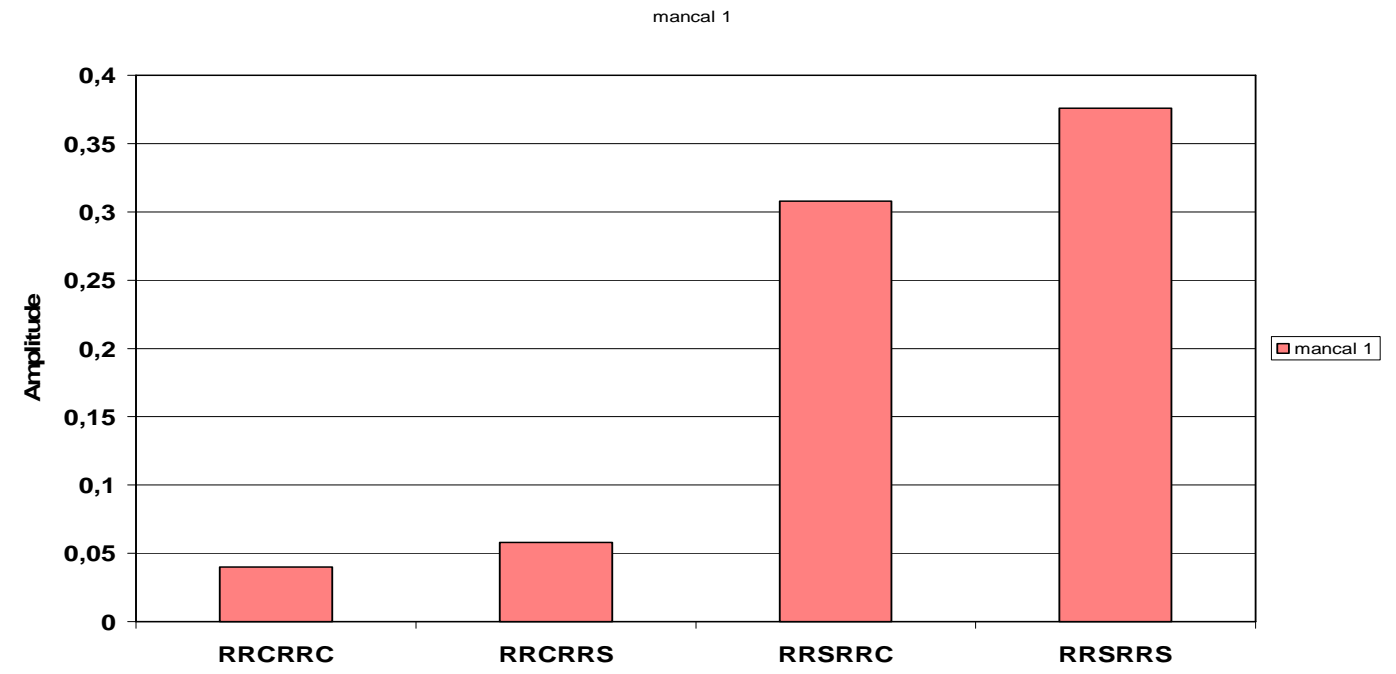

Figura 5. 6: Resultados para os mancais 1 e 2 com rolamentos ruins e o sensor de EA posicionado no mancal $1-100 \mathrm{kHz}$

Por último, manteve-se o rolamento danificado no mancal 1 e substituiuse o rolamento danificado do mancal 2 por um rolamento novo, esgotando-se assim as possibilidades de variação de montagens com rolamentos novos e danificados. As condições de lubrificação dos 2 mancais foram também variadas, obtendo-se as seguintes alternativas e resultados com o sensor de EA posicionado no mancal 1 (ver resultados nas figuras 5.7 e 5. 8):

- Mancal $1 \mathrm{com}$ rolamento ruim com graxa e mancal 2 com rolamento bom com graxa - RRCRBC.

- Mancal 1 com rolamento ruim com graxa e mancal 2 com rolamento bom sem graxa - RRCRBS.

- Mancal $1 \mathrm{com}$ rolamento ruim sem graxa e mancal 2 com rolamento bom com graxa - RRSRBC.

- Mancal $1 \mathrm{com}$ rolamento ruim sem graxa e mancal 2 com rolamento bom sem graxa - RRSRBS. 


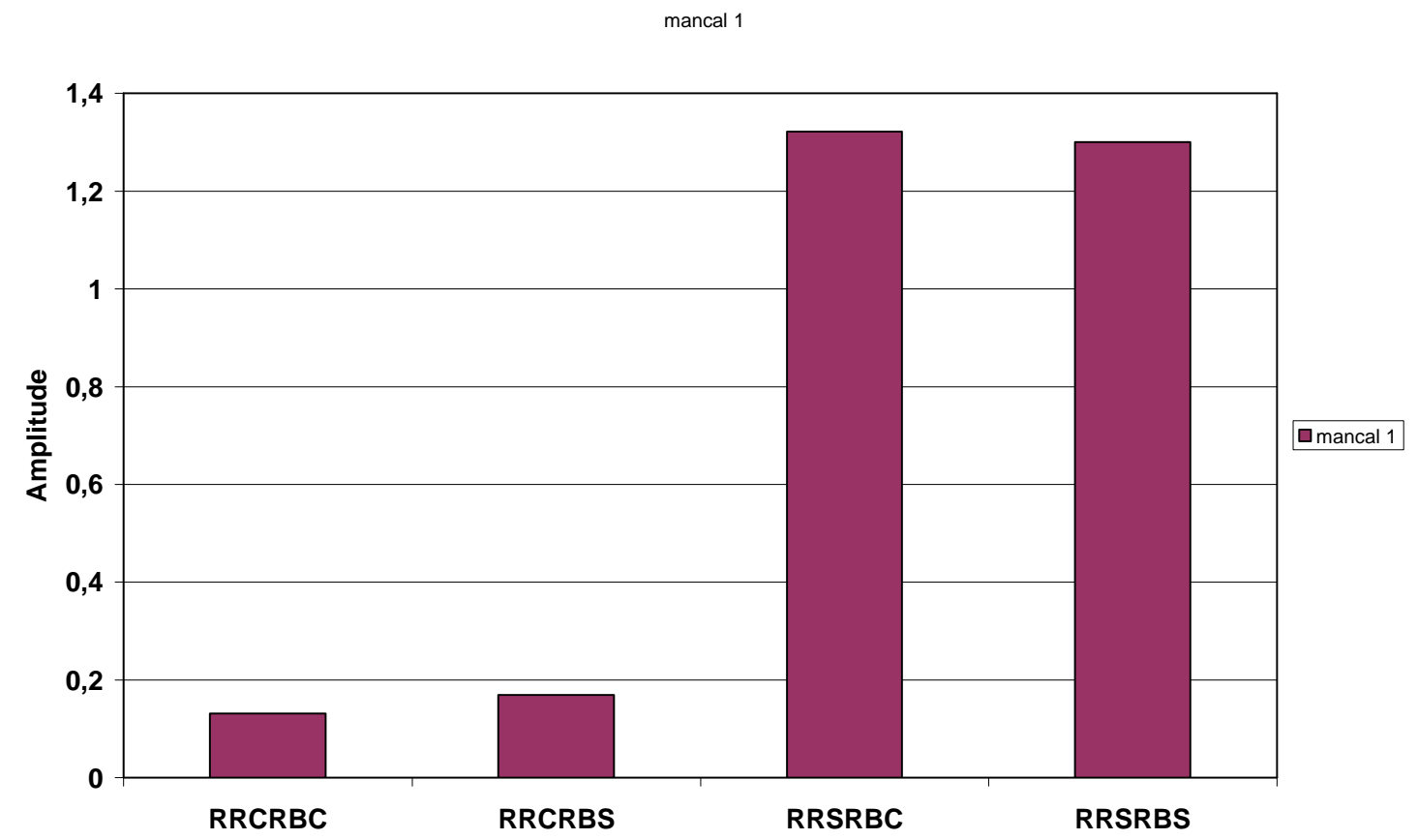

Figura 5. 7: Resultados para o mancal 1 com rolamento ruim e o mancal $2 \mathrm{com}$ rolamento bom e o sensor de EA posicionado no mancal $1-75 \mathrm{kHz}$

mancal 1

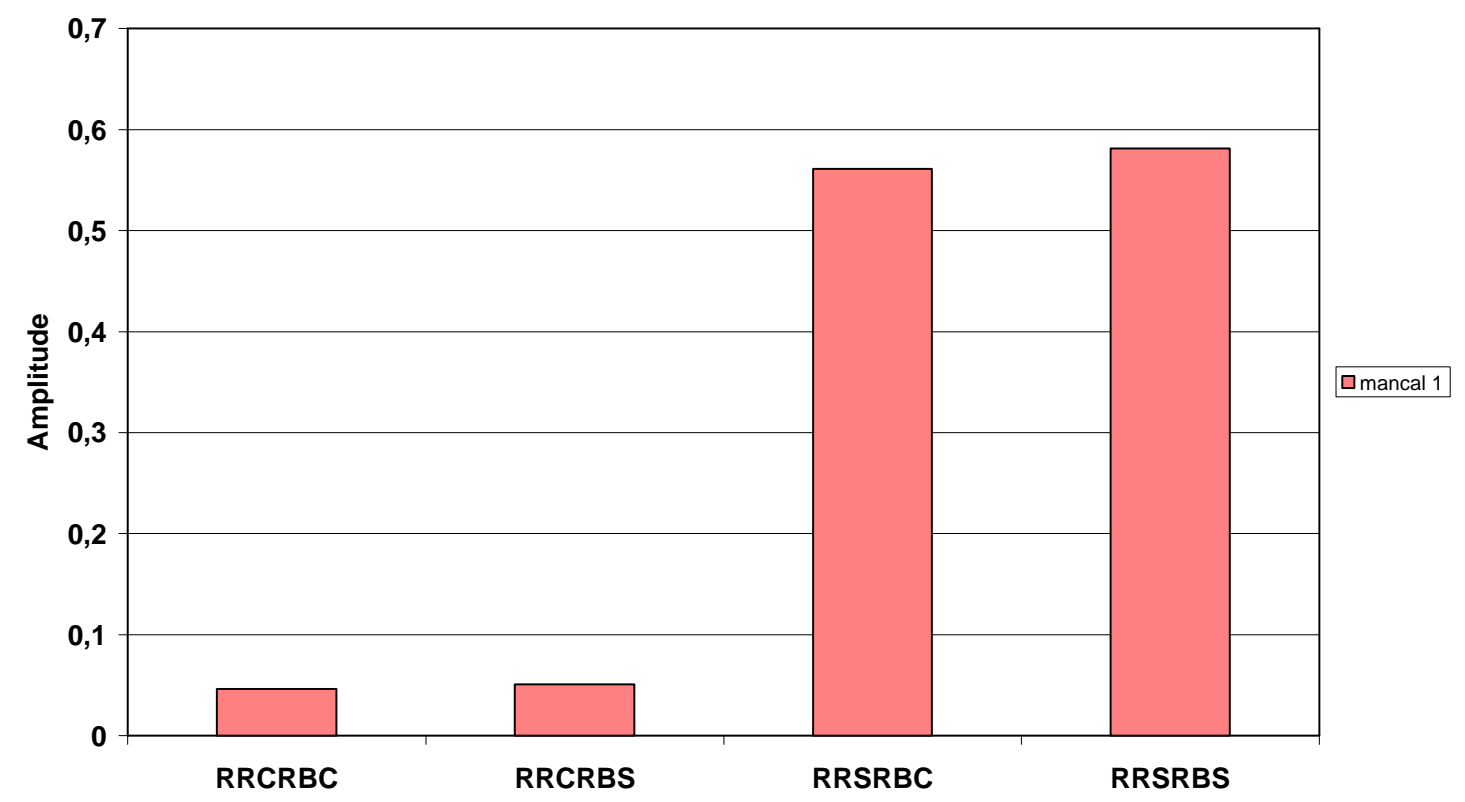

Figura 5. 8: Resultados para o mancal $1 \mathrm{com}$ rolamento ruim e mancal $2 \mathrm{com}$ rolamento bom e o sensor de EA posicionado no mancal $1-100 \mathrm{kHz}$

Para uma melhor visualização e comparação foram lançados todos os resultados obtidos com o sensor posicionado no mancal 1 em único gráfico para cada freqüência. As Figuras 5.9 e 5.10 mostram tais resultados. 
mancal 1

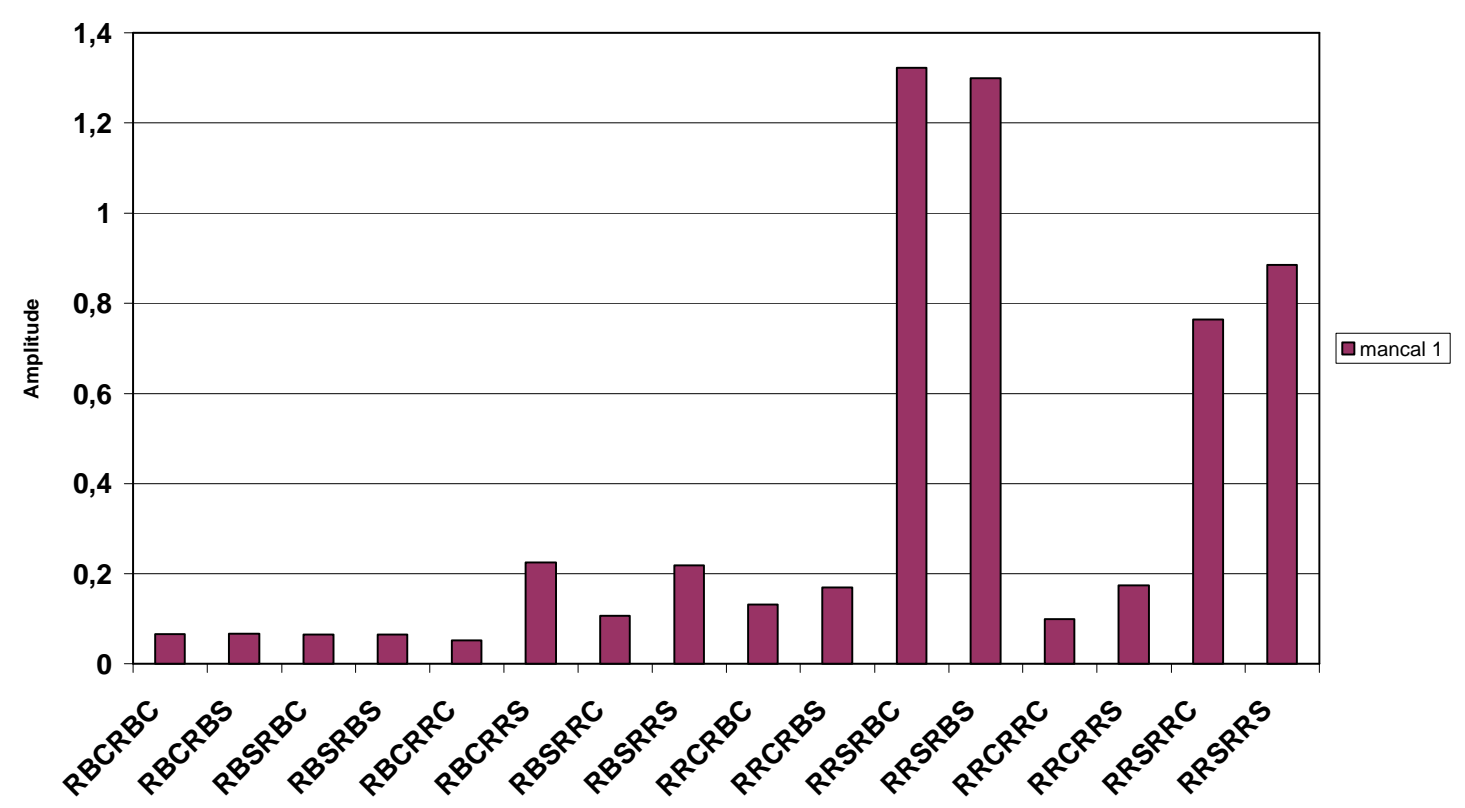

Figura 5. 9: Medidas efetuadas com o sensor de EA posicionado no mancal 1$75 \mathrm{kHz}$

mancal 1

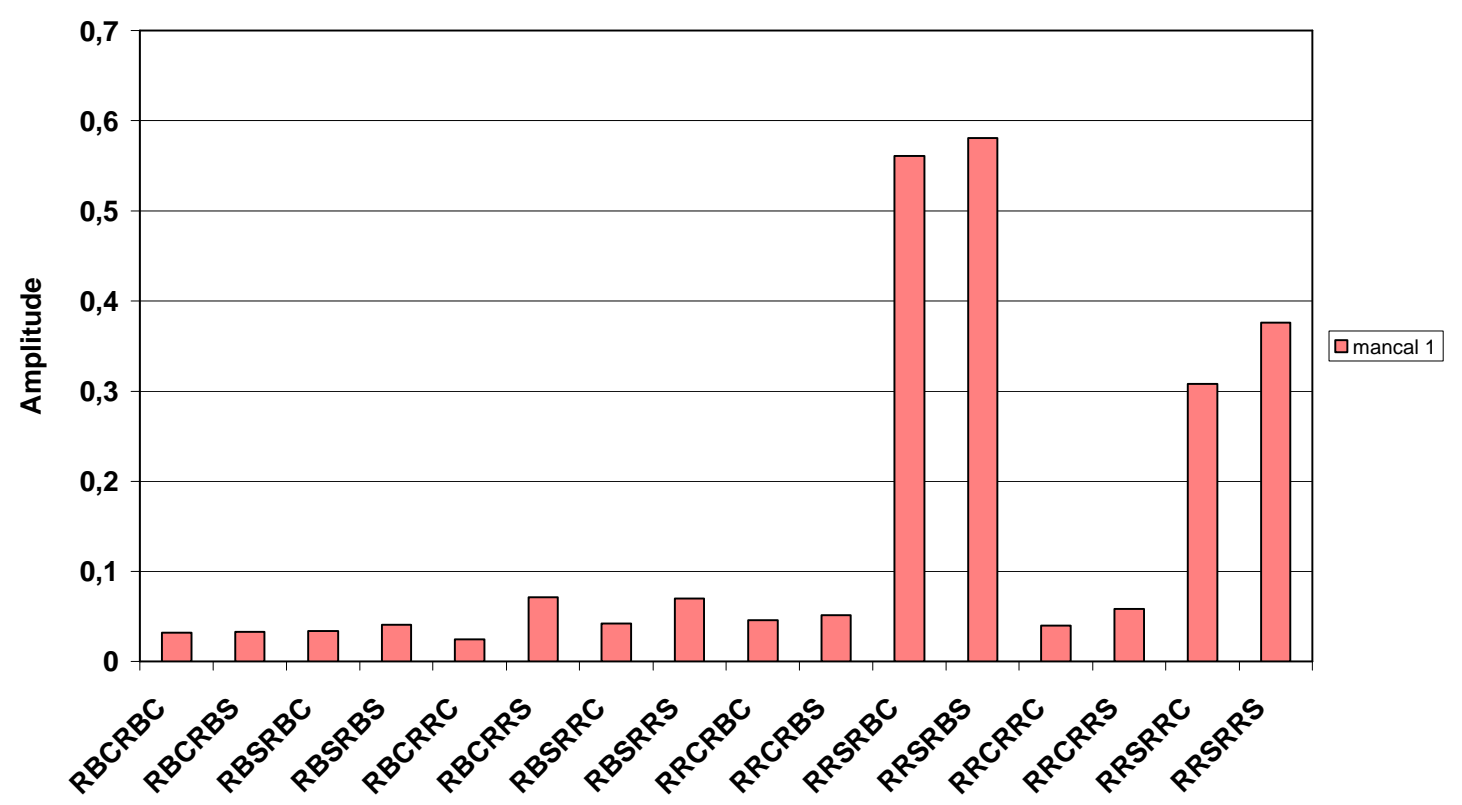

Figura 5. 10: Medidas efetuadas com o sensor de EA posicionado no mancal 1$100 \mathrm{kHz}$

Da mesma forma, foram obtidos os resultados com o sensor de EA posicionado no mancal 2 , que são resumidos e apresentados nos gráficos das figuras 5.11 e 5.12. 
mancal 2

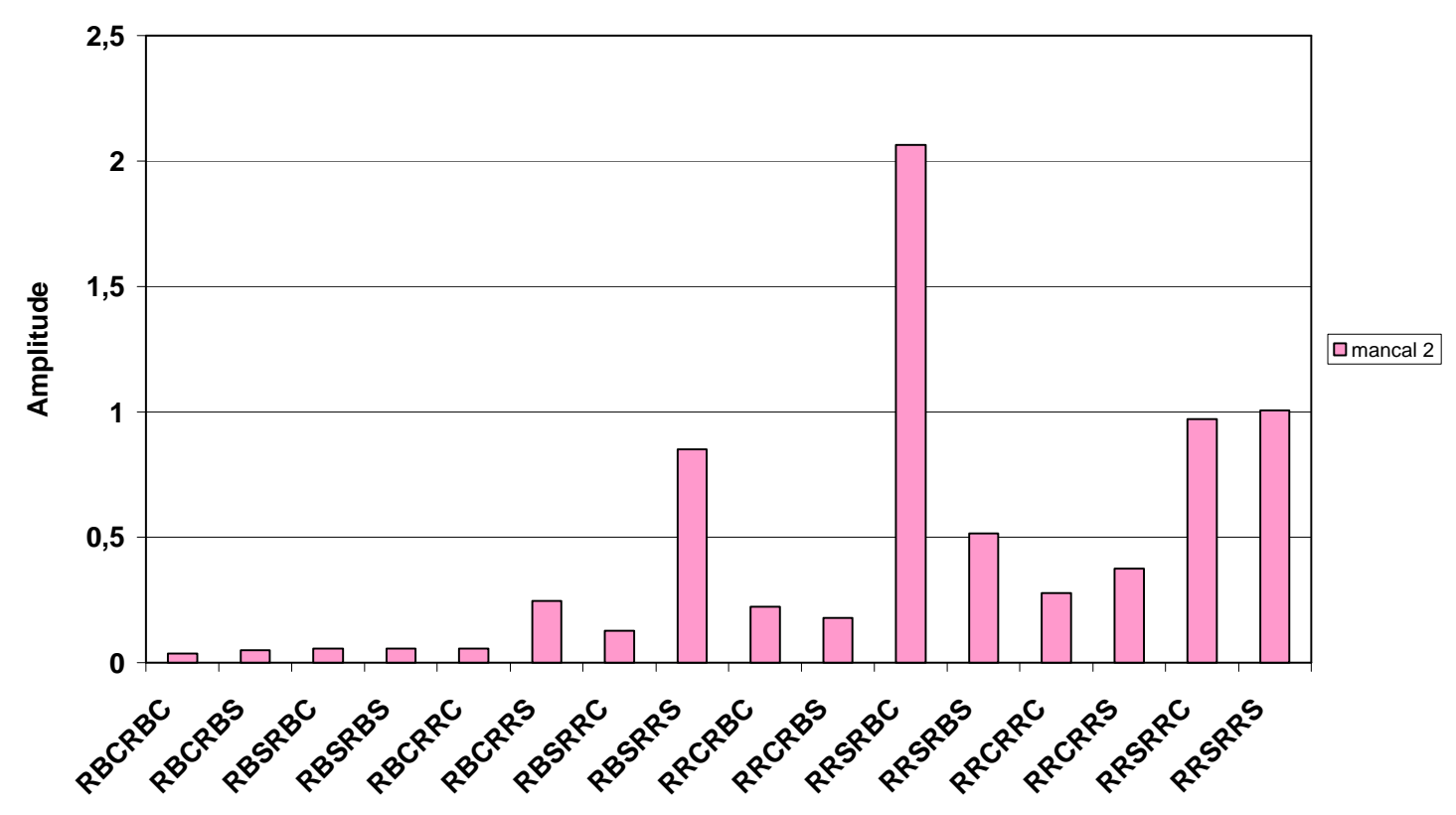

Figura 5. 11: Medidas efetuadas com o sensor de EA posicionado no mancal 2$75 \mathrm{kHz}$

mancal 2

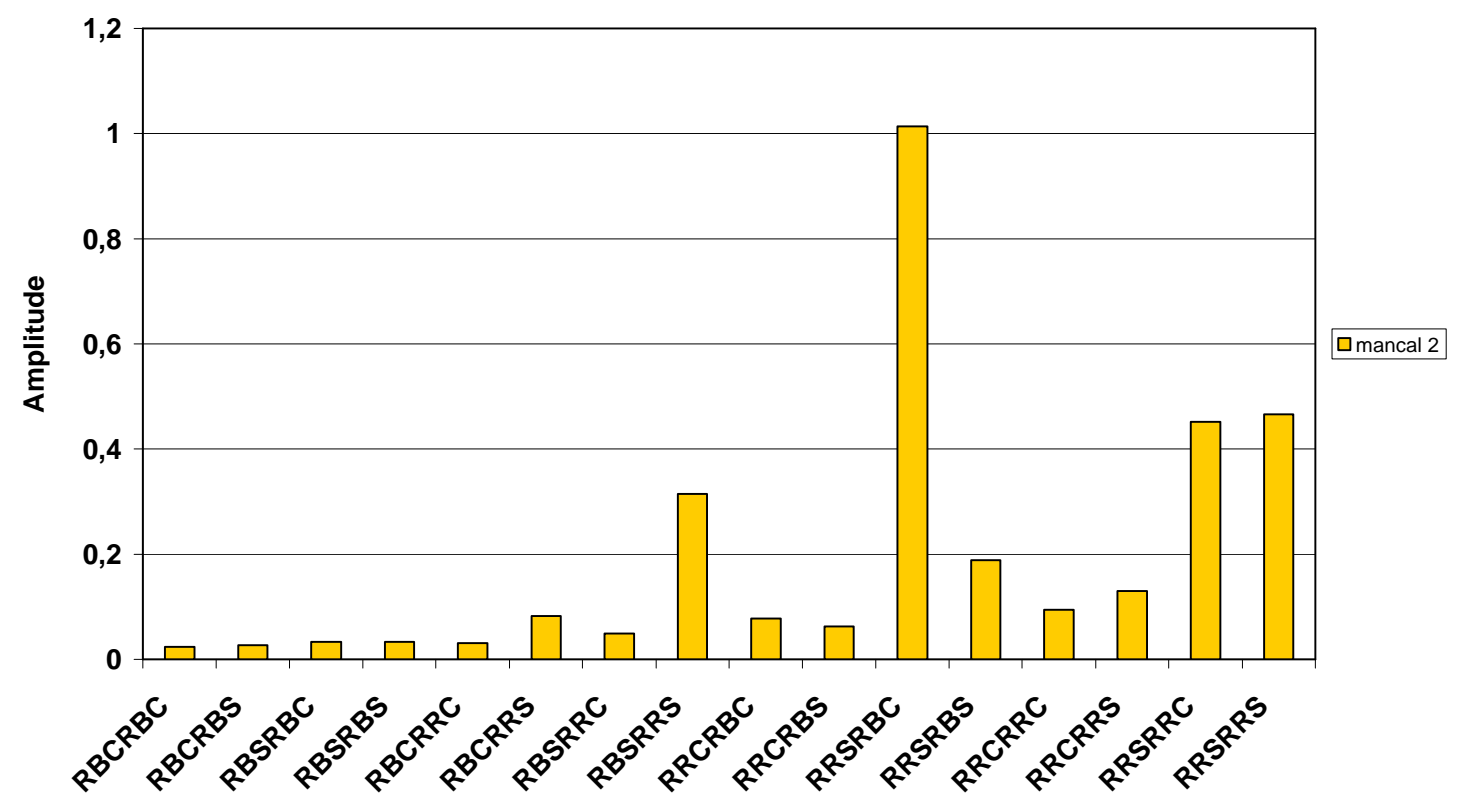

Figura 5. 12: Medidas efetuadas com o sensor de EA posicionado no mancal 2$100 \mathrm{kHz}$

Compondo-se os resultados obtidos para os dois mancais, obtêm-se os gráficos seguintes (Figuras 5.13 e 5. 14): 


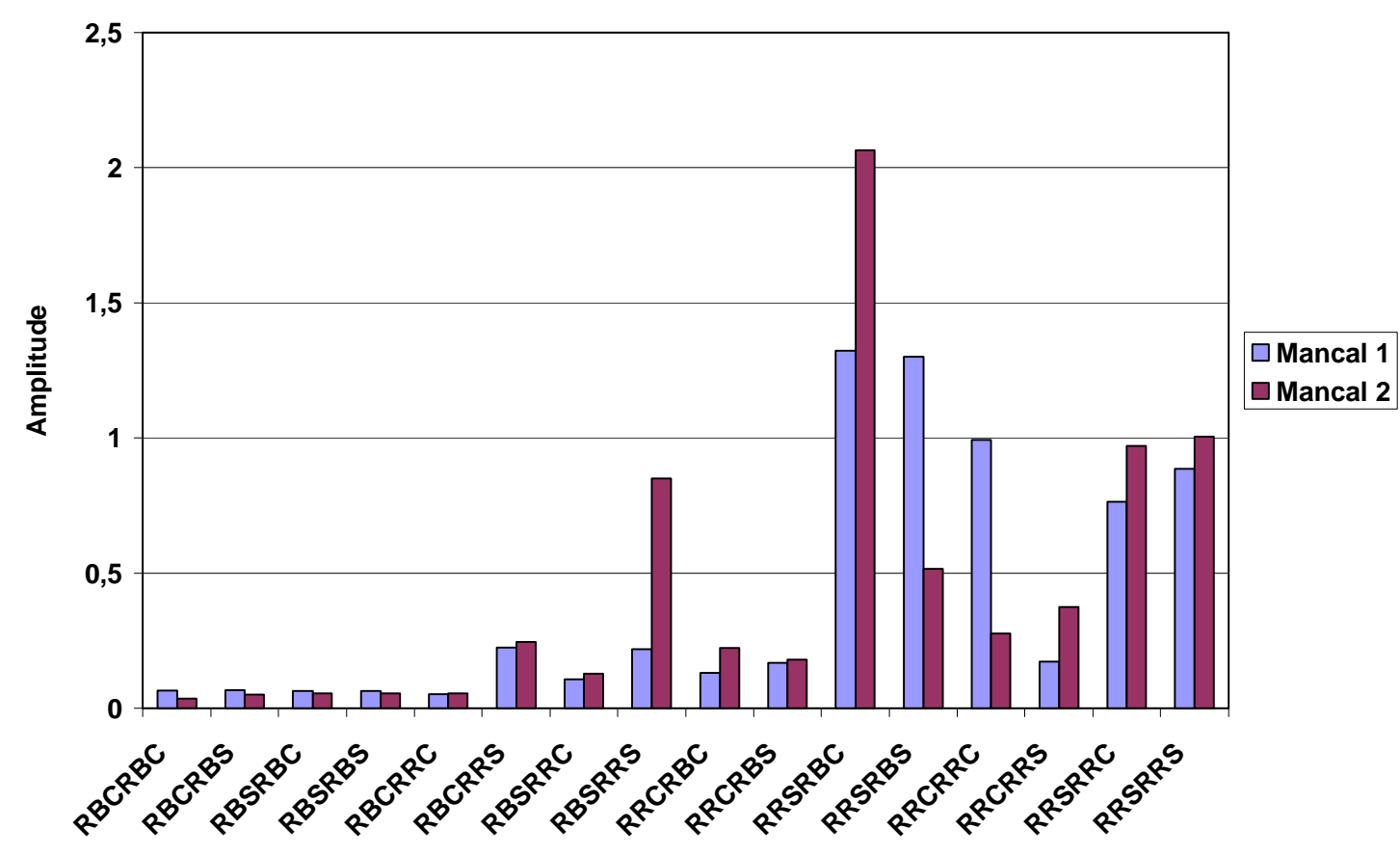

Figura 5. 13: Resultados obtidos nos dois mancais $-75 \mathrm{kHz}$

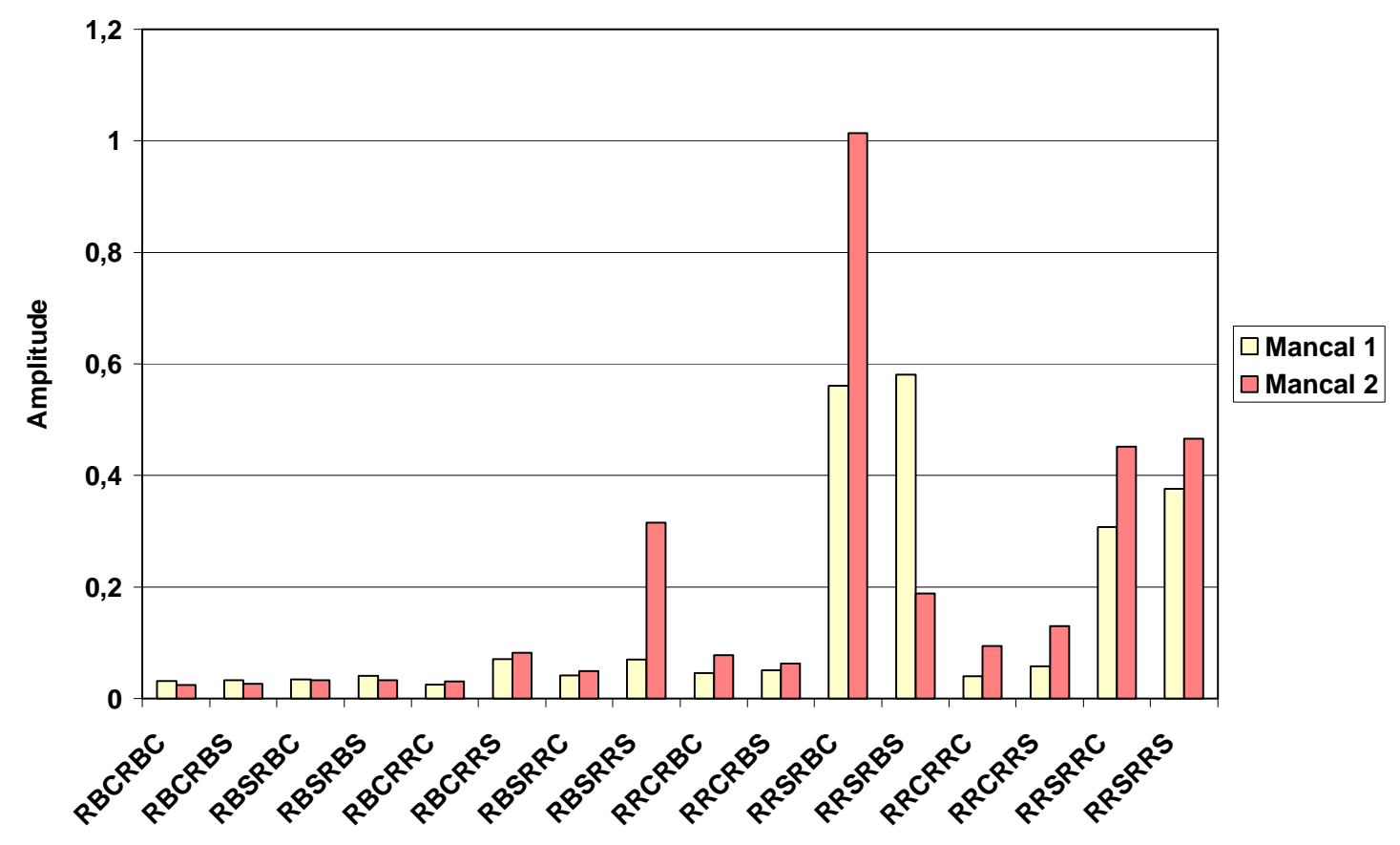

Figura 5. 14: Resultados obtidos nos dois mancais $-100 \mathrm{kHz}$

Dos dados obtidos percebe-se grande influência da lubrificação nos níveis de EA, quando se avaliam rolamentos danificados. Isto parece natural, uma vez que o lubrificante preenche as cavidades resultantes do desgaste das pistas dos rolamentos durante certo período. 
Desta forma, quando o sistema disparar atividades de lubrificação cada vez mais freqüentes, é possível concluir que o rolamento está chegando ao final de sua vida útil, portanto, deve-se proceder a substituição do mesmo. Um ponto positivo indicado pelo sistema reside no fato de, aparentemente, se conseguir protelar a substituição do componente para uma ocasião mais propícia, realizando-se tarefas de lubrificação. Ou seja, a detecção prematura da falha, possibilita uma ação pró-ativa para retardar o colapso do componente.

Em se tratando de rolamentos novos, a lubrificação não parece influir de forma decisiva nos níveis de EA, portanto, recomenda-se que esta atividade seja mantida como tarefa de manutenção preventiva, até que os patamares aceitáveis de EA sejam ultrapassados.

Analisando-se os gráficos, optou-se por considerar como parâmetro responsável pelo disparo das atividades de manutenção a Amplitude do sinal igual 0,2 com o filtro Passa Alta de $100 \mathrm{kHz}$. A freqüência de corte de $100 \mathrm{kHz}$ foi a que apresentou resultados mais coerentes com as condições de manutenção provocadas.

Com a adoção desse fator, somente uma vez, o sistema seria disparado sem necessidade (RBSRRS do mancal 2). A discrepância da medida obtida na alternativa citada, parece indicar a possibilidade de que algum problema possa ter ocorrido na montagem do mancal e que o mesmo não foi identificado neste momento. Este fato, também pode ser uma vantagem do sistema, identificar que uma falha foi introduzida no que deveria ser a correção da mesma.

Observa-se, ainda, que mesmo com os dois rolamentos ruins montados simultaneamente (RRCRRC e RRCRRS), se as condições de lubrificação forem satisfatórias o nível de emissão acústica permanece abaixo do nível de alarme, o que demonstra a importância do uso correto do lubrificante. 


\section{CONCLUSÕES}

Os resultados obtidos mostram que é possível desenvolver um sistema de aquisição de dados para monitoramento da manutenção, nos moldes propostos nesse trabalho.

O sistema possibilitou que informações coletadas on-line de uma máquina rotativa, pudessem ser acessadas e analisadas de maneira confiável e remota, para possibilitar uma tomada de decisão no que refere a função manutenção.

O sistema mostrou que é possível a utilização da emissão acústica, para a obtenção de dados que garantam um bom desempenho nas atividades de manutenção.

Finalmente, o sistema demonstrou que o acompanhamento das condições de um componente possibilita a tomada de decisões pró-ativas que diminuem a chance de ocorrência de uma falha catastrófica. 


\section{PROPOSTAS PARA TRABALHOS FUTUROS}

A seguir, são apresentadas algumas sugestões para trabalhos futuros, que possibilitariam a complementação e o aperfeiçoamento do projeto desenvolvido:

- Realizar testes comparativos entre emissão acústica e análise de vibração para se conhecer o real potencial do monitoramento de outras máquinas rotativas por emissão acústica.

- Implementar um sistema de monitoramento por emissão acústica, que possa desempenhar suas funções de maneira contínua e por longo prazo, a fim de se verificar a existência ou não de uma assinatura de determinado componente em uma determinada condição.

- Estudar a adoção de um banco de dados externo, onde informações de manutenção de vários componentes de diversas empresas pudessem ser armazenadas e utilizadas em conjunto, o que facilitaria a adoção de empresas terceirizadas para a gestão da manutenção. 


\section{REFERÊNCIAS BIBLIOGRÁFICAS}

ABRAMCZUK, A.A. (2003). Qual é o seu problema? Texto base para aula do curso de Metodologia de Pesquisa em Engenharia de Produção - 3‥ Quadrimestre. EPUSP. São Paulo.

ALMEIDA, M.T. (a) Manutenção preditiva: Confiabilidade e qualidade. Artigo tirado da Internet. www.mtaev.com.br/download/mnt1.pdf - Escola Federal de Engenharia de Itajubá. Visitado em 15/11/03.

ALMEIDA, M.T. (b) Manutenção Preditiva: Benefícios e lucratividade. Artigo tirado da Internet. www.mtaev.com.br/download/mnt2.pdf - Escola Federal de Engenharia de Itajubá. Visitado em 15/11/03.

ALMEIDA, M.T.; ALMEIDA, F.R.V. Manutenção preditiva usando análise de vibrações em compressores de parafuso. Artigo tirado da Internet. www.myq.com.br/html/revistas/myq_39/tecnica_39.pdf. Revista Nova Manutenção y Qualidade. Visitado em 30/05/04.

ANHESINE, M.,W., (1999). Uma abordagem sistêmica para diagnósticos em manutenção industrial. Tese de doutorado, apresentado à Escola de Engenharia de São Carlos - USP. São Carlos.

ARIZA, C.F. (1978). Sistema de administração para a manutenção industrial. São Paulo: Mc Graw Hill.

BALDERSTON, H.L. (1972). The broad range detection of incipient failure using the acoustic emission phenomena. American Society for Testing and Materials - Library of Congress Catalog Card Number: 72 -75896, p.297-317. Baltimore.

BEN-DAYA, M. (2000). You may need RCM to enhance TPM implementation. Journal of Quality in Maintenance Engineering, vol. 6, no. 2, p.82-85.

BERTO, R.M.V.S.; NAKANO, D.N. (2000). A produção científica nos anais do Encontro Nacional de Engenharia de Produção: Um levantamento de métodos e tipos de pesquisa. Revista Produção, vol. 9, no. 2, p.65-76. Rio de Janeiro.

BOULDING, K.E. (1956). General Systems Theory - The Skeleton od Science. Management Science, no. 2, p.197-208.

CALDAS, M.P. (2003). Contribuição teórica: Como assim cara pálida? RAE, vol. 43, no. 3, jul/set, p.65-68. São Paulo.

CAPALDO, D.; GUERRERO, V.; ROZENFELD, H. FMEA (Failure Mode and Effect Analysis). Artigo tirado da Internet, www.numa.org.br/conhecimentos, site visitado em 21/03/04.

DHILLON, B.,S. (1999). Engineering Maintainability. Gulf Publishing Company, p.253. Houston. 
DIAS, S.L. (2003). A cultura da mudança e a mudança da cultura. Revista ABRAMAN, no. 94, set/out, p.34-39. São Paulo.

ECO, U. (1989). Como se faz uma tese. $2^{\text {a }}$.ed. São Paulo: Perspectiva.

EDWARDS, D.J.; HOLT, G.D.; HARRIS, F.C. (1998). Predictive maintenance techniques and their relevance to construction plant. Journal of Quality in Maintenance Engineering, vol. 4, no. 1, p.25-37.

FERNANDES, M.A. (2003). Melhoria da disponibilidade dos equipamentos e redução dos custos de manutenção. Revista ABREME, ano 3, no. 27, p.4-10. São Paulo.

FINCH, B.J.; GILBERT, J.P. (1986). Developing maintenance craft labor efficiency through an integrated planning and control system: A prescriptive model. Journal of Operations Management, vol. 6, no. 4, p.449-459.

FINCH, E. (2003). The untethered facilities manager. Facilities, vol. 21, no. 5/6, p.126-133.

FLEURY, A.C.C. (2003). Engenharia de Produção. Texto base para aula do curso de Metodologia de Pesquisa em Engenharia de Produção - 3‥ Quadrimestre. EPUSP. São Paulo.

FMECA.COM. FMEA Methodology. www.fmeca.com/ttmethod/methodol.htm, visitado em 21/03/04.

GHAURI. P. et al. (1995). Research methods in business studies - A pratical guide. Prentice Hall.

GERAGHETY, T. Obtendo efetividade do custo de manutenção através da integração das técnicas de monitoramento de condição, RCM e TPM. Artigo da Internet, www.sqlbrasil.com.br/SQL-RCM2-ttec_integracaombcrcmtpm.html, visitado em 15/11/03.

GONÇALVES, J.E.L. (2000). As empresas são grandes coleções de processos. RAE - Revista de Administração de Empresas, vol 40, no. 1, p.6-19. São Paulo.

GUERINI, F.M. (2002). Planejar e redigir textos científicos em engenharia de produção. São Carlos: Serviço Gráfico EESC - USP.

GUERRERO, V.; ROZENFELD, H. FTA - Fault Tree Analysis. Artigo tirado da Internet. www.numa.org.br/conhecimentos, visitado em 21/03/04.

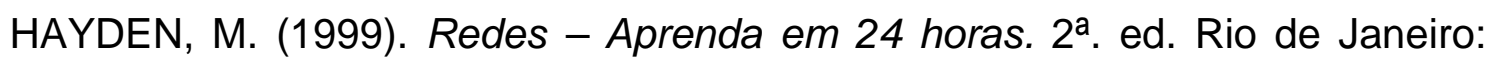
Campus 
HELMAN, H.; ANDREY, P.R.P. (1995). Análise de falhas (Aplicação dos métodos de FMEA - FTA). Belo Horizonte: Fundação Christiano Ottoni.

HOLROYD, T.J., a. Acoustic emission as a basis for the condition monitoring of industrial machinery. Artigo tirado da Internet. www.holroyd-instruments.com, visitado em 12/04/04.

HOLROYD, T.J., b. How does acoustic emission (AE) compare with vibration? Artigo tirado da Internet. www.holroyd-instruments.com, visitado em 12/04/04.

JEONG, K.Y.; PHILLIPS, D.T. (2001). Operational efficiency and effectiveness measurement. International Journal of Operations \& Production Management, vol. 21 , no. 11, p.1404-1416.

KARLSSON, C. (2002). Special issue on research methodology in operations management. Operations \& Production Management, vol. 22, no. 2.

KENNETH, C.D. Análise das modalidades e dos efeitos de falha (FMEA). Artigo tirado da Internet. http://216.239.37/, visitado em 21/03/04.

LAVE, C.A.; MARCH, J.G. (1975).An introduction to models in the social sciences. Harper \& Row Publishers, Inc. New York.

LIPTAI, R.B.; HARRIS, D.O.; TATRO, C.A. (1972). An introduction to acoustic emission. American Society for Testing and Materials - Library of Congress Catalog Card Number: 72 -75896, p.3-10. Baltimore.

LOVEJOY, W.S. (1998). Integrated operations: A proposal for operations management teaching and research. Production and Operations Management, vol. 7, no. 2, p.106-124.

MAGEE, B. (1973). As idéias de Popper. 3a․ ed. São Paulo: Cultrix.

MAZZEI, A., FREITAS JR., D.J. (1997). Diminuição dos custos pela Associação de manutenção pró-ativa e preditiva. III Seminário Brasileiro de Manutenção Preditiva e Inspeção de Equipamentos, p.119-147).

MEDEIROS, E.B. Monitoramento em manutenção preditiva: Avaliação de operação normal e fadiga. Artigo da Internet. www.ufsj.edu.br/demec/eman1/agenda.html - Departamento de Engenharia Mecânica da UFMG. Belo Horizonte. Visitado em 01/11/03.

MEIRELES, G.S.C. (2000). Desenvolvimento de sistema de aquisição de dados em operações de usinagem visando o monitoramento de linhas ou células de produção. Dissertação de mestrado, apresentado à Escola de Engenharia de São Carlos - USP. São Carlos.

MIRSHAWKA, V.; OLMEDO, N.L. (1993). Manutenção combate aos custos da não-eficácia - A vez do Brasil. São Paulo: Makron Books. 
MOTTA, S.B. (1999). Periodicidade de manutenções preventivas em dispositivos de proteção de sistemas elétricos de potência - Aplicação de técnicas quantitativas de confiabilidade à engenharia de manutenção. Dissertação de mestrado apresentada à Escola de Engenharia da Universidade Federal de Minas Gerais. Belo Horizonte.

MOUBRAY, J. (1992). Reliability-centered maintenance. New York: Industrial Press Inc.

MOUBRAY, J. (1999a). Reliability- centered maintenance - An introduction. Aladon Ltd. Retirado do site www.aladon.com.uk, visitado em 04/04/04.

MOUBRAY, J. (1999b). The responsible custodianship of physical assets. Aladon Ltd. Retirado do site www.aladon.com.uk, visitado em 04/04/04.

MURTHY, D.N.P.; ATRENS, A.; ECCLESTON, J.A. (2002). Strategic maintenance management. Journal of Quality in Maintenance Engineering, vol. 8, no. 4, p.287-305.

NAKAJIMA, S. (1989). Introdução ao TPM. São Paulo: IMC Internacional Sistemas Educativos.

NAKANO, D.N.; FLEURY, A.C.C. (1996). Métodos de pesquisa na Engenharia de Produção.

NASA - LEWIS RESEARCH CENTER. Fault Tree Analysis (FTA). Artigo tirado da Internet, http://www.nepss.org/presentations/dfr10.pdf, visitado em 28/03/04.

NETO, A.P.R. Medição de vibrações para manutenção preditiva de máquinas. COPPE/UFRJ. Artigo tirado da Internet, www.microsyn.com.br, visitado em 10/11/03.

PASQUA, M.C. (1999). Desenvolvimento de uma sistemática para padronização e gerenciamento da programação da manutenção de equipamentos e instalações a partir dos conceitos da qualidade. Dissertação de mestrado apresentada à Escola de Engenharia de São Carlos - USP. São Carlos.

PINTO, A.K.; XAVIER, J.A.N. (1999). Manutenção: Função estratégica. $2^{a}$. ed. Rio de Janeiro: Qualitymark.

PRICKETT, P.W. (1999). An integrated approach to autonomous maintenance management. Integrated Manufacturing Systems, vol. 10, no. 4, p.233-242.

RIIS, J.O. LUXHOJ, J.T. THORSTEINSSON, U. (1997). A situational maintenance model. International Journal of Quality \& Reliability Management, vol. 14, no. 4, p.349-366. 
RODRIGUES, M. (2003). Manutenção industrial em Curitiba e cidades circunvizinhas: Um diagnóstico atual. Dissertação de mestrado apresentada ao Centro Federal de Educação Tecnológica do Paraná. Curitiba.

SLACK, N. et al. (1999). Administração da produção - Edição compacta. $1^{\text {a }}$. ed. São Paulo: Atlas.

TAKAHASHI, Y., OSADA, T. (1993). TPM/MPT Manutenção produtiva total. $1^{\mathrm{a}}$. ed. São Paulo: IMAN.

TAVARES, L.A. (1987). Controle de manutenção por computador. Rio de Janeiro: Jr. Ed. Técnica.

TSANG, A.H.C. (1995). Condition-based maintenance: tools and decision making. Journal of Quality in Maintenance Engineering, vol. 1, no. 3, p.3-17.

TSANG, A.H.C. (2002). Strategic dimensions of maintenance management. Journal of Quality in Maintenance Engineering, vol 8, no. 1, p.7-39.

VERSCHUREN, P.; DOOREWAARD, H. (1999). Designing a research project. Ultrecht: Lemma.

VOSS, C. et al. (2002). Case research in Operations Management. International Journal of Operations \& Production Management, vol. 22, no. 2, p.195-219.

WHETTEN, D.A. (2003). O que constitui uma contribuição teórica? RAE, vol. 43, no. 3, p.69-73. São Paulo.

UNIVERSIDADE DE SÃO PAULO. Escola de Engenharia de São Carlos. Serviço de Biblioteca. (2003). Diretrizes para elaboração de dissertações e teses na EESC - USP. São Carlos.

WYREBSKI, J. (1997). Manutenção produtiva total: Um modelo adaptado. Dissertação de mestrado apresentada à Universidade Federal de Santa Catarina.

XENOS, H.G. (1998). Gerenciando a Manutenção Produtiva. Belo Horizonte: Editora de Desenvolvimento Gerencial. 


\section{APÊNDICE A - Manutenção Produtiva Total (TPM)}

A Manutenção Produtiva Total, mais conhecida pela sua sigla em inglês TPM (Total Productive Maintenance) - atividades de manutenção produtiva com participação de todos os funcionários da empresa - está entre as mais eficazes ferramentas de manutenção. Na TPM a operação da planta se transforma num gerenciamento orientado para o equipamento. Para que essa transformação ocorra, é necessário que todos (inclusive a alta gerência, os supervisores e os operários) reconheçam a importância e o valor do gerenciamento orientado para o equipamento, voltando suas atenções a todos os componentes da fábrica, tais como matrizes, dispositivos, ferramentas, sensores, etc. (TAKAHASHI e OSADA, 1993, p.1).

O desenvolvimento da Manutenção Produtiva Total - TPM, começou no Japão no início dos anos 70, na empresa Nippon Denso, integrante do grupo Toyota, como uma evolução da Manutenção Preventiva adotada pioneiramente pelas empresas americanas nos anos 50. A Manutenção Preventiva evoluiu para a Manutenção do Sistema Produtivo, incorporado a Prevenção de Manutenção, além de itens da Engenharia de Confiabilidade. Todos esses conhecimentos resultaram na TPM, que é a manutenção com a participação de todos (NAKAJIMA, 1989, p.9-10; BEN-DAYA, 2000, p.82; RODRIGUES, 2003, p.50).

Para Nakajima (1989, p.1) "TPM representa uma forma de revolução, pois conclama a integração total do homem $x$ máquina $x$ empresa, onde 0 trabalho de manutenção dos meios de produção passa a constituir a preocupação e a ação de todos".

Segundo Hamrick ${ }^{16}$ (1994 apud WYREBSKI, 1997, p.11) "TPM significa uma manutenção autônoma da produção que tenta otimizar a habilidade do operador e o conhecimento do seu próprio equipamento para aumentar ao máximo a sua eficiência de operação".

Pasqua (1999, p.31) resume as várias definições de TPM como: "um sistema de manutenção que envolve todos os trabalhadores de várias áreas da

16 HAMRICK, J. (1994). Industrial Engineering apud WYREBSKI, J. (1997). Manutenção produtiva total: Um modelo adaptado. p.11. 
empresa, principalmente engenharia, manutenção e operação e tem como objetivos principais alcançar zero falhas e zero defeitos".

Dos conceitos apresentados conclui-se que a TPM tem basicamente duas características próprias:

- Foco na gestão do equipamento e

- autonomia dos funcionários.

\section{OBJETIVOS DA TPM}

Ben-Daya (2000, p.83) destaca que as metas da TPM incluem, embora não se limitem, os seguintes objetivos:

- impor qualidade ao produto;

- reduzir desperdícios:

- impor o estado de manutenção; e

- autonomia dos funcionários.

Segundo Takahashi e Osada (1993, p.8) a TPM concentra seus pontos de gerenciamento no equipamento e seus componentes e ressaltam os seguintes aspectos:

- determinação da qualidade do produto;

- controle da produção e da entrega;

- garantia da proteção ambiental e segurança;

- educação dos operários.

Para Willmott ${ }^{17}$ (1994 apud WYREBSKI, 1997, p.12) o objetivo da TPM é a "melhoria da estrutura empresarial mediante a melhoria da qualidade de pessoal e de equipamento".

De acordo com a definição proposta 1971 pelo JIPM (Japan Institute of Plant Maintenance) e revista em1989, TPM significa:

1. constituição de uma estrutura empresarial que busca a máxima eficiência do sistema de produção (eficiência global);

2. construir mecanismos para prevenir as diversas perdas, visando atingir "zero defeito", "zero falha/quebra" e "zero acidente", englobando todo o ciclo de vida útil do equipamento, dentro do próprio local de trabalho;

${ }^{17}$ WILLMOTT, P. (1994). The TQM Magazine - Total quality with teeth apud WYREBSKI, J. (1997). Manutenção produtiva total: Um modelo adaptado. p.12. 
3. um sistema onde todos os departamentos estão envolvidos, começando pela produção e se estendendo aos setores de desenvolvimento, vendas, administração, etc.;

4. um sistema com a participação de todos, desde a alta direção até os últimos dos operários;

5. atingir perda zero por meio de atividades sobrepostas de pequenos grupos (NAKAJIMA, 1989, p.12; WYREBSKI, 1997, p.13; TAKAHASHI e OSADA, 1993, p.21).

Nakajima (1989, p.16) ensina que a TPM visa maximizar o desempenho operacional das máquinas, e para que isto se realize, deve-se eliminar as "Seis Grandes Perdas", que são:

1. perda por parada acidental

2. perda durante a mudança de linha (set up)

3. operação em vazio/pequenas paradas

4. queda da velocidade de trabalho

5. defeito no processo

6. defeito no início de produção (start up)

As duas primeiras perdas se referem à parada do equipamento e estão relacionadas à disponibilidade do mesmo. As perdas 3 e 4 se referem à mudança de velocidade e se relacionam a performance. Já as perdas 5 e 6 se referem a produtos defeituosos e se relacionam a qualidade.

De acordo com Nakajima (1989, p.21) o índice de rendimento operacional global - OEE (do inglês overall equipment effectiveness) é dado pelo produto dos três fatores relacionados às perdas, ou seja:

OEE $=$ disponibilidade $\mathrm{x}$ taxa de desempenho $\mathrm{x}$ taxa de qualidade

Prickett (1999, p.234) afirma que tanto o meio acadêmico como a indústria reconhecem que a adoção e prática da TPM são um passo chave para o aumento do OEE nas plantas de produção.

Jeong e Phillips (2001, p.1404) destacam que o OEE é um índice de medida capaz de avaliar o progresso da TPM, e que uma contribuição importante do OEE foi considerar perdas ocultas na utilização dos equipamentos, uma vez que antes do advento do OEE somente a 
disponibilidade era considerada, o que resultava numa sobre estimação da utilização dos equipamentos.

\section{OS PILARES DE SUSTENTAÇÃO DA TPM}

Visando a eliminação das "Seis Grandes Perdas", enumeradas por Nakajima (1989, p.16), são implementadas atividades, conhecidas por pilares de sustentação do desenvolvimento da TPM. Esses pilares foram propostos pelo JIPM (Japan Institute of Plant Maintenance).

Rodrigues (2003, p.51) destaca que a definição dos pilares adotada na TPM deve ser personalizada em função da estrutura e da filosofia da empresa e de acordo com a cultura empresarial já existente e a nova cultura desejada pela implantação da TPM.

Inicialmente, foram estabelecidos cinco pilares básicos de sustentação para a TPM (NAKAJIMA, 1989, p.42). Posteriormente foram incluídos mais três pilares, que se relacionam à melhoria da qualidade, gerenciamento $e$ segurança/meio ambiente (WYREBSKI, 1997, p. 3; RODRIGUES, 2003, p.52).

Segundo os autores citados no parágrafo anterior, os oito pilares de sustentação do TPM basicamente são:

1. Incorporação de melhorias individuais e específicas do equipamento para se atingir um aumento da eficiência e da eficácia.

2. Manutenção autônoma - permitir e encorajar os operadores, que utilizam os equipamentos, a assumir a responsabilidade por pelo menos uma parcela das tarefas de manutenção, bem como incentivar o pessoal da manutenção a se responsabilizar pela melhoria do desempenho da manutenção (SLACK, et al., 1999, p.496).

3. Estruturação do setor de manutenção para condução da manutenção planejada - planejar e controlar efetivamente a manutenção.

4. Capacitação técnica e busca de novas habilidades para os operários tanto da operação quanto da manutenção - gerar um contingente de operários com conhecimentos de instalações de manufatura e com diversas aptidões (TAKAHASHI E OSADA, 1993, p.36).

5. Elaboração de uma estrutura de controle inicial do equipamento acompanhamento do pessoal de manutenção desde a concepção de novos projetos ou aquisições, busca a prevenção da manutenção. 
6. Manutenção da qualidade (obtenção de qualidade através das instalações) - eliminação de ocorrências crônicas de defeitos com o estabelecimento de um programa de falha zero.

7. Gerenciamento - envolvimento da área administrativa no programa TPM.

8. Segurança, higiene e meio ambiente - organização de condições básicas e criação de um ambiente de trabalho disciplinado, saudável e seguro tanto humano quanto ambiental.

\section{AS DOZE ETAPAS PARA A IMPLANTAÇÃO DA TPM}

Nakajima (1989, p.46) comenta que o tempo gasto desde a introdução até a consolidação da TPM varia de empresa para empresa, mas que são consumidos no mínimo de dois a três anos.

O JIPM (Japan Institute of Plant Maintenance) sugere que implantação da TPM seja feita em doze etapas:

1. Manifestação da alta administração sobre a decisão de introduzir a TPM.

2. Campanha de divulgação e treinamento para a introdução da TPM.

3. Estrutura para a implantação da TPM.

4. Estabelecimento de diretrizes básicas e metas para a TPM.

5. Elaboração do plano diretor para a implantação da TPM.

6. Início do programa de TPM.

7. Melhoria individualizada nos equipamentos para maior rendimento operacional.

8. Estruturação para a manutenção espontânea.

9. Estruturação da manutenção programada pelo departamento de manutenção.

10. Treinamento para melhoria do nível de capacitação da operação e da manutenção.

11. Estruturação do controle da fase inicial de operação dos equipamentos.

12. Execução total da TPM e elevação do nível geral.

$\mathrm{Na}$ tabela Apêndice A. 1 a seguir se reproduz às etapas para a condução da TPM (NAKAJIMA, 1989, p.46-47). 
Tabela Apêndice A. 1: As 12 etapas para implantação da TPM

Fonte: Adaptado de Nakajima (1989, p 47).

\begin{tabular}{|c|c|c|}
\hline Fases & Etapas & Conteúdo \\
\hline \multirow{5}{*}{ 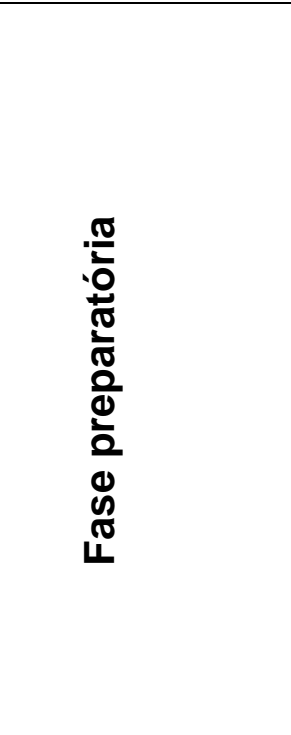 } & $\begin{array}{l}\text { decisão da adoção pela alta } \\
\text { direção e anúncio oficial }\end{array}$ & $\begin{array}{l}\text { - divulgação acerca da TPM por toda a } \\
\text { organização } \\
\text { - uso de meios de comunicação } \\
\text { disponível (murais, jornais internos, } \\
\text { etc.). }\end{array}$ \\
\hline & $\begin{array}{l}\text { campanha para a introdução } \\
\text { e esclarecimentos iniciais }\end{array}$ & $\begin{array}{l}\text { - } \begin{array}{l}\text { seminários específicos dirigidos às } \\
\text { hierarquias superiores } \\
\text { - } \\
\text { projeção de vídeo para elementos } \\
\text { operacionais }\end{array} \\
\end{array}$ \\
\hline & $\begin{array}{l}\text { estruturação do órgão } \\
\text { encarregado da } \\
\text { implementação }\end{array}$ & $\begin{array}{l}\text { - estruturação dos Comitês para a } \\
\text { Implementação }\end{array}$ \\
\hline & $\begin{array}{l}\text { definição da política básica e } \\
\text { metas a serem alcançadas }\end{array}$ & $\begin{array}{l}\text { - escolha do alvo e definição das metas } \\
\text { a serem alcançadas }\end{array}$ \\
\hline & $\begin{array}{l}\text { elaboração do plano-diretor } \\
\text { de implementação }\end{array}$ & - detalhamento do plano-diretor \\
\hline Fase inicial & $\begin{array}{l}\text { atividades relativas à } \\
\text { introdução }\end{array}$ & $\begin{array}{ll}\text { - } & \text { convite a fornecedores, clientes e } \\
\text { empresas aliadas }\end{array}$ \\
\hline \multirow{4}{*}{ 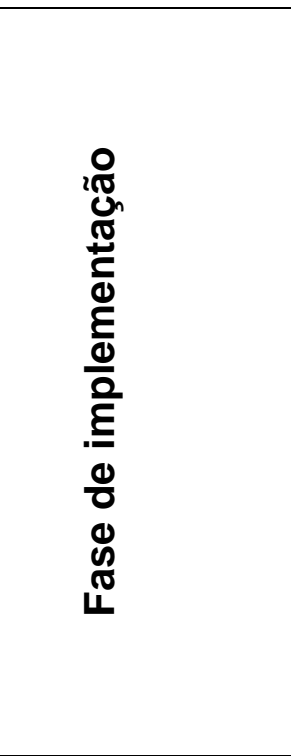 } & $\begin{array}{l}\text { incorporação de melhorias } \\
\text { individualizadas sobre as } \\
\text { máquinas e equipamentos }\end{array}$ & $\begin{array}{l}\text { - escolha da área piloto e estruturação } \\
\text { da equipe de trabalho }\end{array}$ \\
\hline & $\begin{array}{l}\text { estruturação da Manutenção } \\
\text { Autônoma }\end{array}$ & $\begin{array}{l}\text { - implementação por etapas } \\
\text { - } \quad \text { auditoria de cada desenvolvimento e } \\
\text { aprovação }\end{array}$ \\
\hline & $\begin{array}{l}\text { estruturação do setor de } \\
\text { Manutenção e condução da } \\
\text { manutenção planejada }\end{array}$ & $\begin{array}{l}\text { - } \quad \text { condução da manutenção periódica } \\
\text { - } \quad \text { peças de reposição, ferramentas, } \\
\text { desenhos técnicos, etc. }\end{array}$ \\
\hline & $\begin{array}{l}\text { educação e treinamento para } \\
\text { melhoria das habilidades do } \\
\text { pessoal da Produção e de } \\
\text { Manutenção; } \\
\text { estrutura para gestão dos } \\
\text { equipamentos na fase inicial } \\
\text { de funcionamento }\end{array}$ & $\begin{array}{l}\text { - } \\
\text { - } \\
\text { educaçação e treinamento em cascata } \\
\text { - } \quad \text { condução do projeto com prevenção da } \\
\text { manutenção } \\
\text { - } \quad \text { controle da fase inicial de } \\
\text { funcionamento } \\
\text { - custo do ciclo de vida } \\
\end{array}$ \\
\hline $\begin{array}{c}\text { Fase de } \\
\text { consolidacão }\end{array}$ & $\begin{array}{l}\text { consolidação do TPM e } \\
\text { incremento do seu nível }\end{array}$ & - definição de objetivos de maior porte \\
\hline
\end{tabular}

Para Nakajima (1989, p.46) "a fase preparatória é necessária para desbravar um ambiente ainda incipiente e preparar um local propício à introdução do TPM". A seguir "tem-se a partida ou a decolagem, similar ao início de uma partida esportiva", a implementação e a consolidação. O autor faz 
uma analogia a um processo produtivo, onde o manuseio inicial das matérias primas corresponde à introdução, o processamento equivale a implementação e a inspeção final é a etapa de consolidação.

\section{RESULTADOS DA TPM}

Nakajima (1989, p.4) relata que os empresários, cujas empresas ganharam o Prêmio PM (láurea outorgada pelo JIPM à empresa cuja Produção se caracteriza com resultados significativos aferidos através da implementação do TPM junto a toda organização), dizem que a "TPM é sinônimo de lucratividade, sendo que a sua implementação propicia resultados significativos". O autor apresenta a tabela Apêndice A. 2, onde são destacados os resultados alcançados por estas empresas.

Tabela Apêndice A. 2: Resultados alcançados com a implementação da TPM Fonte: Nakajima (1989, p.7).

\begin{tabular}{|c|c|}
\hline item & resultados \\
\hline $\begin{array}{c}\mathbf{P} \\
\text { (Produtividade) }\end{array}$ & $\begin{array}{ll}- & \text { produtividade da mão-de-obra: } 1,4 \text { (M Co.), 1,5 (F Co.) } \\
\text { - } & \text { valor agregado per capta 1,47 (A Co.), 1,17 (AS Co.) } \\
& \text { indice operacional das máquinas } \\
& \text { incremento de } 17 \%(68 \%-86 \%)(T \text { Co.) } \\
\text { - } & \text { paradas acidentais das máquinas } 1 / 50 \text { (1000 - } 20 \text { casos/mês) (TK Co.) }\end{array}$ \\
\hline $\begin{array}{c}\mathbf{Q} \\
\text { (Qualidade) }\end{array}$ & $\begin{array}{ll}\text { - } & \text { índice de produtos defeituosos no processo } 1 / 10 \text { (1\% - 0.1\%) (MS Co.) } \\
\text { - } \quad \text { índice de refugos } 1 / 3(0,23 \%-0,085) \text { (T Co.) } \\
\text { - } \quad \text { índice de reclamação dos clientes } 1 / 2 \text { (TK Co.), } 305 \text { (F Co.) } 30 \% \text { (NZ Co.) }\end{array}$ \\
\hline $\begin{array}{c}\text { C } \\
\text { (Custo) }\end{array}$ & $\begin{array}{ll}\text { - } & \text { redução do número de estágios do processo 30\% (TS Co.), 30\% (C Co.) } \\
\text { - } & \text { redução do custo de manutenção 15\% (TK Co.), 30\% (F Co.), 30\% (NZ } \\
& \text { Co.) } \\
\text { - } & \text { economia de energia } 30 \% \text { (C Co.) }\end{array}$ \\
\hline $\begin{array}{c}\mathbf{D} \\
\text { (Entrega) }\end{array}$ & $\begin{array}{ll}\text { - } & \text { estoque de produtos (em dias) } 50 \% \text { ( } 11-5 \text { dias) (T Co.) } \\
\text { - } & \text { índice de rotação do estoque } 2 \text { vezes ( } 3-6 \text { vezes } / \mathrm{mês}) \text { (C Co.) }\end{array}$ \\
\hline $\begin{array}{c}\mathbf{S} \\
\text { (Segurança) }\end{array}$ & $\begin{array}{ll}- & \text { falta de funcionários acidentados zero (M Co.) } \\
\text { - } & \text { poluição zero (diversas empresas) }\end{array}$ \\
\hline $\begin{array}{c}\text { M } \\
(\text { Moral) }\end{array}$ & $\begin{array}{l}\text { - número de sugestões para melhoria 2,3 vezes (36,8-83,6 } \\
\text { sug/pessoa/ano) ( } \mathrm{N} \text { Co.) } \\
\text { número de reuniões mensais dos pequenos grupos } 2 \text { vezes }(2-4 \\
\text { vezes/mês) (C Co.) }\end{array}$ \\
\hline
\end{tabular}




\section{APÊNDICE B - Metodologia de pesquisa: Revisão bibliográfica.}

Com a redefinição e a caracterização do problema, teve início uma revisão bibliográfica mais aprofundada, buscando uma consolidação dos conceitos e teorias envolvidas.

Em conformidade com os conceitos estudados na disciplina "metodologia de pesquisa em engenharia de produção", na revisão bibliográfica procura-se os paradigmas estabelecidos, e alternativas para se resolver o problema proposto, utilizando-se produtos, componentes e tecnologia já existentes, porém de uma forma inovadora.

Pela definição do problema proposto, a realização de uma pesquisa quantitativa (BRYMAN ${ }^{18}, 1989$ - Apud NAKANO e FLEURY,1996), pesquisa empírica ou método científico tradicional (WESTBROOK ${ }^{19}, 1995$ - Apud NAKANO e FLEURY, 1996) parece ser a mais indicada para a solução do mesmo.

Segundo Lave e March (1975), numa forma sucinta, o método hipotéticodedutivo consiste em quatro passos:

Passo 1: Observe alguns fatos.

Passo 2: Analise os fatos como se eles fossem o resultado final de um processo (modelo). Em seguida especule sobre possíveis processos que poderiam ter produzido tal resultado.

Passo 3: Deduza outros resultados (implicações/ conseqüências/ previsões) a partir do modelo.

Passo 4: Questione se estas outras implicações são verdadeiras, produza novos modelos, se necessário.

\footnotetext{
${ }^{18}$ BRYMAN, A. (1989). A research and organization studies. Unwin Hyman, Londres apud NAKANO, D. N. e FLEURY, A. C. C. (1996) Métodos de pesquisa na Engenharia de produção.

${ }^{19}$ WESTBROOK, R. (1995). Action Research: a new paradigm for research in production and operations management apud NAKANO, D. N. e FLEURY, A. C. C. (1996) Métodos de pesquisa na Engenharia de produção.
} 
O modelo de pesquisa "tradicional" apresentado por Bryman ${ }^{20}$, (1989 apud NAKANO e FLEURY, 1996), também mostra os passos a serem seguidos pelo pesquisador, neste tipo de trabalho (Figura Apêndice B. 1).

O modelo citado mostra que qualquer caso exige coleta sistemática de dados, criatividade, relevância dos dados coletados e atualizados com novas idéias e teorias deve ser feito de maneira cíclica.

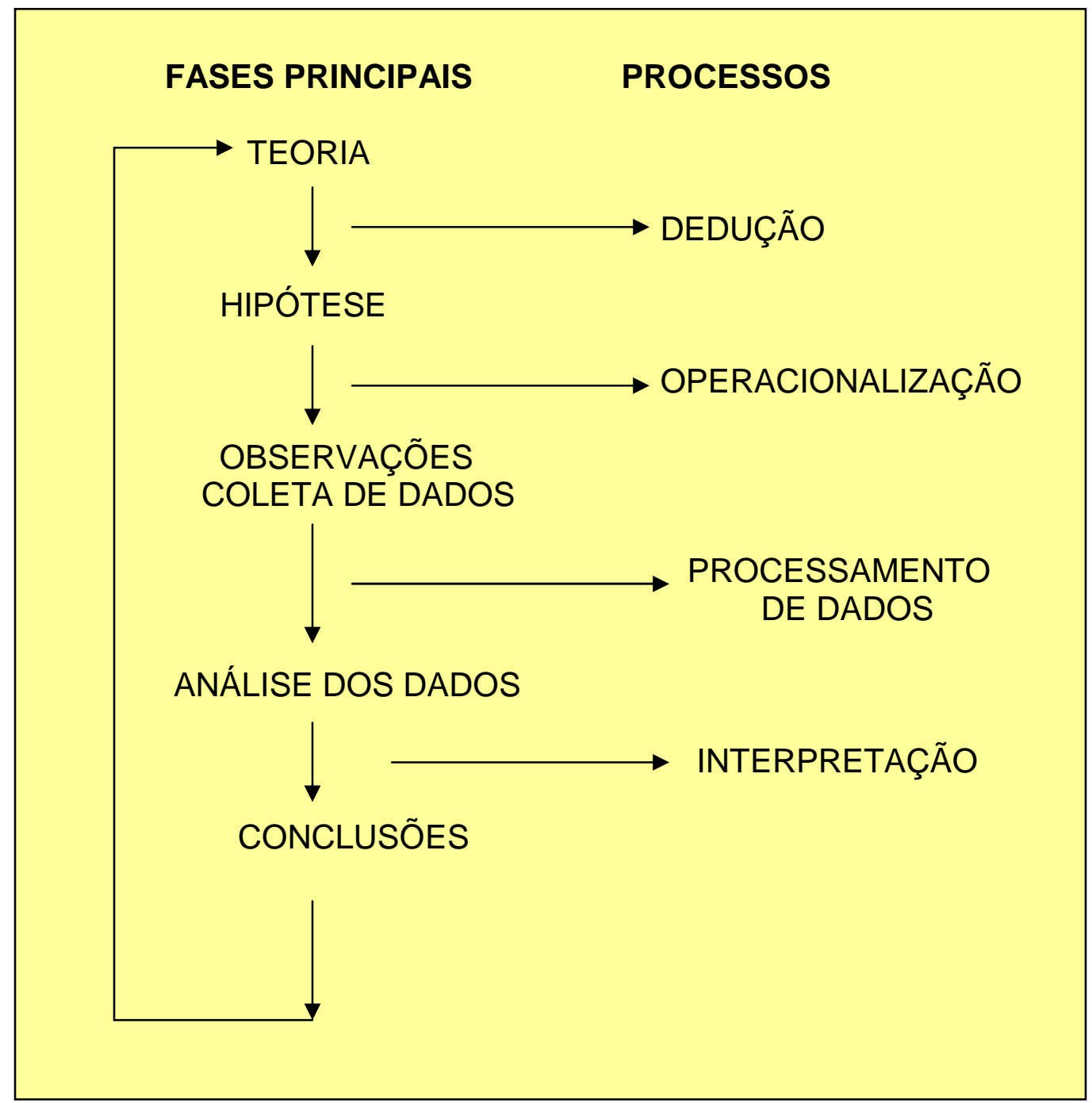

Figura Apêndice B. 1: O método da pesquisa "tradicional" Fonte: Bryman $^{20}$ (1989 apud NAKANO e FLEURY, 1996).

${ }^{20}$ BRYMAN, A. (1989). A research and organization studies. Unwin Hyman, Londres apud NAKANO, D. N. e FLEURY, A. C. C. (1996) Métodos de pesquisa na Engenharia de produção. 
Tendo em mente os roteiros acima, deve-se procurar o delineamento do experimento. Em se tratando do tipo de pesquisa escolhido, o método adotado será uma pesquisa experimental.

A pesquisa experimental, como o próprio nome diz, faz o teste de hipóteses através de um experimento controlado, projetado de forma a produzir os dados necessários, podendo ser realizado em laboratório ou no próprio campo (NAKANO E FLEURY, 1996).

Neste tipo de procedimento, se buscam explicar as relações de causa/efeito e, através de generalizações de resultados, possibilitar replicações (BERTO E NAKANO, 1998). 